UNIVERSIDADE DE BRASILIA

INSTITUTO DE CIÊNCIAS BIOLÓGICAS

DEPARTAMENTO DE FITOPATOLOGIA

PROGRAMA DE PÓS-GRADUAÇÃO EM FITOPATOLOGIA

Progresso temporal e espacial de begomovirose e crinivirose em tomateiro

Mônica Alves de Macedo

Brasília- DF

2016

Mônica Alves de Macedo 
Progresso temporal e espacial de begomovirose e crinivirose em tomateiro

TESE APRESENTADA À UNIVERSIDADE DE BRASÍLIA COMO REQUISITO PARCIAL PARA A OBTENÇÃO DO TÍTULO DE DOUTOR EM FITOPATOLOGIA PELO PROGRAMA DE PÓS-GRADUAÇÃO EM FITOPATOLOGIA

ORIENTADORA: ALICE KAZUKO INOUE NAGATA

CO-ORIENTADOR: ARMANDO BERGAMIN FILHO

ORIENTADOR NO DOUTORADO SANDUICHE: ROBERT LEONARD GILBERTSON

BRASÍLIA

DISTRITO FEDERAL - BRASIL

2016 


\section{FICHA CATALOGRÁFICA}

Macedo, Mônica Alves.

Progresso temporal e espacial de begomovirose e crinivirose em tomateiro. / Mônica Alves de Macedo.

Brasília, 2016.

Número de páginas p.138 il.

Tese de doutorado. Programa de Pós-graduação em Fitopatologia, Universidade de Brasília, Brasília.

1. Epidemiologia, viroses.

I. Universidade de Brasília. PPG/FIT.

II. Progresso temporal e espacial de begomovirose e crinivirose em tomateiro. 
Aos meus pais, Severino Pereira de Macedo e Maria de Jesus Alves de Macedo, pelo amor e incentivo, dedico. 


\section{AGRADECIMENTOS}

À minha orientadora Alice K. Inoue Nagata, que desde o mestrado vem me incentivando a continuar na área da pesquisa, agradeço pela oportunidade, pela paciência, pelos ensinamentos valiosos, por ter colocado a "mão-na-massa" para a realização desse trabalho e por ter acreditado em mim durante toda essa trajetória;

Ao meu co-orientador Armando Bergamin Filho, agradeço pelos preciosos ensinamentos epidemiológicos, pela partilha de conhecimentos que foram fundamentais para a elaboração desse trabalho e pela agradável companhia que tornaram as visitas de trabalho à Piracicaba mais prazerosas;

Ao meu co-orientador Robert L. Gilbertson, por ter aberto as portas do seu laboratório, pelos valiosos ensinamentos fitopatológicos, pelo incentivo, paciência e dedicação e também pelos happy hours que tornaram meu Doutorado Sanduíche mais divertido;

Ao Júlio C. Barbosa, agradeço pela paciência e disposição em ajudar na parte epidemiológica desse trabalho.

Ao José Luiz Pereira, que foi indispensável à realização das saídas de campo fundamentais ao desenvolvimento desse trabalho, agradeço pela disposição e bom humor nos momentos difíceis durante as avaliações de campo.

À Maria Rojas e Minor Maliano que me acolheram no Laboratório de Virologia Vegetal da UCDavis, me fazendo sentir parte daquele ambiente novo, tornando-se rapidamente grandes amigos e parceiros de trabalho; agradeço a eles e à Juliana Osse por tornarem minha experiência durante o Doutorado Sanduiche mais alegre e divertida;

Ao pesquisador Miguel Michereff Filho pela troca de experiência no estudo da dispersão de insetos vetores e toda a equipe de entomologia da Embrapa Hortaliças pelo apoio técnico nas coletas e avaliações de mosca-branca;

A todos os meus colegas do laboratório de Virologia da Embrapa Hortaliças, pela ajuda, troca de experiências e pelos momentos de descontração.

A toda a equipe do laboratório de Virologia da Universidade de Davis, pelo acolhimento e ensinamentos valiosos. 
A todos os colegas e amigos da fitopatologia da UnB.

Aos funcionários do Laboratório de Virologia Embrapa Hortaliças, em especial para Hamilton, Lúcio Flávio, Oneilson Medeiros e Erich, por serem sempre prestativos e por facilitarem a execução do trabalho.

A todos os funcionários da Embrapa Hortaliças que ajudaram direta ou indiretamente na condução dos experimentos de campo e de casa-de-vegetação, e nas saídas de campo desse trabalho.

A todos os professores e funcionários da Fitopatologia da UnB, pelos ensinamentos científicos.

Aos meus familiares e amigos, em especial aos meus irmãos, Lucélia, Thiago e Yamara, pela paciência, apoio e incentivo;

A toda a equipe das empresas e fazendas parceiras, Agricenci, Cargill, Fazendas do Sr. Iron de Lima, Fazenda Larga Grande, Fazenda Village, Goiás Verde, Minas Mais, Olé, Produtos Dez e Tomilho por disponibilizarem pessoal e infraestrutura e abrirem as porteiras das fazendas para a realização dos trabalhos de epidemiologia nos campos de produção comercial de tomateiro industrial;

Aos agricultores das áreas de produção de tomate mesa de Goianápolis, Boa Esperança, Taquara e DAIA que disponibilizaram suas áreas de produção para a realização dos experimentos epidemiológicos;

Aos membros da comissão de avalição de tese Adalberto Corrêa Café Filho e Cláudio L. Costa pela disponibilidade em contribuir com sugestões para melhoria desse trabalho;

Aos membros avaliadores dessa tese, Dr. Adalberto Corrêa Café Filho, Dr. Alexandre F. S. Mello, Dr. Valdir Lourenço Jr, Dr. Jorge A. M. Rezende e a Dr ${ }^{a}$ Rita de Cássia por terem aceitado participar da avaliação desse trabalho;

Ao Programa de Pós-Graduação em Fitopatologia da Universidade de Brasília pela oportunidade;

À Capes e ao CNPq pela concessão das bolsas de estudos; 
Ao programa Ciência Sem Fronteiras pela concessão da Bolsa de Doutorado Sanduiche (processo 202653/2014-5);

À FAPDF, FAPESP, CNPq e Embrapa por disponibilizarem recurso financeiro para a realização desse trabalho;

À Embrapa Hortaliças e Universidade de Davis por fornecerem a infraestrutura necessária à realização do trabalho. 
Trabalho realizado junto ao programa de pós-graduação em Fitopatologia do Instituto de Ciências Biológicas da Universidade de Brasília sob orientação da $\operatorname{Dr}^{a}$ Alice Kazuko InoueNagata e co-orientação do Dr. Armando Bergamin Filho e Dr. Robert Leonard Gilbertson. Apoio institucional da Embrapa Hortaliças e Universidade de Davis (USA) e financeiro da Capes, FAPDF, FAPESP, CNPq, Embrapa e do programa ciência sem fronteiras por possibilitarem a realização da pesquisa.

\title{
PROGRESSO TEMPORAL E ESPACIAL DE BEGOMOVIROSE E CRINIVIROSE EM TOMATEIRO
}

\author{
MÔNICA ALVES DE MACEDO
}

TESE APROVADA EM 22/03/2016

Dra. Alice Kazuko Inoue Nagata (Orientadora)

Universidade de Brasília, Embrapa Hortaliças

Dr. Adalberto Corrêa Café Filho

Universidade de Brasília

Dr. Alexandre Furtado Silveira Mello

Embrapa Hortaliças

Dr. Jorge Alberto Marques Rezende

Escola Superior de Agricultura "Luiz de Queiroz"

Dr. Valdir Lourenço Junior

Embrapa Hortaliças

BRASÍLIA, DISTRITO FEDERAL, BRASIL, 2016 


\section{Sumário}

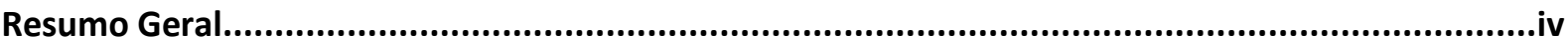

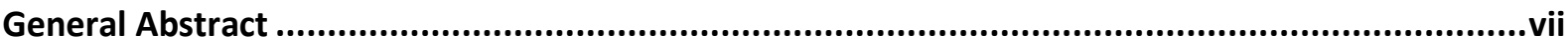

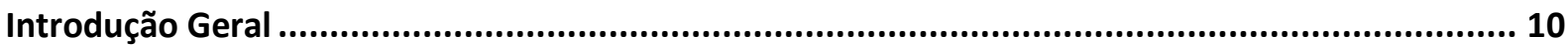

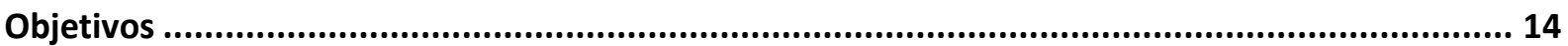

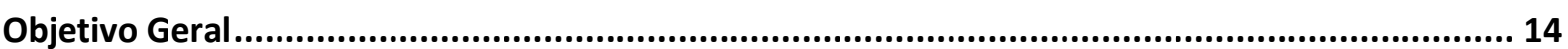

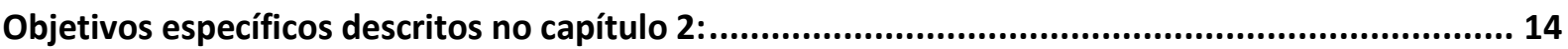

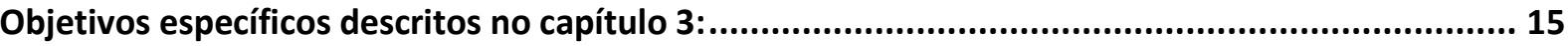

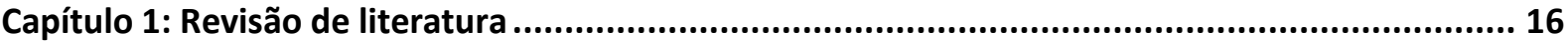

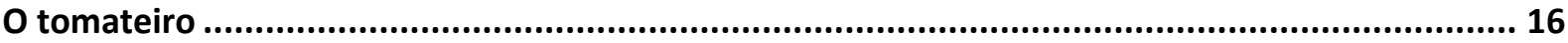

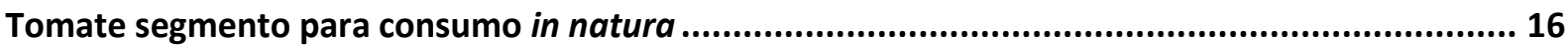

Tomate segmento para processamento industrial ..................................................................... 17

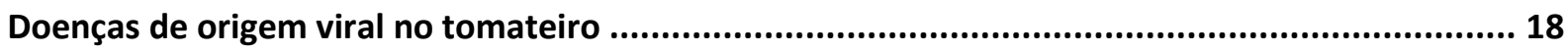

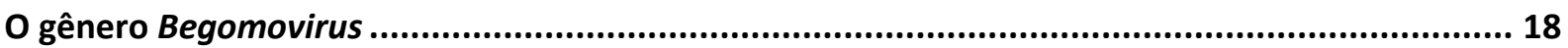

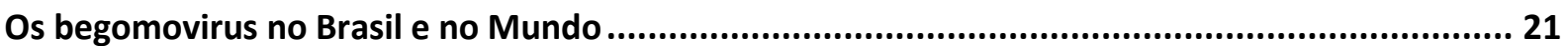

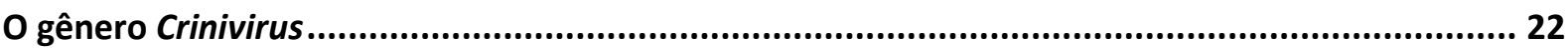

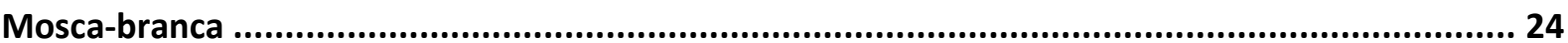

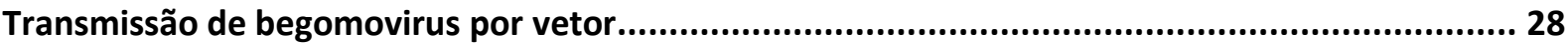

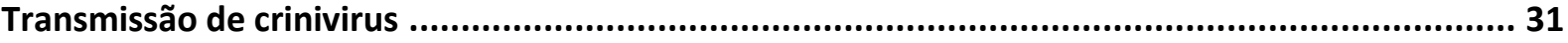

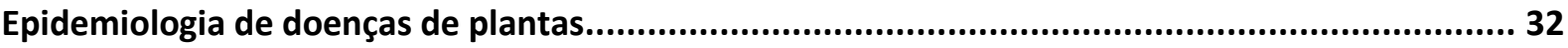

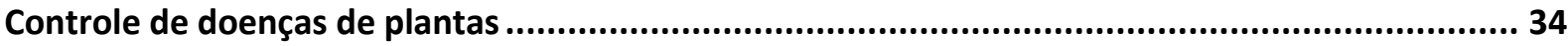

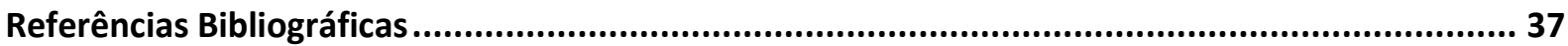

Chapter 2: Temporal and spatial dynamics of a begomovirus disease in processing tomato in

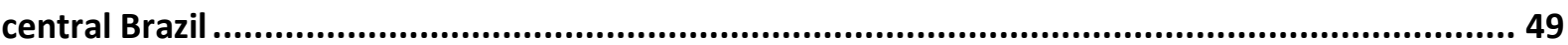

Resumo

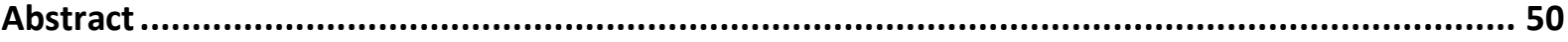

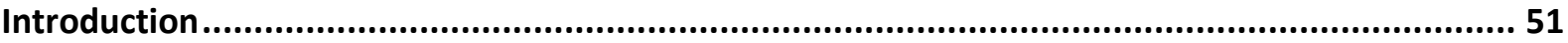

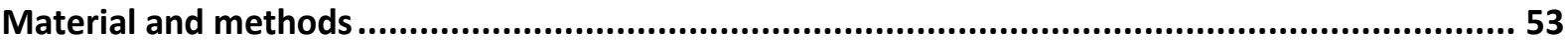

Location, experimental design and data collection ................................................................... 53

Detection and identification of the virus species .......................................................................... 54

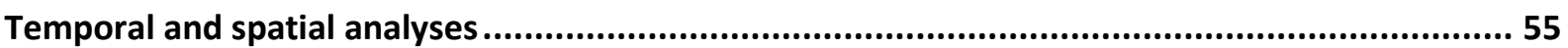

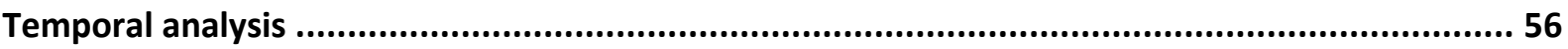

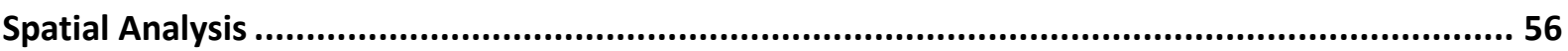

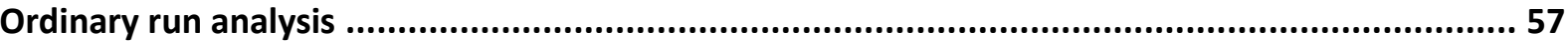




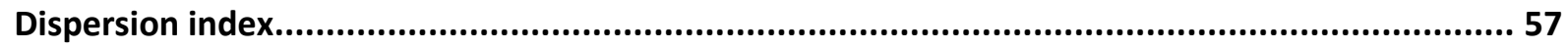

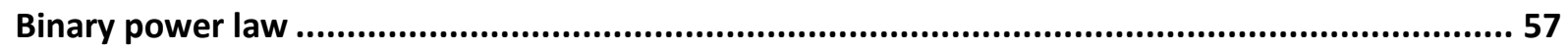

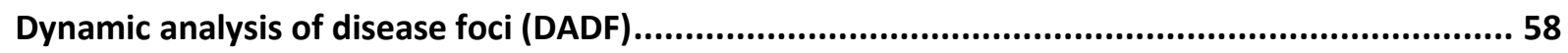

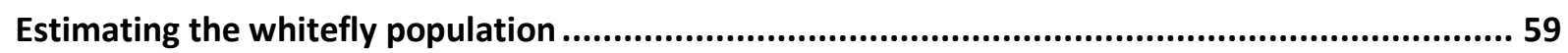

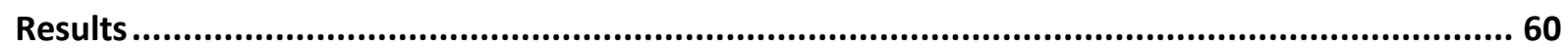

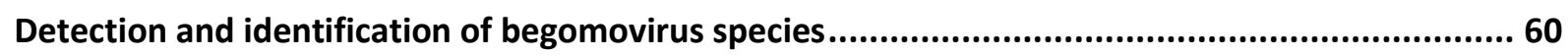

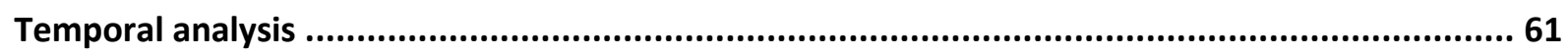

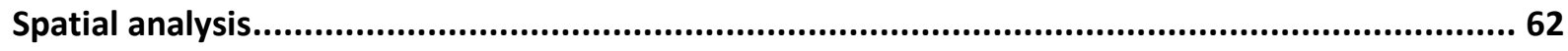

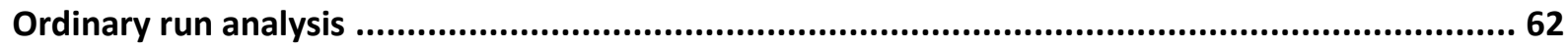

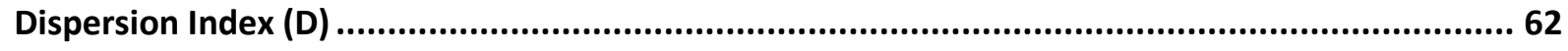

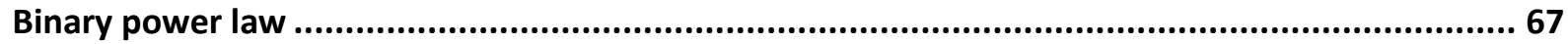

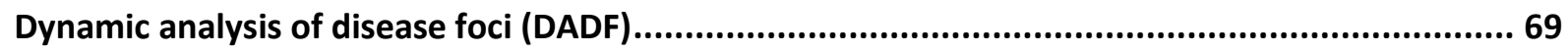

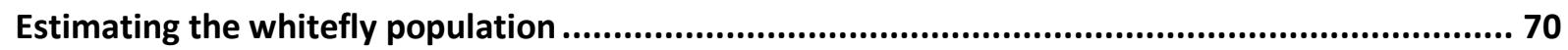

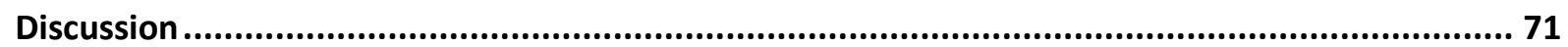

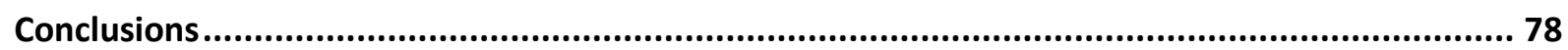

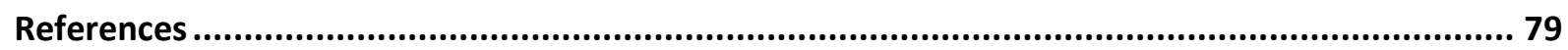

Capítulo 3 - Progresso temporal e espacial de crinivirose e begomovirose em tomateiro de

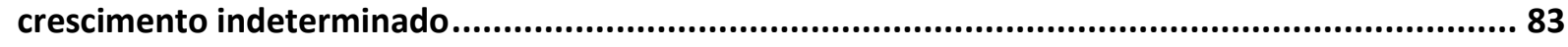

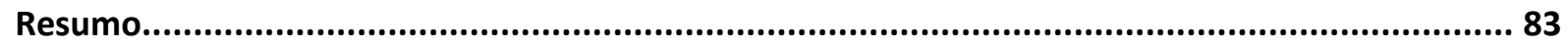

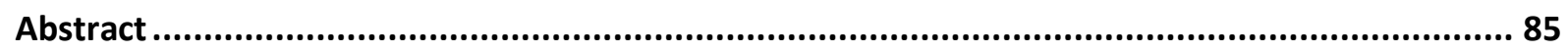

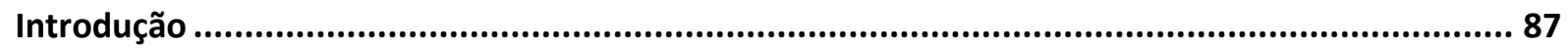

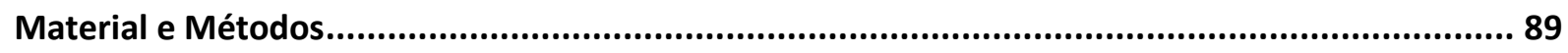

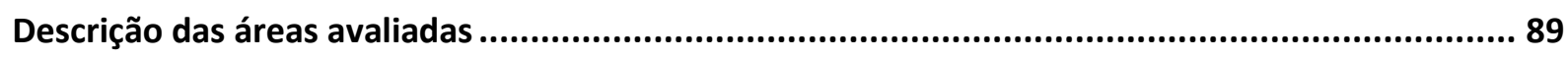

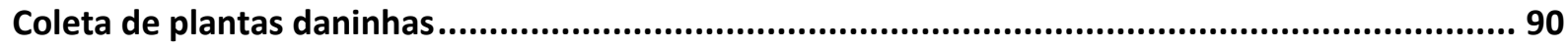

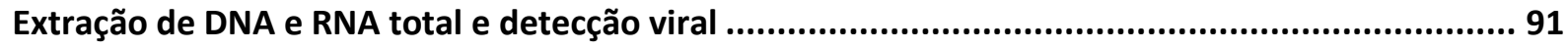

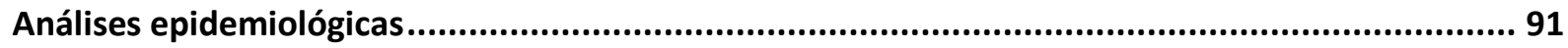

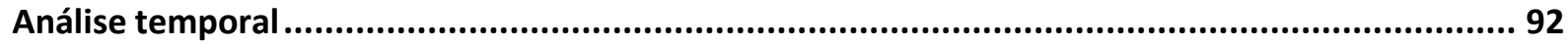

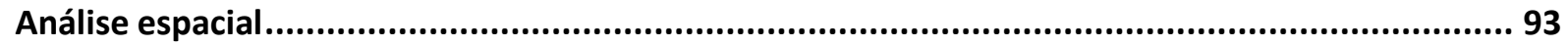

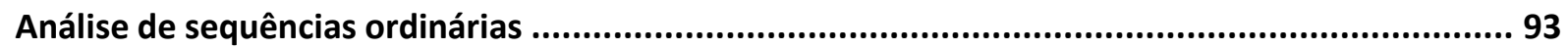

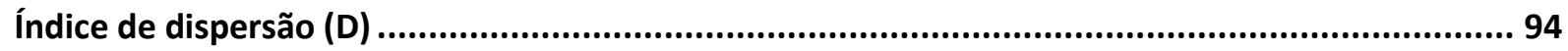

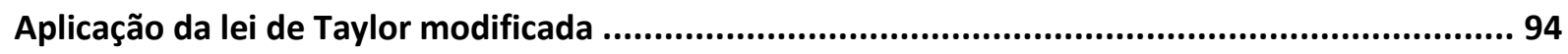

Análise da dinâmica de focos da doença (ADFD) ..................................................................... 95

Associação entre begomovirose e crinivirose ................................................................................. 96

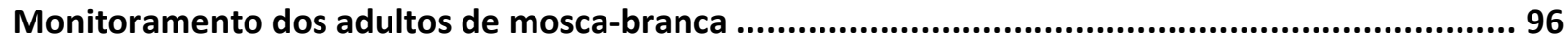


Resultados 97

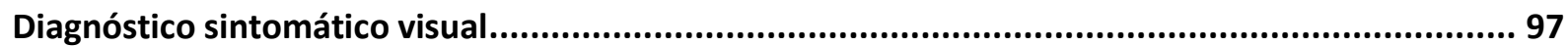

Deteç̧ão e identificação das espécies virais em campo ............................................................. 99

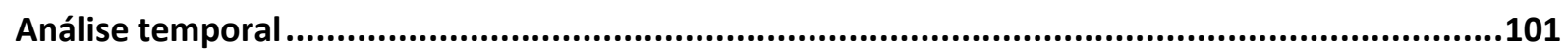

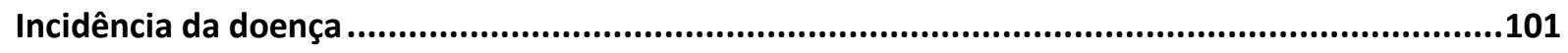

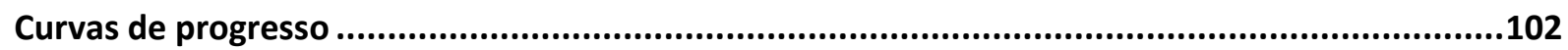

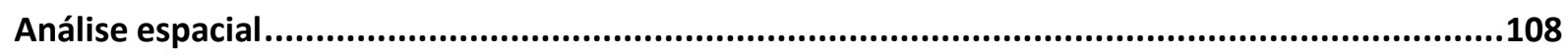

Análise de sequências ordinárias .......................................................................................108

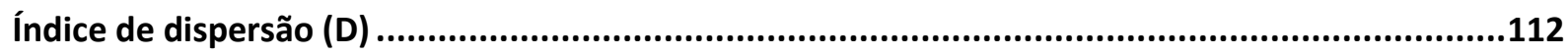

Aplicação da Lei de Taylor modificada....................................................................................112

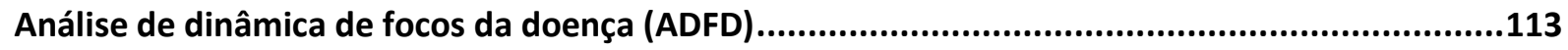

Associação entre begomovirose e crinivirose ..........................................................................115

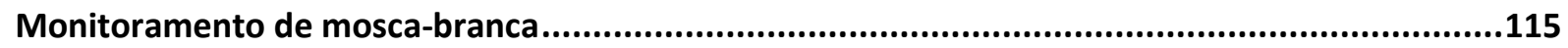

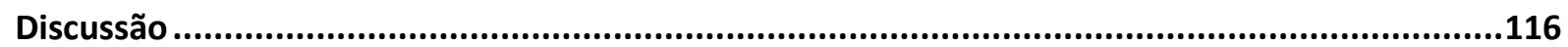

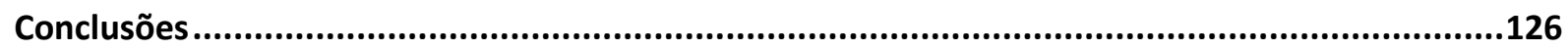

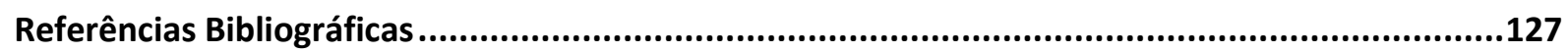

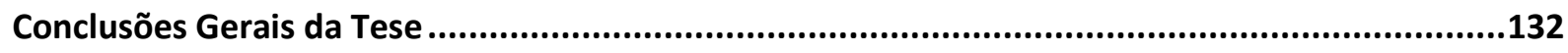

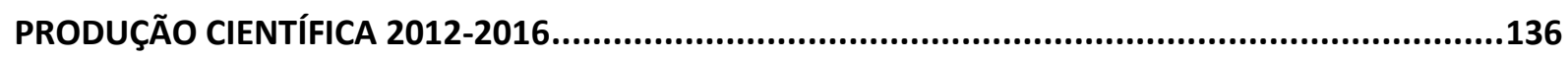


Macedo, Mônica Alves. Progresso temporal e espacial de begomovirose e crinivirose em tomateiro. 2016 (138p). Tese (Doutorado em Fitopatologia) - Universidade de Brasília, Brasília, DF.

\section{Resumo Geral}

Até meados da última década, as tospoviroses e begomoviroses eram as duas viroses que mais preocupavam os tomaticultores brasileiros. No entanto, em 2006, outra virose, a crinivirose, foi identificada em plantas de tomate no estado de São Paulo. Hoje, as viroses com maior incidência em tomateiro são a begomovirose e a crinivirose. O manejo adequado de doenças transmitidas por vetores ainda é um desafio devido à grande carência de informações sobre os processos epidemiológicos dessas doenças sob condições de campo. Em vista dessa carência de informação, os principais objetivos desse trabalho foram estudar os processos epidemiológicos envolvidos na begomovirose e crinivirose em tomateiro com o intuito de obter informações que possam ajudar na elaboração de estratégias de manejo para a redução dos prejuízos causados por viroses em tomateiro. Os temas deste trabalho foram divididos em três capítulos. O capítulo 1 foi destinado à revisão bibliográfica. $\mathrm{O}$ capítulo 2 descreve o estudo do progresso espacial e temporal de begomovirose em tomateiro de crescimento determinado. O capítulo 3 foi destinado ao estudo do progresso temporal e espacial de begomovirose e crinivirose em tomateiro de crescimento do tipo indeterminado. Nos estudos de distribuição e espacial de viroses, parcelas de 15 x 15 plantas foram demarcadas e avaliadas semanalmente, quanto à presença ou ausência de sintomas característicos das viroses. Um monitoramento da população de moscas-brancas, coleta e detecção de vírus em plantas daninhas e cultivadas presentes dentro e/ou ao redor das parcelas experimentais foi realizado. Tomato severe rugose virus (ToSRV) e Tomato chlorosis virus (ToCV) foram respectivamente a espécie de begomovirus predominante e a única espécie de crinivirus 
encontrada nas amostras coletadas. Algumas plantas cultivadas e não cultivadas estavam infectadas com ToSRV ou ToCV, indicando que são potenciais plantas hospedeiras alternativas. Não foi observada correlação positiva entre a incidência de begomovirose ou crinivirose e a flutuação das populações de mosca-branca. Nas áreas monitoradas, o progresso da doença foi invariavelmente rápido, com um padrão levemente agregado das plantas sintomáticas de begomovirus (tomateiro estaqueado e rasteiro) / ou crinivirus (tomateiro estaqueado). Não foi verificada diferença significativa nas análises temporais e espaciais entre as duas espécies virais ou entre áreas de produção. No entanto, foi observada uma diferença significativa entre parcelas experimentais localizadas no centro (PC) e na borda (PE) dos pivôs centrais (área de cultivo) em tomateiro para processamento. Os resultados de análises temporais mostraram que os valores de incidência e área abaixo da curva de progresso da doença de begomovirus foram menores em PC do que em PE. Em análises espaciais, plantas sintomáticas em PC foram mais agregadas que em PE. Todos esses resultados sugerem fortemente que a distribuição de plantas sintomáticas de begomovirus em PC e PE é governada por diferentes mecanismos de disseminação. Embora essas análises temporal e espacial comparativas entre parcelas localizadas na borda e centro só tenham sido realizadas em tomateiro rasteiro, acredita-se que a dinâmica das begomoviroses e criniviroses em tomateiro estaqueado segue mesmo padrão. Em especial, verificou-se que o padrão de distribuição da crinivirose e da begomovirose é semelhante, mesmo as duas viroses apresentando modos de transmissão distintos pela mosca-branca. Esse padrão foi similar ao observado em PE, indicando que a dispersão primária assume papel relevante na disseminação das duas doenças. Levando em consideração os resultados obtidos no trabalho recomenda-se como manejo de viroses em tomateiro: a realização de um planejamento de plantio evitando associação de cultivos susceptíveis a begomovirus e também com bons hospedeiros do inseto-vetor; a prevenção de plantio escalonado; a eliminação de restos 
culturais e plantas de tomate voluntárias; e o controle do inseto vetor durante todo o cultivo do tomateiro dentro e fora da lavoura até a eliminação total das plantas. Todas essas medidas de manejo devem ser realizadas de forma integrada e regional para o sucesso de controle das viroses em tomateiro.

Palavras-chaves: begomovirus, crinivirus, epidemiologia, Solanum lycopersicum

Orientadora: Alice Kazuko Inoue Nagata, Universidade de Brasília, Embrapa Hortaliças.

Co-orientador: Armando Bergamin Filho, Escola Superior de Agricultura "Luiz de Queiroz".

Orientador do doutorado sanduiche: Robert Leonard Gilbertson, Universidade de Davis. 
Macedo, Mônica Alves. Temporal and spatial progress of begomovirus and crinivirus in

tomatoes. 2016 (138 pag). Thesis (Doctorate in Plant Pathology) - Universidade de Brasilia, Brasilia, DF, Brazil.

\section{General Abstract}

Tospovirus and begomovirus diseases are the two most important viral diseases that affect Brazilian tomato crops in the last two decades. However, in 2006, another viral disease caused by a crinivirus was identified infecting tomato plants in the state of São Paulo, Brazil. Today, the viral diseases with higher incidence in tomato are the ones caused by begomoviruses and criniviruses. Management of vector-borne diseases remains a challenge due to the great lack of information on epidemiological aspects of these diseases under field conditions. In view of this lack of information, the main objectives of this work were to study the epidemiological processes involved in begomovirus and crinivirus diseases in tomato; evaluate the effect of a tomato-free-period in the incidence of the diseases caused by begomovirus and tospovirus in this crop; and evaluate the potential of five plant species as alternative host for Tomato severe rugose virus (ToSRV) and Bean golden mosaic virus (BGMV) in order to obtain information that could help in the development of management strategies to reduce the losses caused by these viral diseases. The subjects of this study were divided into five chapters. Chapter 1 contains the literature review. The chapter 2 describes the spatial and temporal distribution of the begomovirus disease in processing tomato production areas. Chapter 3 reports the temporal and spatial progress of begomovirus and crinivirus diseases in fresh market tomato production areas. In chapters 2 and 3 , plots of $15 \mathrm{x}$ 15 plants were marked and weekly evaluated for the presence or absence of characteristic symptoms of these diseases in the plants. Monitoring of the whitefly populations, collection and detection of viruses in weeds and in cultivated plants present inside or around of the 
experimental plots were carried out. These studies revealed that ToSRV and Tomato chlorosis virus (ToCV) were the predominant begomovirus species and the only crinivirus species found in the areas. Some cultivated and uncultivated plants were infected with ToSRV or ToCV, indicating that they are potential alternative host plants. There was no positive correlation between the incidence of begomovirus or crinivirus disease and the fluctuation of the whitefly population. In the monitored areas, the progress of the diseases was invariably fast, with a slightly aggregated pattern of symptomatic plants infected by begomovirus or crinivirus. There was no significant difference in the temporal and spatial analysis between the two viral species or among the tomato production areas. However, a significant difference was observed between the experimental plots located in the center (PC) and the edge (PE) of the central pivot described in Chapter 2. These results have shown that the values of incidence and the area under disease progress curve of begomovirus were lower in PC than in PE. In the spatial analyses, symptomatic plants in PC were more aggregated than in PE. All these results strongly suggest that the distribution of begomovirus symptomatic plants in PC and PE is ruled out by different spreading mechanisms. Although these temporal and spatial analyses of comparative plots located at the edge and in the center have only been carried out in processing tomato areas, it is believed that the spread of begomovirus and crinivirus disease in fresh market tomato crops follows the same pattern. In particular, it was found that the distribution pattern of crinivirus and begomovirus is similar, although they have different transmission mechanisms by whiteflies. The spatial distribution pattern of these diseases was similar to that observed in begomovirus disease in PE in processing tomato areas, indicating that the primary dispersion assumes an important role in the spread of the two diseases. In Taking all these results together, for the management of tomato viruses it is recommended: avoid areas with susceptible hosts for begomoviruses and good insect-vector hosts; prevention of continuous planting; elimination of crop residues and voluntary tomato plants; insect vector 
control during the cultivation of tomato inside and outside the field until the total elimination of the crop. All these management measures should be undertaken in an integrated and regional basis for a successful control of these viruses in tomato.

Keywords: Begomovirus, Crinivirus, epidemiology, Solanum lycopersicum

Advisor: Alice Kazuko Inoue Nagata, University of Brasília, Embrapa Hortaliças

Co-Advisor: Armando Bergamin Filho, Escola Superior de Agricultura "Luiz de Queiroz"

Advisor of sandwich PhD: Robert Leonard Gilbertson, University of Davis. 


\section{Introdução Geral}

O tomateiro (Solanum lycopersicum) é uma hortaliça cultivada em regiões tropicais e subtropicais durante todas as estações do ano. No Brasil essa hortaliça possui elevada importância sócio-econômica, devido à grande demanda de mão-de-obra e à extensão da área cultivada. No Brasil, atualmente 64,36 mil hectares de terra são destinados à tomaticultura, sendo que nessa área são produzidas aproximadamente 4,2 milhões de toneladas de frutos por ano, dados referentes ao ano de 2014 (IBGE, 2016). No ano de 2010, aproximadamente 56\% da produção de tomate no País foi destinado ao consumo in natura e aproximadamente $44 \%$ à indústria (Clemente \& Boiteux, 2012). As principais áreas de cultivo de tomate encontram-se nos estados de Goiás, Minas Gerais, São Paulo, Bahia, Rio Grande do Sul e Paraná (IBGE, 2016).

O cultivo ininterrupto do tomateiro favorece o aparecimento de diversas doenças que diminuem a produção e afetam a qualidade do fruto. Essas doenças são causadas por diversos patógenos e aquelas de origem viral são as que apresentam maior dificuldade de controle. No Brasil, as principais doenças de origem viral são causadas por espécies de vírus dos gêneros Begomovirus (Fernandes et al., 1983), Tospovirus (Kurozawa \& Pavan, 2005) e Crinivirus (Barbosa et al., 2011; Macedo et al., 2014). A begomovirose e a crinivirose são as que ocorrem em maior incidência na cultura, devido principalmente à forma de disseminação; alta população do inseto vetor; grande quantidade de hospedeiras alternativas em campo; à falta de cultivares resistentes principalmente no segmento rasteiro e à falta de um manejo integrado e regional.

No Brasil, a begomovirose em tomateiro é causada por diversas espécies de Begomovirus, no entanto, a espécie Tomato severe rugose virus (ToSRV) é a espécie predominante (Fernandes et al., 2008; Macedo et al., 2014). Os begomovirus pertencem à família Geminiviridae, possuem DNA circular fita simples e podem apresentar um 
(monopartidos) ou dois componentes genômicos (bipartidos), denominados DNA-A e DNA-B (Brown et al., 2015). A crinivirose em tomateiro é causada por duas espécies de Crinivirus, porém apenas o Tomato chlorosis virus (ToCV) já foi relatado no País (Barbosa et al., 2008; Barbosa et al., 2011; Macedo et al., 2014). Espécies do gênero Crinivirus pertencem à família Closteroviridae e possuem genoma composto por RNA fita simples positiva (Wisler et al., 1998). Begomovirus e crinivirus são vírus transmitidos naturalmente pelo mesmo inseto vetor, a mosca-branca, porém possuem inter-relação vírus-vetor distinta. Os begomovirus são transmitidos de maneira circulativa-persistente por diversos biótipos de B. tabaci (Ghanim et al., 1998; Morin et al., 1999; Rubinstein \& Czosnek 1997, Rosen et al., 2015) e crinivirus são transmitidos de maneira não circulativa semi-persistente por B. tabaci e duas espécies de Trialeurodes, T. vaporariorum e T. abutilonea (Wisler et al., 1998), sendo essa última ainda não relatada no Brasil.

Devido à alta incidência de begomovirose em tomateiro e alta população de moscabranca, aliados à dificuldade do manejo em tomateiro de crescimento determinado (tomateiro rasteiro), foi implementada uma instrução normativa (IN 024, SDA, de 2003, MAPA) como medida de controle para essa doença. Essa medida de controle prevê a modificação do calendário de plantio de tomateiro rasteiro, com a implementação de um período entre 60 a 120 dias consecutivos livres de tomateiro destinado à indústria de processamento, além de determinar algumas práticas de manejo integrado de pragas. Apenas o estado de Goiás regulamentou essa medida (IN 05 de 2007, Agrodefesa, GO), onde o transplantio é permitido somente entre os meses de fevereiro a junho, outros estados produtores de tomateiro rasteiro adotam um calendário de plantio semelhante, embora não oficialmente. Em municípios onde existe produção significativa de tomate para consumo in natura (estaqueado), a eficiência dessa medida pode ser comprometida. Existe uma grande dificuldade de se estender a instrução normativa para o tomateiro estaqueado, pois a demanda por frutos in natura é 
contínua e a produção é realizada por pequenos produtores o que dificulta a fiscalização. No estado de Goiás, no entanto, o plantio de tomateiro estaqueado em alguns municípios já é obrigatório seguir o calendário de plantio de tomateiro rasteiro (IN 006/2011, Agrodefesa, GO). A adoção de uma medida de controle similar foi implementada com sucesso no controle de begomovirose em tomateiro na Republica Dominicana que instituiu um período livre de hospedeiros de moscas-brancas igual a 90 dias (Salati et al., 2002).

No Brasil, surtos de begomovirose em tomateiro ainda foram observados mesmo após a implementação dessa medida de controle (Macedo et al., 2014). Apenas a ausência de tomateiro em campo pode não ser eficiente no controle da virose devido a diversos fatores, como a presença de inúmeras plantas alternativas suscetíveis ao vírus e altíssima população do inseto vetor em campo logo nos primeiros plantios. Espécies de plantas daninhas como Nicandra physaloides (Barbosa et al., 2009), Crotalaria spp., Euphorbia heterophylla, e Sida spp. já foram reladas como hospedeiras alternativas de ToSRV no Brasil (Barreto et al., 2013). Espécies de plantas cultivadas também podem ser hospedeiras alternativas de ToSRV como Solanum tuberosum (Souza-Dias et al., 2008), Capsicum baccatum (Bezerra-Agasie et al., 2006), Capsicum annuum (Nozaki et al., 2006), Glycine max e Phaseolus vulgaris (dados não publicados). A presença dessas espécies hospedeiras alternativas nas proximidades das áreas de produção de tomateiro pode levar à diminuição da eficiência do vazio fitossanitário. Portanto, existem dúvidas sobre a real eficácia desta medida como controle de begomovirose em tomateiro e dos fatores que possam interferir na eficiência dessa medida para essa cultura no Brasil.

O manejo de doenças transmitidas por insetos vetores como a tospovirose, crinivirose e begomovirose ainda é um desafio. Estudos dirigidos para essa área da fitopatologia são raros, o que leva à existência de uma enorme lacuna no conhecimento do progresso das epidemias dessas doenças, dificultando a elaboração de estratégias de controle eficientes. 
Com o intuito de gerar informações que possam ajudar a preencher algumas dessas lacunas o objetivo desse trabalho foi estudar os aspectos epidemiológicos de begomovirose e crinivirose em tomateiro; avaliar o efeito do vazio fitossanitário na incidência de begomovirose e tospovirose em tomateiro rasteiro e avaliar o potencial de plantas associadas ao tomateiro como hospedeiras alternativas de ToSRV. 


\section{Objetivos}

\section{Objetivo Geral}

O objetivo geral desse trabalho foi estudar aspectos epidemiológicos das principais viroses em tomateiro e avaliar a distribuição espacial e temporal de begomovirose e crinivirose.

\section{Objetivos específicos descritos no capítulo 2:}

$\checkmark$ Estudar o progresso temporal e espacial de begomovirose em tomateiro de crescimento do tipo determinado;

$\checkmark$ Estudar como os componentes de disseminação de begomovirus que afetam a distribuição espacial e temporal de begomoviroses em tomateiro de crescimento determinado;

$\checkmark$ Determinar as espécies de Begomovirus predominantes em cultivares de crescimento determinado;

$\checkmark$ Identificar espécies de plantas daninhas e cultivadas infectadas naturalmente com begomovirus de tomateiro;

$\checkmark$ Monitorar a população de mosca-branca e confrontar com a incidência de begomovirose. 


\section{Objetivos específicos descritos no capítulo 3:}

$\checkmark$ Estudar o progresso temporal e espacial de begomovirose e crinivirose em tomateiro de crescimento do tipo indeterminado;

$\checkmark$ Estudar como os componentes de disseminação de begomovirus e crinívirus afetam a distribuição espacial e temporal de begomoviroses e criniviroses em tomateiro indeterminado;

$\checkmark$ Determinar as espécies de Begomovirus e Crinivirus predominantes em cultivares de crescimento indeterminado;

$\checkmark$ Identificar espécies de plantas daninhas e cultivadas infectadas naturalmente com begomovirus e crinivirus de tomateiro;

$\checkmark$ Monitorar a população de mosca-branca e confronta com a incidência de begomovirose e crinivirose. 


\section{Capítulo 1: Revisão de literatura}

\section{O tomateiro}

O tomateiro (Solanum lycopersicum) pertence à família Solanaceae e é originário da região hoje correspondente ao território do Peru, Chile, Bolívia, Equador e Colômbia (Esquinas-Alcázar \& Nuez, 1995; Fontes \& Silvas, 2002; Rick \& Holle, 1990). A partir dessa região, o tomateiro foi introduzido em diversos países, e, em pouco tempo, a tomaticultura foi amplamente disseminada em todos os continentes. Essa cultura possui atualmente relevante importância econômica no mundo inteiro, sendo que o Brasil ocupa a $8^{\text {a }}$ posição no ranking dos maiores produtores de tomate do mundo (FAO, 2015).

No Brasil no ano de 2014, 64,36 mil hectares foram destinados à tomaticultura, sendo que nessa área foram produzidas anualmente 4,3 milhões de toneladas de frutos (IBGE, 2015). Uma estimativa feita em 2011 revelou que aproximadamente 58\% da produção de tomate no Brasil são destinados ao consumo in natura e 42,5\% são destinados à indústria (Clemente \& Boiteux, 2012). A produtividade do tomateiro é muito variável de acordo com o tipo de produção, tipo de fruto e a região onde é cultivado. A região Centro-Oeste é a região com maior produtividade atingindo uma média de 85,73 ton/ha, em seguida está a região Sudeste com média 68,59 ton/ha, sendo que essas duas regiões concentram os principais estados produtores (IBGE, 2015).

\section{Tomate segmento para consumo in natura}

No Brasil, a cultura do tomateiro para consumo in natura (tomate de mesa) tem sido uma importante fonte de emprego ao longo de toda a cadeia produtiva (ABCSEM, 2009). O cultivo do tomate para esse segmento é normalmente conduzido em sistemas estaqueados ou tutorados, gerando intensa mão-de-obra (Boiteux et al., 2008).

A produção de tomate para mesa distribui-se entre as regiões Sudeste $(59,3 \%)$, CentroOeste $(7,1 \%)$, Sul $(18,2 \%)$, Nordeste $(15,1 \%)$ e Norte $(0,3 \%)$. Os principais estados 
produtores nesse segmento são: Minas Gerais (20\%), São Paulo $(19,1 \%)$, Rio de Janeiro (9,7\%), Bahia (9\%), Paraná (8,2\%), Goiás (6,3\%), Santa Catarina (6\%) e Rio Grande do Sul (4\%) (ABCSEM, 2009; Boiteux et al., 2008).

O Brasil apresenta uma grande diversidade de sistemas de cultivo de tomate para consumo in natura ocupando de 38 a 42 mil hectares (ABCSEM, 2009; Tavares, 2002). Os tomates para consumo in natura podem ser divididos em diferentes grupos varietais de acordo com o formato de seus frutos e sua finalidade de uso. Os segmentos varietais de maior importância no país são: salada indeterminado e determinado; Santa Cruz, italiano/saladete e cereja (ABCSEM, 2009).

\section{Tomate segmento para processamento industrial}

Atualmente, a cadeia agro-industrial brasileira de tomate para processamento industrial é considerada dinâmica, eficiente e competitiva (Clemente \& Boiteux 2012). A incorporação vigorosa de avanços tecnológicos fez a produtividade aumentar de 35t /ha na década de 90 para uma média atual próxima a 80t /ha (IBGE, 2010).

A distribuição das áreas de produção de tomateiro industrial sofreu grande modificação a partir da década de 90. Até então, a região Nordeste concentrava a maior parte da produção, mas teve sua área gradativamente reduzida devido a inúmeros problemas, principalmente fitossanitários que levaram ao fechamento de várias fábricas (Clemente \& Boiteux 2012). A partir do final da década de 90, a produção de tomateiro industrial já era concentrada na região Centro-Oeste brasileira, especialmente o estado de Goiás (Clemente \& Boiteux 2012). Estimativas de 2011 mostraram que Goiás possui mais de $84 \%$ da área de produção de tomateiro rasteiro, seguido por São Paulo, com 13,4\% e Minas Gerais com 1,79\%, sendo que os demais estados produtores representam menos de 1\% das áreas cultivadas (IBGE, 2012). Atualmente esse cenário não deve ser mais o mesmo, pois esse segmento é dinâmico devido à 
abertura, deslocamento e fechamento de fábricas de processamento de tomateiro que ocorrem com certa frequência.

\section{Doenças de origem viral no tomateiro}

A ocorrência de doenças é um dos fatores que mais preocupam os tomaticultores e certamente constituem os principais fatores que contribuem para a diminuição da produção na cultura do tomateiro. Dentre as doenças de origem viral destacam-se as causadas por espécies de vírus dos gêneros Tospovirus, Begomovirus (Kurozawa \& Pavan, 2005) e Crinivirus (Barbosa et al., 2009; Macedo et al., 2014), mas outras espécies pertencentes aos gêneros Potyvirus, Cucumovirus, Tobamovirus também afetam a cultura (Lopes, 2005). Tanto o cultivo de tomateiro estaqueado como o rasteiro são afetados pelas principais doenças de origem viral. No entanto o segmento rasteiro é mais carente na oferta de cultivares resistentes a begomovirus e tospovirus que o segmento mesa que disponibiliza um leque maior de opções de cultivares. A seguir será realizada uma descrição sucinta dos três principais gêneros de vírus que afetam o cultivo do tomateiro no País.

\section{O gênero Begomovirus}

O gênero Begomovirus pertence à família Geminiviridae, família considerada mais numerosa dentre os vírus de plantas, possuindo atualmente 325 espécies, sendo que 288 são espécies do gênero Begomovirus (ICTV on line, 2015). A família Geminiviridade é formada por sete gêneros: Becurtovirus, Begomovirus, Curtovirus, Eragrovirus, Mastrevirus, Topocuvirus e Turncurtovirus, assim divididos de acordo com a gama de hospedeiros, inseto vetor, organização genômica e relacionamento filogenético (ICTV on line, 2015). Os vírus dessa família possuem DNA circular de fita simples e são encapsidados em partículas com morfologia geminada, se replicam no núcleo da célula hospedeira a partir de um intermediário de DNA dupla fita através do mecanismo de círculo rolante (Saunders et al. 1991; Stenger et 
al. 1991). Os vírus dos gêneros Becurtovirus, Curtovirus, Eragrovirus, Mastrevirus, Topocuvirus e Turncurtovirus possuem apenas um componente genômico enquanto aqueles do gênero Begomovirus podem possuir um (monopartido) ou dois componentes (bipartido) (Adams et al., 2013).

As partículas virais da maioria dos begomovirus são restritas ao tecido floemático da planta e são transmitidas naturalmente por insetos-vetores (Stanley, 2005). Nos begomovirus bipartidos os dois elementos genômicos são essenciais para o sucesso da infecção viral (Sunter \& Bisaro, 1992). Existem poucos casos onde os begomovirus bipartidos são capazes de causar infecção sistêmica apenas com um dos componentes virais, o DNA-A, por exemplo, um caso de um begomovirus do velho mundo (Rojas et al., 2005) e outro do novo mundo (Galvão et al., 2003). O DNA-A possui cinco ORFs, quatro no sentido complementar (Rep, TrAP, REN e AC4) e uma no sentido Viral (CP) (Stanley, 2005). O DNA-B possui duas ORFs, uma no sentido viral (NSP) e a outra no sentido complementar (MP) (Stanley, 2005). O DNA-A codifica proteínas envolvidas na replicação e transcrição do DNA viral (Rep, TrAP, REN) e a proteína capsidial (CP) e o DNA-B é fundamental para a síntese de proteínas responsáveis para o movimento célula-a-célula, via plasmodesmas (MP) e para o movimento intracelular do núcleo para o citoplasma e vice-versa (NSP) (Rojas et al., 2005). A CP é uma das proteínas mais importantes para a transmissão de vírus por vetores em begomovirus. A CP é uma proteína multifuncional, que além de proteger o DNA viral, desempenha funções durante a transmissão mecânica ou por vetor, sendo essencial na determinação da especificidade do inseto-vetor (Unseld et al., 2004). O DNA-A e o DNA-B não possuem homologia na sequência de nucleotídeos, exceto por uma região intergênica de aproximadamente 200 nucleotídeos, denominada região comum (RC), que é altamente conservada entre os dois componentes de uma determinada espécie viral (acima de 90\% de 
homologia). A partir desta região os genes virais divergem nos sentidos viral e complementar (Lazarowitz, 1992; Stanley \& Gay, 1983).

A variabilidade gênica em begomovirus ocorre por meio de mutação, recombinação e pseudo-recombinação. As mutações são pouco frequentes em vírus com genoma de DNA, uma vez que estes possuem a capacidade de corrigir erros de leitura durante a replicação (“proof-reading”) da DNA polimerase (Roossinck, 1997). Entretanto, trabalhos recentes demonstraram que para alguns vírus de ssDNA, como geminivirus, a frequência de mutação pode ser semelhante a taxa de mutação dos vírus de RNA, o que leva esses vírus a apresentarem taxas evolutivas similares a dos vírus de RNA (Duffy \& Holmes, 2009) A existência de dois componentes genômicos na maioria dos begomovirus possibilita um mecanismo alternativo para a existência de variabilidade gênica. Este mecanismo de troca de elementos genômicos entre vírus distintos é chamado de pseudo-recombinação (“reassortment”) (Stanley et al., 1985). A recombinação é considerada o principal mecanismo de variabilidade gênica na família Geminiviridae (Padidam et al., 1995). A recombinação de DNA em geminivírus pode ocorrer não somente entre isolados de um mesmo vírus, mas também entre espécies de gêneros distintos, o que resulta no rápido surgimento de novas formas virais (Seal et al., 2006). Devido a essa alta taxa de recombinação nos begomovirus, pequenos fragmentos de genoma não podem ser usados como critérios para a definição de novas espécies. Em 2015, Brown e colaboradores realizaram uma revisão detalhada dos critérios de demarcação de espécies, estirpes e isolados, a partir da análise de 3123 sequências de nucleotídeos do DNA-A de isolados de begomovirus depositados em bancos de dados públicos (Brown et al., 2015). Os critérios demarcados nesse trabalho para a classificação de novas espécies incluem dentre outros aspectos, o número de componentes genômicos (presença ou ausência do DNA-B), a organização do genoma (presença ou ausência da ORF AV2) e o sequenciamento de nucleotídeos completo do DNA-A. A porcentagem de 
identidade de nucleotídeos deve estar abaixo de 91\% utilizando Sequence Demarcation Tool (SDT) v. 1.0 (Muhire et al., 2014) e MUSCLE (Edgar, 2004) como opção de alinhamento, para que o isolado seja considerado uma nova espécie. Se o isolado apresentar níveis de identidade entre $91 \%$ a 94\%, o isolado em questão é considerado uma nova estirpe (Brown et al., 2015). Em consequência desses novos critérios, algumas espécies foram re-classificadas como isolados, enquanto outros, previamente classificados como isolados foram elevados ao nível de espécie (Brown et al., 2015).

\section{Os begomovirus no Brasil e no Mundo}

Entre os begomovirus de maior importância econômica mundial pode-se citar o Bean golden mosaic virus (BGMV), o African cassava mosaic virus (ACMV) e o Tomato yellow leaf curl virus (TYLCV) (Moriones \& Navas-Castilho, 2000; Were \& Winter, 2004). Desses vírus apenas o BGMV, um begomovirus bipartido, ocorre no Brasil, e ainda não há relatos da presença desses outros dois begomovirus.

O primeiro relato de um begomovirus no Brasil foi feito em 1950 por Costa e Bennett. Eles demonstraram que um begomovirus identificado em plantas de Euphorbia prunifolia era transmitido por mosca-branca (Costa \& Bennett, 1950). Uma década mais tarde foi feito o primeiro relato de begomovirus em tomateiro (Flores et al., 1960). Cinco anos mais tarde foi feito o primeiro relato de begomovirus afetando a cultura do feijão comum (Phaseolus vulgaris) (Costa, 1965).

O aumento da incidência de begomoviroses no país é atribuído principalmente a dois eventos. O primeiro foi o aumento da área plantada com soja no país, observando-se um grande surto populacional do inseto vetor de begomovirus, pois a soja é excelente hospedeira de mosca-branca (Musa \& Ren, 2005) e não sofre grandes danos com o ataque da praga (Faria et al., 2000). Como consequência, nos anos 70 essa doença tornou-se fator limitante para o cultivo de feijoeiro no Brasil (Faria, 1994). Outras culturas passaram, então, a ser afetadas por 
begomovirus e relatos de begomovirus em tomateiro passaram a ser mais frequentes (Costa $e t$ al., 1975). No mesmo ano, o vírus do mosaico dourado do tomateiro foi purificado e nomeado como Tomato golden mosaic virus (TGMV) (Matyis et al., 1975). O segundo evento foi à introdução do biótipo B de Bemisia tabaci no país na década de 90, ocorrendo um grande surto de begomoviroses em diversas culturas, mas principalmente em tomateiro (Valle \& Lourenção, 2002).

Hoje, os bancos de dados públicos listam a ocorrência de 16 espécies de begomovirus isoladas de tomateiro no Brasil e consideradas espécies definitivas pelo ICTV: Tomato bright yellow mosaic virus, Tomato chlorotic mottle virus, Tomato common mosaic virus, Tomato golden mosaic virus, Tomato golden leaf spot virus, Tomato golden leaf distortion virus, Tomato golden vein virus, Tomato interveinal chlorosis virus, Tomato leaf distortion virus, Tomato mild mosaic virus, Tomato mottle leaf curl virus, Tomato rugose mosaic virus, Tomato severe rugose virus, Tomato yellow mottle virus, Tomato yellow spot virus, Tomato yellow vein streak virus (ICTV on line 2015). Das dezesseis espécies de begomovirus presentes no País, apenas três espécies foram consideradas predominantes, ToSRV que está presente em todo o país, TGVV, que predomina no Sudeste e TMoLCV que se concentra no Nordeste brasileiro (Fernandes et al., 2008). Trabalhos realizados com begomovirus coletados no país mostraram que os vírus são autenticamente brasileiros, e não resultantes de introduções recentes de vírus exóticos (Albuquerque et al., 2010; Castillo-Urquiza et al., 2008).

\section{O gênero Crinivirus}

A família Closteroviridae inclui vírus lineares, com genoma ssRNA senso positivo, com aproximadamente $20 \mathrm{~kb}$, sendo encapsidado em partículas longas e flexuosas. Esta família possui 39 espécies distribuídas em quatro gêneros, sendo que o gênero Crinivirus, possui o maior número de espécies. Dentro desta família quatro espécies não estão classificadas em 
nenhum gênero. O gênero Crinivirus possui um genoma bipartido com duas moléculas de RNA, encapsidados em partículas alongadas e flexuosas de comprimento de 800-850nm. O RNA 1 apresenta quatro ORFs que traduzem em proteínas responsáveis por diversas funções na replicação viral. O RNA 2 possui nove ORFs, traduzido em algumas proteínas que devem atuar principalmente na encapsidação viral, no movimento célula-a-célula, na transmissão através do vetor e no domínio transmembrana (ICTV on line, 2015). O gênero Crinivirus é formado por treze espécies, mas apenas duas são capazes de causar infecção em plantas de tomateiro, a Tomato chlorosis virus (ToCV) e a Tomato infectious chlorosis virus (TICV). Ambas as espécies não são transmitidas mecanicamente, sendo dispersas em condições naturais exclusivamente pelo inseto vetor, a mosca-branca (Wintermantel \& Wisler et al., 2006). O ToCV é transmitido por biótipos de Bemisia tabaci e espécies de Trialeurodes, enquanto que o TICV é transmitido exclusivamente por Trialeurodes vaporariorum (Wisler et al., 1998). O primeiro relato de crinivirus em tomateiro foi realizado no estado da Flórida em 1996 em plantas de casa-de-vegetação, o vírus então presente era o TICV (Wisler et al., 1998). Desde então diversos relatos foram feitos em várias partes do mundo. No Brasil, o primeiro relato de crinivirus em tomateiro foi realizado em plantas de tomateiro no município de Sumaré, no estado de São Paulo em 2008 (Barbosa et al., 2008), em seguida foram realizados relatos em mais cinco estados brasileiros, Bahia, Espírito Santo, Goiás, Minas Gerais e Rio de Janeiro (Barbosa et al., 2011). No ano seguinte altas incidência de ToCV foram verificadas em áreas de produção de tomate localizadas no Distrito Federal e no estado de Goiás (Macedo et al., 2014). Os sintomas característicos de plantas de tomateiro infectadas com ToCV são clorose internerval, enrolamento e espessamento foliar nas folhas baixeiras enquanto o dossel superior permanece sem grandes alterações (Wisler et al., 1998). Este vírus apresenta um longo período de latência em plantas infectadas, apresentando sintomas somente após 3 a 4 semanas da infecção (Wintermantel \& Wisler, 2006). Apesar da ausência de 
sintomas, plantas com infecção latente servem como fonte de inóculo para a dispersão do vírus pelo inseto vetor (Wintermantel \& Wisler, 2006).

\section{Mosca-branca}

A mosca-branca foi descrita pela primeira vez na Grécia, em 1889, como Aleurodes tabaci por Gennadius, em plantas de fumo (Caciagli, 2001). São insetos sugadores que pertencem à ordem Hemiptera, família Aleyrodidae (Gallo et al., 2002), apresentando cinco gêneros principais: Bemisia, Aleurothrixus, Dialeurodes, Trialeurodes e Aleurodicus. Embora existam cerca de 1200 espécies de moscas-brancas, menos de 40 espécies são consideradas pragas (Martin, 1999). Mesmo assim, a mosca-branca se tornou um grande problema para a agricultura em áreas tropicais e subtropicais do mundo (Oliveira et al., 2003). As espécies Bemisia tabaci e Trialeurodes vaporariorum causam os prejuízos mais graves (Byrne et al., 1990).

As moscas-brancas são insetos que sugam a seiva do floema das plantas hospedeiras, tanto na fase imatura como na adulta, provocando alterações no desenvolvimento vegetativo e reprodutivo da planta (dano direto) podendo causar também danos indiretos, sendo a transmissão de vírus o dano mais sério causado pelas moscas-brancas (Byrne \& Bellows JR, 1991). Além disso, esses insetos excretam substâncias açucaradas que cobrem as folhas das plantas e servem de substrato para fungos, resultando na formação de fumagina, reduzindo o processo de fotossíntese e o valor comercial das culturas (Inbar \& Gerling, 2008). Em tomateiro, ocorre também o efeito da injeção de toxinas pelas moscas-brancas que causam o amadurecimento irregular dos frutos, o que dificulta o reconhecimento do ponto de colheita e reduz a produção e a qualidade da pasta após o processamento, além de causar a isoporização da polpa, diminuindo a qualidade e levando ao prejuízo da comercialização do produto (Villas-Boas et al., 1997). 
As ninfas como os adultos de mosca-branca possuem aparelho bucal do tipo sugador (Martin \& Mound, 2007). Os adultos possuem dois pares de asas membranosas e medem entre 1-2mm, sendo a fêmea maior que o macho. As ninfas são translúcidas e têm a coloração amarela a amarelo-pálido e os adultos possuem o dorso de cor amarelo e as asas brancas (Villas-Boas et al., 1997). Todos os estádios habitam a face inferior das folhas e apenas o adulto é capaz de migrar até novas plantas e os estádios imaturos permanecem o tempo todo em uma mesma planta (Villas-Boas et al., 1997). No entanto, a fase inicial da ninfa, primeiro instar é móvel, sendo as demais fases sésseis (Inbar \& Gerlin, 2008).

A mosca-branca, B. tabaci, apresenta metamorfose incompleta, passando pelas fases de ovo, ninfa e adulto, sendo que a fase de ninfa apresenta quatro estádios. A reprodução dessa espécie pode ser sexual ou partenogenética. Na reprodução sexual, a prole será de machos e fêmeas e quando partenogenética, ela será constituída somente de machos (Blackman \& Cahill, 1998). Existe também uma regulação na taxa sexual, quando a população de machos está maior que das fêmeas, a reprodução sexual aumenta, para aumentar a proporção de fêmeas (Byrne et al., 1990). A fêmea coloca de 100 a 300 ovos durante toda a sua vida. Em média ocorrem entre 11 e 15 gerações por ano. O tempo que o inseto demora para emergir desde o ovo até o adulto é de aproximadamente 20 dias, mas esse período varia de acordo com a temperatura (Byrne \& Bellow, 1991; Brown \& Bird, 1992). A longevidade do inseto depende da temperatura e da planta fonte de alimentação. Em tomateiro a longevidade de fêmeas foi igual a 19 dias (Salas et al., 1995), em repolho a longevidade variou de 12 a 30 dias e em feijoeiro o tempo de vida máximo foi igual a 40 dias (Villas-Boas et al., 2002).

A mosca-branca $B$. tabaci se caracteriza por ser polífaga e explorar um grande número de plantas hospedeiras (Brown et al., 1995). Além de plantas cultivadas, muitas espécies de plantas daninhas são hospedeiras desse inseto. Mas pouco é conhecido sobre a interação da praga com suas plantas hospedeiras e os fatores que regulam o comportamento de seleção de 
novos hospedeiros, bem como seu potencial de adaptação para novas espécies. A B. tabaci é primeiramente atraída por plantas de cor amarela e é determinada pelo contato e picada de prova (Berlinger, 1986). Se o inseto pousar em um hospedeiro adequado permanecerá nele, para futura alimentação e ovoposição. Por outro lado, se o hospedeiro não foi adequado, o inseto deixará a planta (Berlinger, 1986). Em um estudo de preferência de hospedeiras, foi verificada que as plantas com maior números de adultos foram plantas de aboborinha, tomate, feijão, pepino, berinjela, repolho e soja em detrimento a mandioca, milho e pimentão (VillasBôas et al., 2001).

A existência de biótipos de $B$. tabaci foi proposta na década de 50, após a descoberta de populações morfologicamente semelhantes, que exibiam traços biológicos diferentes com relação à afinidade para a planta hospedeira, aos graus de sintoma de viroses, a resistência a inseticidas, a morfologia e ao comportamento dos insetos (Bedford et al., 1994; Brown et al., 1995; Costa \& Brown, 1991). O complexo B. tabaci é formado por cerca de 41 biótipos morfologicamente indistinguíveis (De Barro et al., 2005).

No Brasil, os primeiros relatos da ocorrência da mosca-branca datam de 1923, que ocorriam nessa época em várias culturas em baixa infestação (Bondar, 1928). Um pouco mais tarde entre o final da década de 60 e início na década de 70, surtos populacionais foram verificados em lavouras de algodão, soja, feijão no norte do estado do Paraná e na região sul do estado de São Paulo (Costa et al., 1973). Depois desses relatos, somente no início da década de 90, novos surtos de mosca-branca foram observados, mais precisamente no estado de São Paulo (Lourenção \& Nagai, 1994). Esse novo surto de mosca-branca foi associado à introdução de um novo biótipo de B. tabaci no País, o biótipo B (Lourenção \& Nagai, 1994). Após a constatação desse novo biótipo em São Paulo, esse rapidamente se espalhou para as demais regiões agrícolas do Brasil (Lourenção \& Nagai, 1994; França et al., 1996). 
A introdução do biótipo B de B. tabaci no Brasil foi provavelmente através da planta ornamental poinsétia (Euphorbia pulcherrima) (Lourenção \& Nagai, 1994; Melo, 1992). O biótipo nativo brasileiro, denominado biótipo A, foi gradativamente substituído pelo biótipo B, que é atualmente o biótipo predominante no País (Lima et al., 2000). Por muito tempo não foi mais verificada a presença do biótipo A, no entanto estudos recentes verificaram a presença de dois biótipos de B. tabaci nativos do Brasil, biotipo A e biótipo BR (Marubayashi et al., 2013). E mais recentemente foi relatada a presença de um biotipo de $B$. tabaci exótico no sul do Brasil, o biótipo Q (Fonseca et al., 2015). O resultado dessa nova introdução poderá modificar o cenário de distribuição de biótipos de $B$. tabaci no País, além de possíveis alterações na gama de hospedeiros e espécies susceptíveis de vírus transmitidos por B. tabaci, como foi observado após a introdução do biótipo B.

A classificação de acordo com biótipos é baseada em aspectos biológicos e morfológicos, sendo considerado um método de difícil reprodução entre laboratórios distintos, podendo gerar resultados divergentes para indivíduos pertencentes ao mesmo biótipo (De Barro et al., 2011). Atualmente o método mais informativo e reproduzível para classificação do complexo B. tabaci é baseado na análise da sequência parcial do gene Mitocondrial Citocromo Oxidase I (mtCOI) (De Barro et al., 2011). Com base nessa nova classificação tem sido geralmente aceito que, em vez de um complexo de espécies, B. tabaci é um complexo de 11 grupos com alto nível de distinção que englobam pelo menos 36 espécies morfologicamente indistinguíveis, todas separadas por um mínimo de 3,5\% de identidade da sequência parcial do gene mtCOI (Dinsdale et al., 2010; De Barro et al., 2011; Hu et al., 2011; Alemandri et al., 2012; Boykin et al., 2012; Tay et al., 2012; Firdaus et al., 2012). Os biótipos A e BR nativos do Brasil e os exóticos no País B e Q, de acordo com essa nova classificação foram denominados respectivamente como espécie New World (NW); New world 2 (NW2); Middle East-Asia Minor 1 (MEAM1); e Mediterranean (MED). Nesse 
trabalho foi adotada a classificação de $B$. tabaci, baseada em biótipos pela facilidade e familiaridade com essa classificação.

Atualmente, a mosca-branca é considerada um grupo importantíssimo em âmbito mundial, veiculando mais de 40 fitovirus diferentes (Brown \& Bird, 1992). A mosca-branca além de transmitir vírus pertencentes ao gênero Begomovirus, também pode transmitir espécies dos gêneros Crinivirus, Carlavirus e Ipomovirus. Porém, a grande maioria das espécies transmitidas por mosca-branca encontra-se no gênero Begomovirus (Canto et al., 2007; Jones, 2003).

\section{Transmissão de begomovirus por vetor}

Os begomovirus são naturalmente transmitidos por moscas-brancas a partir de fontes de vírus próximas, não sendo transmitidos por contato entre plantas, nem por sementes (Costa, 1976). No entanto, dois trabalhos recentes tem mostrado evidencias de que duas espécies de begomovirus podem ser transmitidas por sementes (Kim et al., 2015; Kil et al., 2016), no entanto ainda não é uma informação plenamente aceita. A transmissão de begomovirus por moscas-brancas é do tipo persistente-circulativa (Cohen \& Nitzanv 1966; Rubinstein \& Czosnek, 1997; Ghanim et al., 1998; Morin et al., 1999; Rosen et al., 2015). Existe ainda muita controvérsia se ocorre ou não replicação de begomovirus no inseto vetor, então até o momento a inter-relação begomovirus-vetor, tem sido considerada como não-progativa. Estudos realizados por Pakkianathan et al. (2015) demostraram uma evidência de replicação de Tomato yellow leaf curl virus (TYLCV) (ssDNA) no corpo de B. tabaci. O período de retenção ou persistência do vírus no vetor é relativamente longo, de algumas semanas ou por toda a vida do inseto (Costa, 1998).

O movimento de begomovirus através do corpo da mosca-branca segue uma via específica, exigindo a superação de inúmeras barreiras, membranas no corpo do inseto (Hogenhout at al., 2008; Blanc et al., 2011). O caminho percorrido inicia-se no estilete, passa 
pelo esófago, atravessa o intestino médio, entra na hemolinfa e deve chegar na glândula salivar primária (Czosnek et al., 2002). Estudos de imunolocalização sugeriu que a câmara filtro e a porção anterior do intestino médio são os locais possíveis envolvidos no transporte de begomovirus do lúmen intestinal para a hemolinfa (Hunter et al., 1998).

O DNA viral é detectável no corpo dos insetos após um pequeno período de acesso de alimentação, mas os insetos não são imediatamente capazes de transmitir os vírus para plantas sadias (Cohen \& Nitzanv, 1966). Assim, existe um período de tempo entre a alimentação na planta infectada e inoculação na planta sadia, em que mesmo as partículas virais presentes no corpo do vetor, o inseto é incapaz de transmiti-las, este período é chamado de período de latência (Cohen \& Nitzanv, 1966). O período de latência varia com a espécie de vírus e inseto-vetor. Em 1950, Costa e Bennett realizaram diversos testes para determinar o período de latência do agente causal do mosaico da euphorbia, um begomovirus bipartido extraído de plantas de Euphorbia sp. Neste trabalho, eles demonstraram que o período de latência desse vírus em B. tabaci foi de no mínino 5 horas e que o intervalo de tempo em que o inseto é capaz de transmitir o vírus para o maior número de plantas situou-se entre 8 e 24 h (Costa $\&$ Bennett, 1950). O período de latência de Tomato yellow leaf curl virus (TYLCV), um begomovirus monopartido, no vetor varia entre 12-24h (Cohen \& Nitzanv, 1966).

Apesar dos begomovirus serem adquiridos pelos insetos por períodos muito curtos, de aproximadamente $10 \mathrm{~min}$, a probabilidade de transmissão aumenta com o aumento dos tempos de alimentação na fonte de vírus, até 24 horas (Costa, 1998). O mesmo ocorre com o período de inoculação que aumenta com o tempo de alimentação na planta-sadia (Costa, 1998). Santos et al. (2003) demonstraram que, para o Tomato rugose mosaic virus, o período mínimo de acesso de alimentação é de 15 min, de inoculação é de pelo menos 30 min, que o de latência é superior às $16 \mathrm{~h}$ e que a capacidade do inseto transmitir o vírus aumenta com o aumento do período de alimentação. 
Os begomovirus, na ausência de plantas cultivadas, perpetuam na natureza principalmente em plantas silvestres e daninhas. No entanto, existe evidência da sobrevivência do begomovirus monopartido TYLCV através da passagem transovariana, isto é, a passagem do vírus para a progênie dos insetos-vetores (Ghanim et al., 1998). Nesse trabalho foi demonstrada a detecção de TYLCV em ovos, ninfas e adultos provenientes de insetos virulíferos, sendo os adultos capazes de transmitir o vírus para plantas sadias (Ghanim et al., 1998). Para begomovirus bipartidos há relato de passagem transovariana para ovos, ninfas, e adultos, provenientes de fêmeas virulíferas mantidas em plantas não hospedeiras do vírus (Santos et al., 2003). Mas o adulto oriundo dessa fêmea, mesmo apresentando partículas virais detectáveis por PCR, não é capaz de transmitir o vírus para plantas sadias (Santos et al., 2003), provavelmente o adulto perde a capacidade de transmitir para novas plantas, devido à diminuição da carga viral no corpo do inseto.

As moscas-brancas abrigam populações de endossimbiontes que são divididos em dois grupos denominados endossimbiontes obrigatórios e facultativos também conhecidos respectivamente como primário e secundário. $\mathrm{O}$ endossimbionte primário mais conhecido é Portiera aleyrodidarum (Baumann et al., 2004) e exemplos de endossimbiontes secundários são: Wolbachia (Zchori-Fein \& Brown 2002) Rickettsia (Gottlieb et al., 2006) Cardinium (Weeks et al., 2003), Arsenophonus (Thao \& Baumann, 2004), Hamiltonella (Moran et al., 2005) e Fritschea (Everett et al., 2005). Existe uma grande diversidade de endossimbiontes em B. tabaci, no entanto a função da maioria dessas permanece desconhecida ou não foi totalmente esclarecida. Uma interação conhecida é a do endossimbionte Rickettsia com B. tabaci biótipo B, verificando que a presença desse biótipo aumenta a fecundidade e sobrevivência das fases imaturas até a fase adulta e acelera o desenvolvimento (Kliot et al. 2014). 
Atualmente duas proteínas de choque térmico, BtHSP16 e Bt HSP70 e uma proteína de $63 \mathrm{kDa}$ homóloga à GroEL produzida por endosimbiontes secundários de B. tabaci foram associadas à transmissão de begomovirus, especificamente na interação direta com a CP viral (Gottlied et al., 2010; Ohnesorge \& Bejarano 2009; Gotz et al., 2012).

A proteína GroEL apresenta elevada afinidade com a proteína do capsídeo dos polerovírus, é possível que ela forme um complexo com virions para facilitar a passagem do vírus pelo corpo do inseto-vetor, até que esse possa ser transmitido para o hospedeiro (Morin et al., 1999). Trabalhos realizados com o homólogo da GroEL sintetizada por um endossimbionte de Bemisia tabaci verificaram que essa proteína possuía papel similar na transmissão de TYLCV (Morin et al., 1999). Estudos realizados com o objetivo de verificar a relação da proteína GroEL com a transmissão de TYLCV observaram a redução da transmissão do vírus em aproximadamente $80 \%$, ao alimentar moscas-brancas com antissoro, anti-GroEL (Akad \& Czosnek, 2004).

\section{Transmissão de crinivirus}

A interação da mosca-branca como os crinivirus não está tão esclarescida como a deste vetor com os begomovirus. Sabe-se que espécies do gênero Crinivirus são transmitidas de forma semi-persistente pelo inseto vetor (Wisler et al., 1998), mas pouco se sabe sobre o local de retenção das partículas virais no corpo do inseto. O TICV é transmitido apenas por $T$. vaporariorum, enquanto que ToCV é transmitido por três espécies de Trialeurodes e por Bemisia tabaci (Wisler et al., 1998). Diferenças na eficiência de transmissão de ToCV foram conhecidas desde a primeira caracterização do vírus, embora tenha sido demonstrada anos mais tarde (Wintermantel \& Wisler, 2006). ToCV pode ser transmitido com elevada eficiência tanto por B. tabaci biótipo B e T. abuliloneas, enquanto que a transmissão por outros membros do gênero Trialeurodes é muito menos eficiente (Wintermantel \& Wisler, 2006). Embora a eficiência de transmissão por T. abuliloneus e B. tabaci seja igualmente 
eficiente a persistência do vírus no primeiro vetor (5 dias) excede em muito o de $B$. tabaci biótipo B (3 dias) (Wintermantel \& Wisler, 2006). Enquanto que para T. vaporariorum e $B$. tabaci a persistência foi igual ou inferior a 24 h (Wintermantel \& Wisler, 2006).

\section{Epidemiologia de doenças de plantas}

A epidemiologia de doenças de plantas é determinada por interações das populações do patógeno e do hospedeiro sob o efeito do ambiente. No caso da maioria das doenças de origem viral, um terceiro fator, o vetor, é fundamental para a ocorrência da enfermidade em campo. O vetor da doença é responsável por modificar os modos de sobrevivência e disseminação do vírus e, por esse motivo, o padrão temporal e espacial de doenças virais transmitidas por vetor não tende a ser estático, mas sujeitos a diversas mudanças impostas pelo ambiente e manejo aplicado pelo homem. Em geral, doenças de origem viral são sistêmicas, por isso, frequentemente utiliza-se a incidência da doença em campo para descrever e quantificar o padrão espacial e temporal dessas doenças (Madden et al., 1995; Campbell \& Madden, 1990). O uso da incidência como método de avaliação da doença gera dados binários e a planta analisada é considerada sadia ou doente, isto é, não é levado em consideração a severidade.

A epidemiologia de doenças de plantas é tradicionalmente classificada em dois amplos grupos, dependendo da fonte de inóculo que dará origem ao desenvolvimento da doença (Van der Plank, 1963; Madden et al., 2007). No primeiro grupo, o inóculo que causa a infecção não é produzido durante a epidemia, sendo que este é proveniente de outras fontes, como solo, hospedeiros secundários ou cultivos do mesmo hospedeiro em outras áreas, portanto, neste grupo ocorre apenas um ciclo infeccioso por cultivo (doença monocíclica) (Van der Plank, 1963; Madden et al., 2007; Savary, 2007). No segundo grupo, a disseminação primária é responsável apenas para dar início à epidemia. A partir daí a infecção secundária proveniente destas infecções iniciais se encarrega de dar continuidade à epidemia, assim, diversos ciclos 
de infecção ocorrem durante o mesmo ciclo de cultivo do hospedeiro (doença policíclica) (Van der Plank, 1963; Madden et al., 2007). Esta classificação tem sido adotada para a maioria das doenças de plantas, no entanto, para algumas doenças, como de Huanglongbing em citrus e begomovirose em tomateiro, uma classe intermediária parece ser mais adequada (Bergamin et al., 2016). Para estas doenças, diversos ciclos de infecção e influxos constantes de inóculo primário ocorrem simultaneamente, o que consequentemente dificulta o manejo eficiente destas doenças (Bergamin et al., 2016).

Em doenças transmitidas por vetor, o inóculo inicial pode ser considerado a primeira migração de insetos infectados ou viruliferos. Estes insetos podem ter adquirido o vírus de uma planta hospedeira ou incubados por certo período de tempo no próprio vetor, quando as plantas na área são sadias. Após a introdução da doença na área, a disseminação secundária além da primária dependem de diversos fatores, entre eles o ciclo da cultura, o período de incubação do vírus na planta, período de latência do vírus no vetor e da biologia do inseto vetor. O período de incubação (PI) pode ser definido como o período compreendido entre o primeiro contato do patógeno com o hospedeiro e o aparecimento do sintoma (Vanderplank, 1963; Bergamin Filho \& Amorim, 1996). O período de incubação do patógeno no hospedeiro é extremamente importante na epidemiologia, uma vez que a quantificação da doença frequentemente é realizada a partir de análise visual dos sintomas característicos da doença (Bergamin \& Amorim, 2002). O PI tem efeito direto na curva de progresso da doença, por exemplo, um PI igual a cinco dias, sob condições ambientais constantes implica que as infecções que deram origem aos sintomas no tempo t, ocorreram no tempo t-5 (Bergamin \& Amorim, 2002). Portanto, como a curva de progresso da doença inclui não apenas as plantas visivelmente sintomáticas (lesões mais velhas que o período de incubação) mas também as assintomáticas, as curvas de progresso da doença (visível ou não) são paralelas e defasadas no 
tempo igual ao PI, resultando em iguais taxas de progresso da doença (Bergamin \& Amorim, 2002).

Existem diversos desafios para a modelagem das epidemias de plantas. Cunniffe e colaboradores (2015) explicaram treze principais, como a dificuldade de associar os modelos epidemiológicos à produtividade agrícola; a presença de hospedeiros alternativos do patógeno na área estudada; a obtenção de modelos de dispersão realística que levem em consideração aspectos meteorológicos e a ação do homem; efeito da preferência do vetor na transmissão; a presença não apenas da espécie alvo do estudo, mas de inúmeras outras espécies de patógenos, além de diversas estirpes e isolados distintos da espécie alvo; a dificuldade de aceitação dos modelos proposto pela área de fiscalização e demais partes interessadas como produtores; dentre outros (Cunniffe et al., 2015).

O estudo epidemiológico das doenças de origem viral é escasso tanto para as doenças de vírus que ocorrem no Brasil, quanto para as predominantes no Mundo. Aspectos temporais e espaciais de begomovirus bipartidos em tomateiro foram estudados, Tomato mottle virus em áreas de produção da Flórida, EUA (Polston et al., 1996) e Tomato yellow vein streak virus em áreas de produção do Estado de São Paulo (Della Vecchia et al., 2007) e um estudo temporal de Tomato severe rugose virus também no Estado de São Paulo (Barbosa et al., 2016). Os resultados obtidos nesses trabalhos possuem pontos similares e divergentes que serão discutidos nesse trabalho.

\section{Controle de doenças de plantas}

Diversos métodos de controle podem ser empregados para doenças de plantas transmitidas por vetores, tais como, uso de variedades resistentes, sementes e mudas sadias, isolamento da área de cultivo, evitar o plantio consecutivo, cobertura vegetal do solo para diminuir a atração dos vetores, cultivo em telados, eliminação das plantas fontes de inoculo, 
escolha da época de plantio e realização de colheita adequadas, espaçamento apropriado dentro e entre linhas, nutrição balanceada das plantas, uso de parasitas naturais, roguing e a aplicação de inseticidas visando a eliminação direta dos vetores, que é a prática mais utilizada pelos produtores (Broadbent, 1957). Embora o uso de inseticidas seja o método mais comum, diversos estudos demonstram que a aplicação de pesticidas visando os vetores já presentes no cultivo é muito pouco eficiente (Hoffman, 1952, Broadbent, 1957). Para o controle mais eficiente os produtores deveriam investir recurso para eliminar os vetores antes que estes deixem cultivos velhos e cheguem ao cultivo alvo, visando assim um controle da doença de forma mais regional e não apenas no cultivo alvo (Broadbent, 1957; Bergamin et al., 2016). Para a compreensão da epidemiologia de doenças transmitidas por vetores, o monitoramento e conhecimento a respeito do patógeno e do comportamento do vetor são igualmente importantes.

Uma medida de controle de doenças de plantas, o vazio fitossanitário, tem sido implementada para o controle de algumas viroses importantes no Brasil e no Mundo. O vazio fitossanitário é uma medida de controle que visa o estabelecimento de um período livre do hospedeiro principal do patógeno ou de hospedeiros do patógeno e do inseto vetor. Um exemplo de sucesso da implementação dessa medida, contra uma virose causada pelo begomovirus monopartido TYLCV, foi relatado em 2002 por Salati e colaboradores na República Dominicana. A medida consistia na obrigatoriedade da implementação de um período de três meses livres de hospedeiros de mosca-branca, incluindo tomateiro, feijoeiro, cucurbitáceas, berinjela e pimenta. A redução da incidência de TYLCV foi comprovada pela verificação de que a porcentagem de insetos virulíferos durante o período livre de hospedeiros de moscas-branca era reduzido e aumentava durante o período de cultivo de tomateiro. Eles comprovaram a eficiência dessa medida também pela comparação de áreas com e sem a medida de controle, e demonstraram que a incidência de TYLCV era invariavelmente maior 
em regiões onde a medida não foi implementada. No Brasil medidas de controle similares foram adotadas com o intuito de reduzir a incidência de begomoviroses em feijoeiro (por exemplo, no DF: Portaria 46 de 16/05/13, Secretaria de Estado de Agricultura e Desenvolvimento Rural do Distrito Federal) e tomateiro (IN 024, SDA, de 2003, MAPA), no entanto a eficiência dessas medidas de controle ainda não foi relatada. 


\section{Referências Bibliográficas}

ABCSEM, Associação Brasileira do Comércio de Sementes e Mudas, 2009. Tomate lidera crescimento e lucratividade no setor de hortaliças. http://www.abcsem.com.br/noticia.php?cod=284. Consultado em 15/09/2009.

ADAMS, M. J.; KING, A. M. Q. \& CARSTENS, E. B. 2013. Ratification vote on taxonomic proposals to the International Committee on Taxonomy of Viruses. Archives of Virology 158: 2023-2030.

AKAD, F.; DOTAN, N. \& CZOSNEK, H. 2004. Trapping of Tomato yellow leaf curl virus (TYLCV) and other plant viruses with a GroEL homologue from the whitefly Bemisia tabaci.ArchivesVirology 149(8): 1481-97.

ALBUQUERQUE, L. C.; MARTIN, D. P.; AVILA, A. C. \& INOUE-NAGATA, A. K. 2010. Characterization of Tomato yellow vein streak virus, a begomovirus from Brazil. Virus Genes 40: $140-147$.

ALEMANDRI, V.; DE BARRO, P. J.; BEJERMAN, N.; ARGÜELLO-CARO, E. B.; DUMÓN, A. D.; MATTIO, M. F.; RODRIGUEZ, S. M. \& TRUOL, G. 2012. Species within the Bemisia tabaci (Hemiptera: Aleyrodidae) complex in soybean and bean crops in Argentina. Journal of Economic Entomology 105: 48-53.

BARBOSA, J. C.; BARRETO, S.S.; INOUE-NAGATA, A.K.; REIS, M.S.; FIRMINO, A. C; BERGAMIN FILHO, A. \& REZENDE, J. A. M. 2009. Natural infection of Nicandra physaloides by Tomato severe rugose virus in Brazil. Journal of General Plant Pathology 75: 440-443.

BARBOSA, J. C.; COSTA, H.; GIORIA, R. \& REZENDE, J. A. M. 2011. Occurrence of Tomato chlorosis virus in tomato crops in Five Brazilian states. Tropical Plant Pathology 36(4): 256-258.

BARBOSA, J. C.; REZENDE, J. A. M.; AMORIM, L. \& BERGAMIN FILHO, A. 2016. Temporal Dynamics of Tomato severe rugose virus and Bemisia tabaci in Tomato Fields in São Paulo, Brazil. Journal of Phytopathology 164: 1-10.

BARBOSA, J. C.; TEIXEIRA, A. P. M.; MOREIRA, A. G.; CAMARGO, L. E. A.; BERGAMIN FILHO, A.; KITAJIMA, E. W. \& REZENDE, J. A. M. 2008. First report of Tomato chlorosis virus infecting tomato crops in Brazil. Plant Disease 92:1709.

BARRETO, S. S; HALLWASS, M.; AQUINO, O. M. \& INOUE-NAGATA, A. K. 2013. A study of weeds as potential inoculum sources for a tomato-infecting begomovirus in central Brazil. Phytopathology 103: 436-444. 
BAUMANN, L.; THAO, M. L.; FUNK, C. J.; FALK, B. W.; NG, J. C. K. \& BAUMANN, P. 2004. Sequence Analysis of DNA Fragments from the Genome of the Primary Endosymbiont of the Whitefly Bemisia tabaci. Current Microbiology 48: 77-81.

BEDFORD, I. D.; BRIDDON, R. W.; BROWN, J. K.; ROSELL, R. C. \& Markham, P. G. 1994. Geminivirus transmission and biological characterization of Bemisia tabaci (Gennadius) biotypes from different geographical regions. Annals of Applied Biology 125: 311-325.

BERGAMIN FILHO A. \& AMORIN, L.1996. Doenças de plantas tropicais: epidemiologia e controle econômico. Editora Agronômica Ceres Lda.

BERGAMIN FILHO, A. \& AMORIM L. 2002. Doenças com período de incubação variável em função da fenologia do hospedeiro. Fitopatologia brasileira 27(6).

BERGAMIN FILHO, A.; INOUE-NAGATA, A. K.; BASSANEZI, R. B.; BELASQUE JR, J.; AMORIM, L.; MACEDO, M. A.; BARBOSA, J. C.; WILLOCQUET, L. \& SAVARY, S. 2016. The importance of primary inoculum and area-wide disease management to crop health and food security. Food security 8: 1-18.

BERLINGER, J. M. 1986. Host plant resistance to Bemisia tabaci. Agriculture, Ecosystemsand Environment 17: 69-82.

BEZERRA-AGASSIE, I. C.; FERREIRA G. B.; ÁVILA, A. C. \& INOUE-NAGATA, A, K. 2006. First report of Tomato severe rugose virus in chili pepper in Brazil. Plant Disease 90: 114.

BLACKMAN, R. L. \& CAHILL, M. 1998. The karyotype of Bemisia tabaci (Hemiptera: Aleyrodidae). Bulletin of Entomological Research 88: 213-215.

BLANC, S; UZEST, M. \& DRUCKER, M. 2011. New research horizons in vector transmission of plant viruses. Current Opinion in Microbiology 14: 483-491.

BOITEUX, L. S.; MELO, P. C. T. \& VILELA, N. J. 2008. Tomate para Consumo in natura. In: Albuquerque ACS, Silva AG, eds. Desenvolvimento da Agricultura Tropical: Quatro Décadas de Inovações Tecnológicas, Institucionais e Políticas. Brasília, DF: Embrapa 1: 557567.

BONDAR, G. 1928. Aleyrodideos do Brasil. Boletim Laboratório Pathologia e Veterinária do Estado da Bahia 5:1-37.

BOYKIN, L. M.; ARMSTRONG, K. F.; KUBATKO, L. \& DE BARRO, P. J. 2012. Species delimitation and global biosecurity. Evolutionary Bioinformatics 8: 1-37.

BROADBENT, L. 1957. Insecticidal Control of the spread of plant viroses. Annual Review Entomology 2:339-354. 
BROWN, J. K. \& BIRD, J. 1992. Whitefly transmited geminiviroses and associated disorders in the Americas and the Caribean Basin. Plant Disease 76(3): 220-225.

BROWN, J. K.; FROHLICH, D. R. \& ROSELL, R. C. 1995. The sweetpotato or silverleaf whiteflies: biotypes of Bemisia tabaci or a species complex? Annual Review of Entomology 40: 511-534.

BROWN, J. K.; ZERBINI, F. M; NAVAS-CASTILLO, J.; MORIONES, E.; RAMOSSOBRINHO, R.; SILVA, J. C.; FIALLO-OLIVÉ, E.; BRIDDON, R. W.; HERNÁNDEZZEPEDA, C.; IDRIS, A.; MALATHI, V. G.; MARTIN, D. P.; RIVERA-BUSTAMANTE, R.; UEDA, S.; VARSANI, A. 2015. Revision of Begomovirus taxonomy based on pairwise sequence comparisons.Archives of Virology160(6):1593-619.

BYRNE, D. N. \& BELLOWS, T. S. 1991. Whitefly biology. Annual Review Entomology. 36: $431-57$.

BYRNE, D. N. \& MILLER, W. B. 1990.Carbohydrate and amino acid composition of phloem SAP and honeydew produced by Bemisia tabaci. Journal of Insect Physiology 36: 433-439.

BYRNE, D. N.; BELLOWS-JR, T. S. \& PARRELLA, M. P. 1990.Whiteflies in agricultural systems. In D. Gerling (ed.), Whiteflies: their bionomics, pest status and management; Andover, UK, Intercept: 227-261.

CACIAGLI P. C. 2001. Whitefly-borne viruses in continental Europe. In Harris, K. F.; Smith, O. P. \& Duffus, J. E. Ed. Virus-insect-plant-interaction. Lodon. Academic Press.

CAMPBELL, C. L. \& MADDEN, L. V. 1990. Introduction to Plant Disease 1 Epidemiology.New York, NY, USA, John Wiley and Sons.

CANTO, S. P.; FAVERO, S.; PEREIRA, F. A. R. \& ROSA, G. O. 2007. Distribuição geográfica, hospedeiros e agroquímicos utilizados no controle da mosca-branca no complexo Bemisia em Mato Grosso do Sul. Ensaios e ci 11 (2): 47-49.

CASTILLO-URQUIZA, G. P.; BEZERRA JR, J. E. A.; BRUCKNER, F. P.; LIMA, A. T. M.; VARSANI, A.; ALFENAS-ZERBINI, P. \& ZERBINI, M. F. 2008. Six novel begomoviruses infecting tomato and associated weeds in Southeastern Brazil. Archives of Virology 153: 1985-1989

CLEMENTE, F. M. V. T. \& BOITEUX, L. S. 2012. Produção de tomate para processamento industrial. 1ed.Brasília, DF: Embrapa, 2012.

COHEN, S. \& NITZANV, F. E. 1966. Transmission and host range of the Tomato yellow leaf curl virus. Phytopathotogy 56: 1127-1131. 
COSTA, A. S. 1965.Three whitefly-transmitted virus diseases of beans in São Paulo, Brazil.Food and Agriculture Organization of the United Nations Plant Protection Bulletin 13: 121-130.

COSTA, A. S. 1976. Whitefly-transmitted plant diseases. Annual Review of Phytopathology 14: $429-440$.

COSTA, A. S., \& BENNETT, C. W. 1950. Whitefly-Transmitted Mosaic of Euphorbia Prunifolia. Phytopatology 40: 266-283.

COSTA, A. S., OLIVEIRA, A. R. \& SILVA, D. M. 1975. Transmissão mecânica do Mosaico dourado do tomateiro. Revista da Sociedade Brasileira de Fitopatologia 6: 147.

COSTA, A. S.; COSTA, C. L. \& SAUER, H. F. G. 1973. Surto de mosca-branca em culturas do Paraná e São Paulo. Anais da Sociedade Entomológica do Brasil 2(1): 20-30.

COSTA, C. L. 1998. Vetores de vírus de plantas- 1 insetos. Revisão Anual de Patologia de Plantas 6: 103-167.

COSTA, H. C., \& BROWN, J. K. 1991. Variation in biological characteristics and esterase patterns among populations of Bemisia tabaci, and the association of one population with silverleaf symptom induction. Entomologia Experimentalis at Applicata 61: 211-219.

CUNNIFFE, N. J.; KOSKELLA, B.; METCALF, C. J. E.; PARNELL, S.; GOTTWALD, T. R. \& GILLIGAN, C. A. 2015. Thirteen challenges in modelling plant diseases. Epidemics 10: 6-10.

CZOSNEK, H. \& GHANIM, M. 2002. The circulative pathway of begomoviruses in the whitefly vector Bemisia tabaci - insights from studies with Tomato yellow leaf curl virus. AnnalsAppliedBiology 140: 215-231.

DE BARRO, P. J. \& HART, P. J. 2000. Mating interactions between two biotypes of the whitefly, Bemisia tabaci (Hemiptera: Aleyrodidae) in Australia. Bulletin of Entomological Research 90: 103-112.

DE BARRO, P. J.; LIU, S. S.; BOYKIN, L. M. \& DINSDALE, A. B. 2011. Bemisia tabaci: a statement of species status. Annual Review Entomology 56: 1-19.

DE BARRO, P. J.; TRUEMAN, J. W. H. \& FROHLICH, D. R. 2005. Bemisia argentifolii is a race of $B$. tabaci: The molecular genetic differentiation of $B$. tabaci populations around the world. Bulletin of Entomological Research 95: 193-203.

DELLA VECCHIA, M.G.S.; ROSA, D.D.; BERGAMIN FILHO, A.; AMORIM, L.; REZENDE, J.A.M. \& RIBEIRO, A. 2007. Dinâmica temporal e espacial da begomovirose causada por Tomato yellow vein streak virus em tomateiro na regiao de Campinas-SP. Summa Phytopathologica 33: 388-395. 
DINSDALE, A; COOK, L.; RIGINOS, C.; BUCKLEY, Y. M. \& DE BARRO, P. J. 2010. Refined global analysis of Bemisia tabaci (Hemiptera: Sternorrhyncha: Aleyrodoidea) mitochondrial cytochrome oxidase 1 to identify species level genetic boundaries. Annals of the Entomological Society of America 103: 196-208.

DUFFY, S. \& HOLMES, E. C. 2009. Validation of high rates of nucleotide substitution in geminiviruses: phylogenetic evidence from East African cassava mosaic viruses. Journal of General Virology 90: 1539-1547.

EDGAR R. C. 2004. Muscle: multiple sequence alignment with high accuracy and high throughput. Nucl. Acids Res. 32(5):1792:1797.

ESQUINAS-ALCÁZAR, J. \& NUEZ, F. 1995. Situacion taxonomica, domesticación ydifusion Del tomate In: Nuez F (Ed). El cultivo Del tomate. Ediciones Munidiprensa.

EVERETT, K. D.; THAO, M.; HORN, M.; DYSZYNSKI, G. E. \& BAUMANN, P. 2005. Novel chlamydiae in whiteflies and scale insects: endosymbionts "Candidatus Fritschea bemisiae" strain Falk and "Candidatus Fritscheae riococci" strain Elm. International Journal of Systematic and Evolutionary Microbiology 55: 1581-1587.

FAO, Food and Agriculture Organization of the United Nations, 2010.Statistics at FAO.www.fao.org/waicent/portal/statistics_en.asp. Consultado em 12/10/1010.

FARIA, J. C. 1994. Mosaico dourado; in: Sartorato, A., and Rava, C. A., eds. Principais doenças do feijoeiro comum e seu controle. EMBRAPA-CNPAF: 262-284.

FARIA, J. C.; BEZERRA, I. C.; ZERBINI, F. M.; RIBEIRO, S. G. \& LIMA, M. F. 2000. Situação atual das geminiviroses no Brasil. Fitopatologia Brasileira 25 (2): 125-137.

FERNANDES, F. R.; ALBUQUERQUE, L. C.; BRITTO GIORDANO, L.; BOITEUX, L. S. \& AVILA, A. C. 2008. Diversity and prevalence of Brazilian bipartite begomovirus species associated to tomatoes. Virus Genes 36: 251-258.

FERNANDES, J., CARVALHO, M. \& ALMEIDA, E. 1983. Distribuição do Mosaico em tomatais de duas regiões produtoras de Minas Gerais. Fitopatologia Brasileira, 8, 625.

FIRDAUS, S.; VOSMAN, B.; HIDAYATI, N.; JAYA SUPENA, E. D.; VISSER, R. G. F. \& VAN HEUSDEN, A. W. 2012. The Bemisia tabaci species complex: additions from different parts of the world. Insect Science 20(6): 723-33.

FLORES, E.; SILBERSCHMIDT, K. \& KRAMER, M. 1960. Observações de "clorose infecciosa" das malváceas em tomateiros do campo. Biológico 26: 65-69.

FONSECA, L. B., YUKI, V. A.; MARUBAYASHI, J.M.; DE MARCHI B. R.; PERINI, F. L.; PAVAN, M. A.; DE BARROS D. R.; GHANIM, M.; MORIONES, E.; NAVAS- 
CASTILlO J.; KRAUSE-SAKATE, R. 2015. First report of Bemisia tabaci Mediterranean (Q biotype) species in Brazil. Pest Manag Sci. 71(4):501-4.

FONTES, P. C. R. \& SILVA, D. J. H. 2002 Produção de tomate de mesa Viçosa: Aprenda fácil: 196.

FRANÇA, F.H.; BOAS, G.L.V. \& BRANCO, M.C. 1996. Ocorrência de Bemisia argentifolii Bellows \& Perring (Homoptera:Aleyrodidae) no Distrito Federal. Anais da Sociedade Entomologica do Brasil 25: 369-372.

GALLO, D.; NAKANO, O.; SILVEIRA NETO, S.; CARVALHO, R. P. L.; BAPTISTA, G. C.; BERTI FILHO, E.; PARRA, J. R. P.; ZUCCHI, R. A.; ALVES, S. B.; VENDRAMIM, J. D.; MARCHINI, L. C.; LOPES J. R. S. \& OMOTO, C. 2002. Entomologia Agrícola. FEALQ - Piracicaba.

GALVÃO, R. M.; MARIANO, A. C.; LUZ, D. F.; ALFENAS, P. F.; ANDRADE, E. C.; ZERBINI, F. M.; ALMEIDA, M. R. \& FONTES, E. B. 2003. A naturally occurring recombinant DNA-A of a typical bipartite begomovirus does not require the cognate DNA-B to infect Nicotiana benthamiana systemically. Journal of General Virology 84: 715-726.

GHANIM, M.; MORIN, S.; ZEIDAN, M. \& CZOSNEK, H. 1998. Evidence for transovarial transmission of Tomato yellow leaf curl virus by its vector, the whitefly Bemisia tabaci. Virology 240: 295-303.

GOTTliEB, Y.; GHANIM, M.; CHIEL, E.; GERLING, D.; PORTNOY, V.; STEINBERG,S.; TZURI,G.; HOROWITZ, A. R.; BELAUSOV,E.; NETA MOZESDAUBE; KONTSEDALOV, S.; GERSHON, M.; GAL, S.;KATZIR, N. \& ZCHORI-FEIN, E. 2006. Identification and Localization of a Rickettsia in Bemisia tabaci (Homoptera: Aleyrodidae). Applied Environmental Microbiology 72(5): 3646-3652.

GOTTLIEB, Y.; ZCHORI-FEIN, E.; MOZES-DAUBE， N.; KONTSEDALOV， S.; SKALJAC, M.; BRUMIN, M.; SOBOL, I.; CZOSNEK, H.; VAVRE, F. \& FLEURY, F. 2010. The transmission efficiency of Tomato yellow leaf curl virus by the whitefly Bemisia tabaci is correlated with the presence of a specific symbiotic bacterium species. Journal of Virology 84: 9310-9317.

GÖTZ, M.; POPOVSKI, S.; KOLLENBERG, M.; GOROVITS, R.; BROWN, J. K.; CICERO, J. M.; CZOSNEK, H.; WINTER, S. \& GHANIM, M. 2012. Implication of Bemisia tabaci heat shock protein 70 in begomovirus-whitefly interactions. Journal of Virology 86: 13241-13252.

HOFFMAN, J. R. 1952. Quart. Bull. Mich. Agr. Expt. Sta., 34: 262-65. 
HOGENHOUT, S. A.; AMMAR, E. D.; WHITFIELD, A. E. \& REDINBAUGH, M. G. 2008. Insect vector interactions with persistently transmitted viruses. Annual Review of Phytopathology 46: 327-359.

HU, J.; DE BARRO, P. J.; ZHAO, H.; WANG, J.; NARDI, F. \& LIU, S. S. 2011. An extensive field survey combined with a phylogenetic analysis reveals rapid and widespread invasion of two alien whiteflies in China. PLoS One 6 (1) e16061.

HUNTER, W. B.; HIEBERT, E.; WEBB, S. E.; TSAI, J. H. \& POLSTON, J. E. 1998. Location of geminiviruses in the whitefly Bemisia tabaci (Homoptera: Aleyroididae). Plant Disease 82: 1147-1151.

IBGE, Instituto Brasileiro de Geografia e Estatística. 2010. LEVANTAMENTO SISTEMÁTICO DA PRODUÇÃO AGRÍCOLA. http://www.ibge.gov.br/home/estatistica/indicadores/agropecuaria/lspa/lspa_201009.pdf. Acessado em 24/08/2011.

IBGE, Instituto Brasileiro de Geografia e Estatística. 2012. LEVANTAMENTO SISTEMÁTICO DA PRODUÇÃO AGRÍCOLA. ftp://ftp.ibge.gov.br/Producao_Agricola/Levantamento_Sistematico_da_Producao_Agricola_[ mensal]/Fasciculo/2012/lspa_201202.pdf. Acessado em 11/05/2013.

IBGE, Instituto Brasileiro de Geografia e Estatística. 2015. LEVANTAMENTO SISTEMÁTICO DA PRODUÇÃOO AGRÍCOLA. ftp://ftp.ibge.gov.br/Producao_Agricola/Levantamento_Sistematico_da_Producao_Agricola_[ mensal]/Fasciculo/lspa_201601.pdf. Acessado em 10/02/2016.

ICTV on line, International Committee on Taxonomy of Viruses. http://www.ictvonline.org/virusTaxonomy.asp. Acessado em 21/11/2015.

INBAR, M. \& GERLING, D. 2008. Plant-mediated interactions between whiteflies, herbivores, and natural enemies. Annual Review Entomology 53: 431-48.

JONES, D. R. 2003. Plant viruses transmitted by whiteflies. European Journal of Plant Pathology 109: 195-219.

KIL, E. J.; KIM, S.; LEE, Y. J.; BYUN, H. S.; PARK, J.; SEO, H.; KIM, C. S.; SHIM, J. K.; LEE, J. H.; KIM, J. K.; LEE, K. Y.; CHOI, H. S. \& LEE, S. 2016. Tomato yellow leaf curl virus (TYLCV-IL): a seed-transmissible geminivirus in tomatoes. Scientific Reports6: 19013. KIM, J.; KIL, E. J.; KIM, S.; SEO, H.; BYUN, H. S.; PARK, J.; CHUNG, M. N.; KWAK, H. R.; KIM, M. K.; KIM, C. S.; YANG, J. W.; LEE, K. Y.; CHOI, H. S. \& LEE, S. 2015. Seed transmission of Sweet potato leaf curl virus in sweet potato (Ipomoea batatas). Plant Patology 64 (6): 1284-1291. 
KLIOT, A.; CILIA, M.; CZOSNEK, H. \& GHANIM, M. 2014.Implication of the Bacterial Endosymbiont Rickettsia spp. in Interactions of the Whitefly Bemisia tabaci with Tomato yellow leaf curl virus.Journalof Virology 88(10): 5652-5660.

KUROZAWA, C. \& PAVAN, M. A. 2005. Doenças do tomateiro (Lycopersicon esculentum), pp. 607-626 in Manual de fitopatologia: Doenças das plantas cultivadas, editedby H. Kimati, L. Amorim, J. A. M. Rezende, A. B. Filho and L. E. A. Camargo, São Paulo.

LAZAROWITZ, S. G. 1992. Geminiviruses: Genome structure and gene function. Critical Reviews in Plant Sciences 11: 327-349.

LIMA, L. H. C.; NÁVIA, D.; INGLIS, P. W. \& OLIVEIRA, M. R. V. 2000. Survey of Bemisia tabaci (Gennadius) (Hemiptera: Aleyrodidae) biotypes in Brazil using RAPD markers. Geneticsand Molecular Biology 23: 1-5.

LOPES, C. A. 2005. Doenças do Tomateiro. Embrapa Hortaliças, Brasília, DF. 152p.

LOURENÇÃO, A. L. \& NAGAI, H. 1994. Surtos populacionais de Bemisia tabaci no Estado de São Paulo. Bragantia 53 (1): 53-59.

MACEDO, M. A.; BARRETO, S. S.; HALLWASS, M. \& INOUE-NAGATA, A. K. 2014. High incidence of Tomato chlorosis virus alone and in mixed infection with begomoviruses in two tomato fields in the Federal District and Goiás state, Brazil. Tropical plant pathology 39(6): 449-452.

MADDEN, L. V. \& HUGLES, G. 1995. Plant disease incidence: distribution, heterogeneity, and temporal analysis. Annual Review of Phytopathology 33: 529-564.

MADDEN, L. V.; HUGHES, G. \& Van den BOSCH, F. 2007. The study of plant disease epidemics. St. Paul: American Phytopathological Society, 2007: 421p.

MARTIN, J. H. 1999. The whitefly fauna of Australia (Sternorrhyncha: Aleyrodidae): a taxonomic account and identification guide. Common wealth Scientific and Industrial Research Organization. CSIRO Entomology, Technical Paper 38: 197.

MARTIN, J.H. \& MOUND, L. A. 2007. An annotated check list of the world's whiteflies (Insecta: Hemiptera: Aleyrodidae). Zootaxa, 1492:1-84.

MARUBAYASHI, J. M.;YUKI, V. A.; ROCHA, K. C. G.;MITUTI, T.; PELEGRINOTTI, F. M.; FERREIRA, F. Z.; MOURA, M. F.; NAVAS-CASTILLO, J.; MORIONES, E.;PAVAN, M. A. \&KRAUSE-SAKATE, R. 2013. At least two indigenous species of the Bemisia tabaci complex are present in Brazil. Journal of Applied Entomology 137 (1-2): 113-121.

MAYTIS, J. C.; SILVA, D. M.; OLIVEIRA, A. R. \& COSTA, A. S. 1975. Purificação e morfologia do vírus do mosaico dourado do tomateiro. Summa Phytopathologica 1: 267-274. 
MELO, P. C. T. 1992. Mosca branca ameaça produção de hortaliças. ASGROW. Semente. Informe Técnico: 2 .

MORAN, N. A.; DEGNAN, P. H.; SANTOS, S. R.; DUNBAR, H. E. \& OCHMAN, H. 2005. The players in a mutualistic symbiosis: insects, bacteria, viruses, and virulence genes. Proceedings of the National Academy Sciences of the United States of America 102: 1691926.

MORIN, S.; GHANIM, M.; ZEIDAN, M.; CZOSNEK, H.; VERBEEK, M. \& VAN DEN HEUVEL, J. F. 1999. A GroEL homologue from endosymbiotic bacteria of the whitefly Bemisia tabaci is implicated in the circulative transmission of Tomato yellow leaf curl virus. Virology 256: 75-84.

MORIONES, E. \& NAVAS-CASTILHO, J. 2000. Tomato yellow leaf curl virus an emerging virus complex causing epidemics worldwide. Virus Research 71: 123-134.

MUHIRE, B. M.; VARSANI, A. \& MARTIN D. P. 2014. SDT: A Virus Classification Tool Based on Pairwise Sequence Alignment and Identity Calculation. PLOSone 26(9): e108277.

MUSA, P. D.\& REN, S. 2005. Development and reproduction of Bemisia tabaci (Homoptera: Aleyrodidae) on three bean species. Insect Science 12 (1): 25-30.

NOZAKII, D.N.; KRAUSE-SAKATEI, R.; HASEGAWAI, J.M.; CEZARI, M.A.; DZIUBAII, P.H.; PAVAN, M.A. 2006. First report of Tomato severe rugose virus infecting pepper plants in Brazil. Fitopatologia brasileira 31 (3): 321-321.

OHNESORGE, S. \& BEJARANO, E. 2009. Begomovirus coat protein interacts with a small heat-shock protein of its transmission vector (Bemisia tabaci). Insect Molecular Biology 18: 693-703.

OLIVEIRA, M. R. V. D.; AMANCIO, E.; LAUMANN, R. A. \& GOMES, L. D. O. 2003. Natural enemies of Bemisia tabaci (Gennadius) B biotype and Trialeurodes vaporariorum (Westwood) (Hemiptera: Aleyrodidae) in Brasília, Brazil. Neotropical Entomology 32(1): 151-154.

PADIDAM, M.; BEACHY, R. N. \& FOUQUET, C. M. 1995. Classification and identification of geminivirus using sequence comparisons. Journal General Virology 76: 249263.

PAKKIANATHAN, B. C.; KONTSEDALOV, S.; LEBEDEV, G.; MAHADAV, A.; ZEIDAN, M.; CZOSNEK, H.; GHANIM, M. 2015. Replication of Tomato yellow leaf curl virus in Its Whitefly Vector, Bemisia tabaci. Journal of Virolology 89(19): 9791-803. 
POLSTON, J.E.; CHELLEMI, D.O.; SCHUSTER, D.J.; MCGOVERN, R.J. \& STANSLY, P.A. 1996. Spatial and temporal dynamics of Tomato mottle geminivirus and Bemisia tabaci (Genn.) in Florida tomato fields. Plant Disease 80: 1022-1028.

POZZER, L.; RESENDE, R. O.; LIMA, M. F.; KITAJIMA, E.; GIORDANO, L. B. \& DE ÁVILA A. C. 1996 Tospovirus: uma visão atualizada. Revisão Anual de Patologia de Plantas 4: 95-148.

\section{Referências}

RESENDE, R. O.; POZZER, L.; NAGATA, T.; BEZERRA, I. C.; LIMA, M. I.; GIORDANO, L. B.; KITAJIMA, E. W. \& DE ÁVILA, A. C. 1996. New Tospoviruses Found in Brazil. Proceedings of the International Symposium on Tospovirus and Thrips of Floral and Vegetable Crops.Acta Horticulturae 431 (1): 78-89.

RICK, C. M. \& HOLLE, M. 1990. Andean Lycopersicon esculentum var. cerasiforme: Genetic variation and its evolutionary significance. Economic Botany 44: 69-78.

ROJAS, M. R.; HAGEN, C.; LUCAS, W. J. \& GILBERTSON, R. L. 2005. Exploiting chinks in the plant's armor: evolution and emergence of geminiviruses. Annual Review of Phytopathology 43: 361-94.

ROOSSINCK, M. J. 1997. Mechanisms of plant virus evolution. Annual review of phytopathology 35: 191-209.

ROSEN, R.; KANAKALA, S.; KLIOT, A.; PAKKIANATHAN, B. C.; FARICH, B. A.; SANTANA-MAGAL， N.; ELIMELECH, M.; KONTSEDALOV, S.; LEBEDEV, G.; CILIA, M. \& GHANIM, M. 2015. Persistent, circulative transmission of begomoviruses by whitefly vectors. Current Opinion in Virology 15: 1-8.

RUBINSTEIN, G. \& CZOSNEK, H. 1997. Long-term association of tomato yellow leaf curl virus with its whitefly vector Bemisia tabaci: effect on the insect transmission capacity, longevity and fecundity. Journal General Virology 78: 2683-2689.

SALAS, J.; MENDOZA, J. \& FLORIDA, O. 1995. Biology of the sweetpotato whitefly (Homoptera: Aleyrodidae) on tomato. Entomologist 78: 154-160.

SALATI, R.; NAHKLA, M.K.; ROJAS, M.R.; GUZMAN, P.; JAQUEZ, J.; MAXWELL, D.P. \& GILBERTSON, R.L. 2002. Tomato yellow leaf curl virus in the Dominican Republic: Characterization of an Infectious Clone, Virus Monitoring in Whiteflies, and Identification of Reservoir Hosts. Phytopathology 92(5): 487-496.

SANTOS, C. D. G.; ÁVILA, A. C. \& RESENDE, R. O. 2003. Estudo da interação de um begomovirus isolado de tomateiro com a mosca branca. FitopatologiaBrasileira 28: 664-673. 
SAUNDERS, K.; LUCY, A. \& STANLEY, J. 1991. DNA forms of the geminivirus African cassava mosaic virus consistent with a rolling circle mechanism of replication. Nucleic Acids Research 19: 2325-2330.

SAVARY S. 2007. Epidemics of plant diseases: mechanisms, dynamics and management. In: Ibayrenc M, ed. Encyclopedia of infectious diseases: modern methodologies. London: John Wiley \& Sons, Inc.

SEAL, S. E.; VANDERBOSCH, F. \& JEGER, M. J. 2006. Factors influencing begomovirus evolution and their increasing global significance: implications for sustainable control. Critical Reviews in Plant Science 25: 23-46.

SOUZA-DIAS, J.A.C.; SAWAZAKI, H. E.; PERNAMBUCO-FO, P.C.A. \& ELIAS, L. M. 2008. Tomato severe rugose virus: Another Begomovirus Causing Leaf Deformation and Mosaic Symptoms on Potato in Brazil. March 2008, Volume 92(3): 487

STANLEY, J. \& GAY, M. R. 1983. Nucleotide sequence of cassava latent virus DNA. Nature 301: 260-262.

STANLEY, J.; BISARO, D. M.; BRIDDON, R. W.; BROWN, J. K.; FAUQUET, C. M.; HARRISON, B. D.; RYBICKI, E. P. \& STENGER, D. C. 2005. Family Geminiviridae. ICTV.

STANLEY, J.; TOWNSEND, R. \& CURSON, S. J. 1985. Pseudorecombinantes between cloned DNAs of two isolate of cassava latent virus. Journal General Virology 66: 1055-1061. STENGER, D. C.; REVInGTON, G. N.; STEVEnSON, M. C. \& BISARO, D. M. 1991.Replicational release of geminivirus genomes from tandemly repeated copies: Evidence for rolling circle replication of a plant viral DNA. Proceedings of the National Academy Sciences 88: 8029-8033.

SUNTER, G. \& BISARO, D. M. 1992. Transactivation of geminivirus AR1 and BR1 gene expression by the viral AL2 gene product occurs at the level of transcription. The Plant Cell 4: 1321-1333.

TAVARES, C. A. M. 2002. Perspectivas econômicas da tomaticultura frente aos problemas causados pelos geminivirus. O Biológico 64: 157-158.

TAY, W. T.; EVANS, G. A.; BOYKIN, L. M. \& DE BARRO, P. J. 2012. Will the real Bemisia tabaci please stand up? PLoS One 7(11) e50550.

THAO, M. L. \& BAUMANN, P. 2004. Evolutionary Relationships of Primary Prokaryotic Endosymbionts of Whiteflies and Their Hosts.Applied Environmental Microbiology 70: 3401-3406. 
UNSELD, S.; FRISCHMUTH, T. \& JESKE, H. 2004. Short deletions in nuclear targeting sequences of African cassava mosaic virus coat protein prevent geminivirus twinned particle formation. Virology 318: 90-101.

VALLE, G. E. \& LOURENÇÃO, A. L. 2002. Resistance of Soybean Genotypes to Bemisia tabaci (Genn.) Biotype B (Hemiptera: Aleyrodidae). Neotropical Entomology 31 (2): 285295.

VANDERPLANK, J.E. 1963. Plant Diseases: Epidemics and Control. Academic Press, New York.

VILLAS-BOAS, G. L.; FRANÇA, F. H. \& MACEDO, N. 2002. Potencial biótipo da moscabranca Bemisia argentiolii a diferentes plantas hospedeiras. Horticultura brasileira 20 (1): 7179.

VILLAS-BOAS, G. L.; FRANÇA, F. H.; ÁVILA. A. C. \& BEZERRA, I. C. 1997. Manejo integrado da mosca-branca Bemisia argentifolii. Circular técnica da EMBRAPA Hortaliças: 9. VILLAS-BÔAS, G. L.; FRANÇA, F. H.; MACEDO, N. \& MOITA, A. W. 2001. Avaliação da preferência de Bemisia argentifolii por diferentes espécies de plantas. Horticultura Brasileira 19 (2):130-134.

WEEKS, A. R.; VELTEN, R. \& STOUTHAMER, R. 2003.Incidence of a new sex-ratiodistorting endosymbiotic bacterium among arthropods. Proceedings of the Royal Society B 270: $1857-65$.

WERE, H. K. \& WINTER, S. 2004.Viruses infecting cassava in Kenya. Plant Disease 88: 1722.

WINTERMANTEL, W. M. \& WISLER, G. C. 2006.Vector specificity, host range, and genetic diversity of Tomato chlorosis virus. Plant Disease 90: 814-819.

WISLER, G. C.; DUFFUS, J. E.; LIU, H. Y. \& LI, R. H. 1998. Ecology and epidemiology of whitefly-transmitted closteroviruses. Plant Disease 82: 270-280.

ZCHORI-FEIN, A. E. \& BROWN, J. K. 2002. Diversity of Prokaryotes Associated with Bemisia tabaci (Gennadius); (Hemiptera: Aleyrodidae) Diversity of Prokaryotes Associated with Bemisia tabaci (Gennadius); (Hemiptera :Aleyrodidae). Annals of the Entomological Society of America 95: 711-718. 


\section{Chapter 2: Temporal and spatial dynamics of a begomovirus disease in processing tomato in central Brazil}

\section{Resumo}

A begomovirose tornou-se nas duas últimas décadas uma das principais doenças de origem viral em tomateiro no Brasil. Atualmente a principal estratégia de controle baseada em aplicações frequentes de inseticidas no cultivo alvo não é eficiente para evitar surtos da doença especialmente no cultivo de tomate para processamento industrial. Com o intuito de tentar entender melhor esse patossistema, um estudo do progresso espacial e temporal de begomovirose foi realizado em duas áreas de produção para tomateiro para processamento sob irrigação do tipo pivô central na região central do Brasil. Um total de 24 parcelas $(15 \times 15$ plantas) foi semanalmente avaliada por análise visual da presença de plantas com sintomas de begomovirus (BSP). Tomato severe rugose virus (ToSRV) foi a espécie de begomovirus predominante em tomateiro, sendo também detectada em feijoeiro e algumas plantas daninhas. Nenhuma correlação positiva entre a incidência de begomovirose e a população de mosca-branca foi observada. O progresso da doença nas áreas estudadas foi rápido e mostrou uma leve agregação das plantas sintomáticas. As duas áreas de produção estudadas não apresentaram diferenças significativas na análise especial e temporal, no entanto diferenças foram observadas entre parcelas localizadas na borda (PE) e no centro (PC) dos pivôs avaliados. Na análise temporal, os valores de incidência de begomovirose e da área abaixo da curva de progresso da doença foram menores em PC que PE. Nas análises espaciais, as BSP em PC apresentaram distribuição mais agregadas que em PE. Todos esses resultados sugerem fortemente que a distribuição de BSP em PC e em PE é governada por diferentes mecanismos de disseminação. As implicações da presença desses diferentes mecanismos de disseminação no manejo da begomovirose serão discutidas.

Palavras-chaves: ToSRV, Epidemiologia, Inóculo primário 


\begin{abstract}
Over the last two decades, begomovirus diseases have become one of the most important diseases of Brazilian tomato crops. The major management strategy is the frequent application of insecticides in the target field, but this is often unsuccessful and environmentally undesirable. To better understand the begomovirus disease, we studied the spatial and temporal progression of begomovirus disease in two central pivot irrigated processing tomato production areas in Central Brazil. A total of 24 plots, each composed of $15 \times 15$ plants, were evaluated weekly by visual inspection for begomovirus symptomatic plants. The predominant begomovirus in the monitored tomato fields was Tomato severe rugose virus (ToSRV), which was also detected in a few non-tomato species. No correlation between incidence of begomovirus disease and fluctuation in whitefly population was found. In the monitored fields, disease progression was invariably rapid, with a slightly aggregated begomovirus symptomatic plants distribution pattern. No relevant differences were observed in the temporal and spatial analyses, although an important difference was detected between plots located at the center (PC) and at the edge (PE) of the fields. In the temporal analysis, the begomovirus incidence and area under disease progress curve (AUDPC) values were lower in the PC than in PE. In the spatial analysis, the begomovirus symptomatic plants were more aggregated in the PC than in the PE. These results suggest that the distribution of begomovirus symptomatic plants in the PC and the PE are a result of different dissemination mechanisms. The implications of these differences on disease management are discussed.
\end{abstract}

Key words: Begomovirus, ToSRV, Tomato, Primary inoculum 


\section{Introduction}

Begomoviruses are a large group (288 species) that possess single stranded DNA viruses in twinned icosahedral virions (family Geminiviridae) and cause economically important disease in many crops worldwide, such as beans, cassavas, cucurbits, peppers, cotton and tomatoes. Symptoms include stunting and distorted growth; leaf crumpling, curling, and green to golden mosaic, mottle; and distorted and reduced fruit size. In nature, the begomoviruses are transmitted by whiteflies (Bemisia tabaci) in a persistent manner (Rubinstein \& Czosnek, 1997; Ghanim et al., 1998; Morin et al., 1999; Rosen et al., 2015), although there is some evidence with TYLCV of limited replication on the insect vector (Pakkianathan et al., 2015). This type of transmission involves a latent period (LP) of approximately $16 \mathrm{~h}$ that is required after acquisition followed by transmission for the life of the insect (Santos et al., 2003).

The first tomato begomovirus species identified in Brazil was Tomato golden mosaic virus (TGMV) in 1960 in São Paulo state (Flores et al., 1960; Matyis et al., 1975). The incidence of TGMV was relatively low and no substantial economic losses are reported. Following the introduction of the B biotype of Bemisia tabaci (or MEAM-1 species) in the early 1990's (França et al., 1996), the incidence of begomovirus disease dramatically increased with reports of numerous new begomovirus species (Faria et al., 1994; Ambrozevicius et al., 2002; Ribeiro et al., 2003; Della Vecchia et al., 2007; Fernandes et al., 2008; Macedo et al., 2014; Inoue-Nagata et al., 2016). There are now 16 accepted and a few proposed begomovirus species affecting tomatoes in Brazil. Currently, Tomato severe rugose virus (ToSRV) and Tomato mottle leaf curl virus appear to be the predominant species in central and Northern producing areas in the country, respectively (Fernandes et al., 2008; Inoue-Nagata et al., 2016; unpublished observations).

It is not uncommon in Brazilian tomato producing areas to observe a high incidence of begomovirus disease despite regular application of insecticides (Macedo et al., 2014). Many 
factors have been associated with these outbreaks, including difficulty in managing the insect vector in the complex Brazilian agricultural system, planting season coincident with the period of large whitefly population migrations, lack of resistant varieties, presence of susceptible hosts in the field, and overlapping crops. In an attempt to reduce begomovirus disease damage, a tomato-free period (TFP) of 60 days (December to January) was implemented in 2007 in Goiás state, which is the most important production area for processing tomatoes. However, high incidence of begomovirus disease incidence has continued to occur in some cases despite the implementation of the TFP.

It is common for management of vector-borne plant viruses, such as the begomovirus disease, to emphasize intensive application of insecticides. However, chemical spraying to control insect-vectored viruses is rarely effective, especially when there is a high level of primary inoculum (Perring et al., 1999). Application of insecticides may be more effective for diseases in which secondary spread is predominant (Perring et al., 1999). In the case of tomato begomovirus diseases, the classification based on primary or secondary spread is not completely adequate because the primary spread is a continuous phenomenon strongly influencing the disease progress (Bergamin Filho et al., 2016). Thus, in an effort to better understand the epidemiology of begomovirus disease in processing tomatoes, we studied the temporal and spatial dynamics of begomovirus symptoms in tomato plants as well as the whitefly population and assessed the diversity of begomoviruses in tomato and weed plants in six fields from two regions in central Brazil. 


\section{Material and methods}

\section{Location, experimental design and data collection}

The experimental plots were located within six central pivot irrigated fields ( 100 ha) in two processing tomato production areas in central Brazil: (i) Luziânia in the Goiás state where TFP is mandatory and (ii) PAD-DF in the Federal District region located inside of Goiás state, but where the TFP is not implemented. Three pivots in Luziânia (pivot 1: $16^{\circ} 18^{\prime}$ 53.6' South, $47^{\circ} 43^{\prime} 18.3^{\prime}$ 'W, $983 \mathrm{~m}$ altitude) and three pivots in PAD-DF (pivot 1: $15^{\circ} 51^{\prime}$ 45.0' South, $47^{\circ} 23^{\prime} 50.1^{\prime \prime} \mathrm{W}, 911 \mathrm{~m}$ altitude) were assessed from February to August in 2012 (Fig. 1). For all areas, we used virus- and whitefly-free tomato transplants of the susceptible cultivar AP 533 which were produced in nurseries with high quality control. Transplants ca. 30 days after germination were mechanically planted with $1.2 \times 0.45 \mathrm{~m}$ spacing. The irrigation system, chemical spraying and fertilization management were performed according to the standard cultivation procedures of each grower.

Transplanting in pivots 1, 2 and 3 in Luziânia was performed on 13 March 2012, 01 May 2012, and 12 July 2012, respectively, whereas transplanting in pivots 1, 2 and 3 in PADDF was performed on 05 March 2012, 21 March 2012, and 17 April, 2012, respectively. A total of 24 plots were established, with six at the center and 18 at the edges of the pivots. Each plot consisted of 225 plants, with 15 rows of 15 plants, and every plant was evaluated weekly by visual inspection. Based on extensive previous studies, plants showing interveinal chlorosis, leaf curling and crumpling, rugosity and/or stunting were considered to be begomovirus infected. Symptomatic and asymptomatic tomato, bean, soybean and weed plants were collected from all fields and tested by PCR to detect begomoviruses and to confirm infections. 


\section{Detection and identification of the virus species}

All collected samples were subjected to DNA extraction (Doyle \& Doyle, 1990) and PCR amplification with the degenerated begomovirus primer pair PAR1C496/PAL1v1978, which directs the amplification of an $~ 1.1 \mathrm{~kb}$ DNA fragment (Rojas et al., 1993). Then, a total of 53 positive samples were randomly selected (30 tomatoes, 8 beans and 13 weeds) and used for rolling circle amplification (RCA). The genome was partially sequenced using primer PAL1C496, which directs the amplification of a portion of the capsid protein gene and the intergenic region.

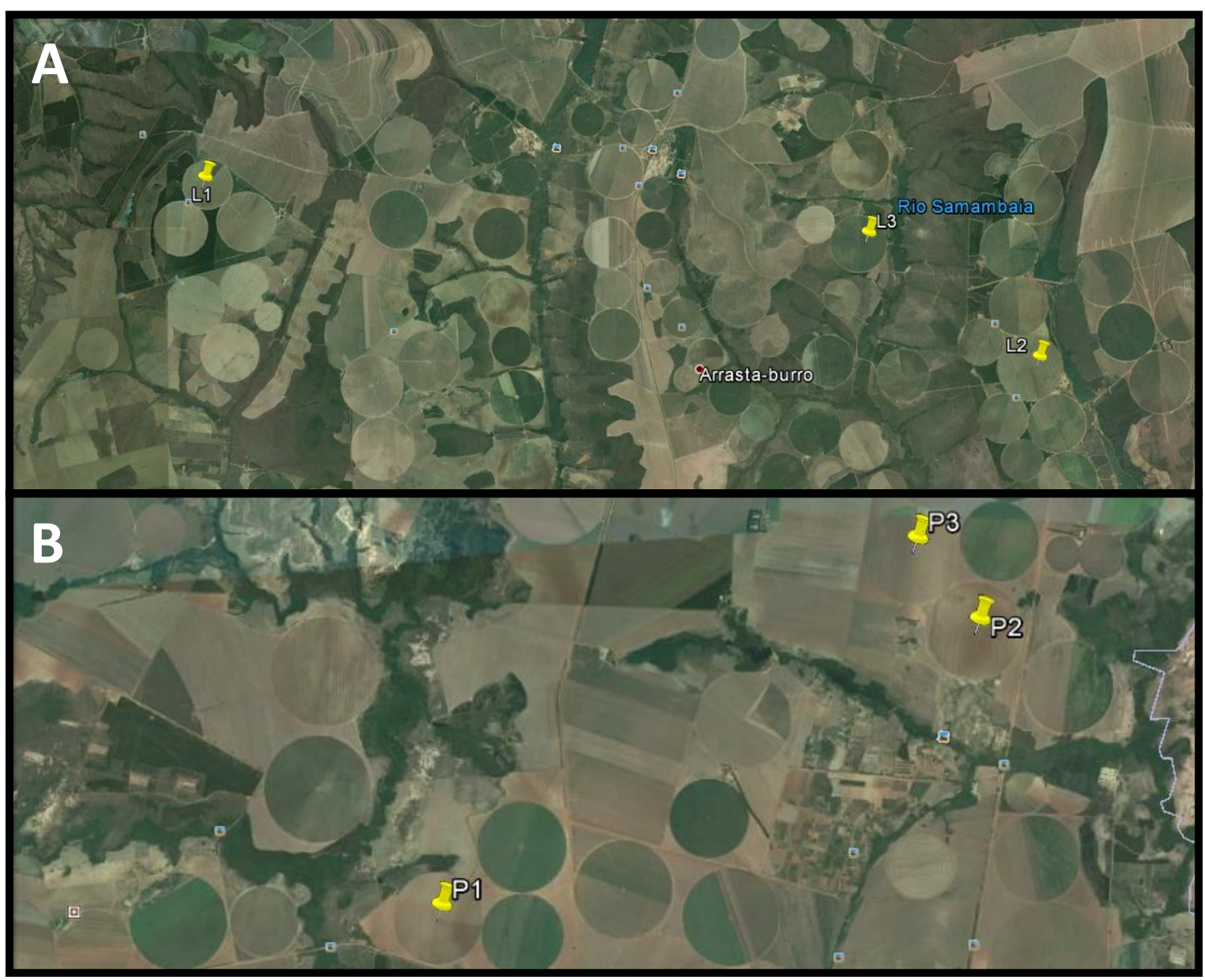

Figure 1. Location of pivots. A: Pivots 1(L1), 2 (L2), and 3 (L3) in the Luziânia region, B: Pivots 1 (P1), 2 (P2) and 3 (P3) in the PAD-DF region. 


\section{Temporal and spatial analyses}

Maps representing the 24 plots at each of the locations were created for each evaluation and used in the temporal and spatial analyses. Symptomatic plants were marked on the $15 \times 15$ grid at the exact position in each evaluation (e.g., Fig. 2). For the spatial analysis, two quadrat sizes were used: $2 \times 3$ (two plants in line and three between lines) and $3 \times 2$ (three plants in line and two between lines).
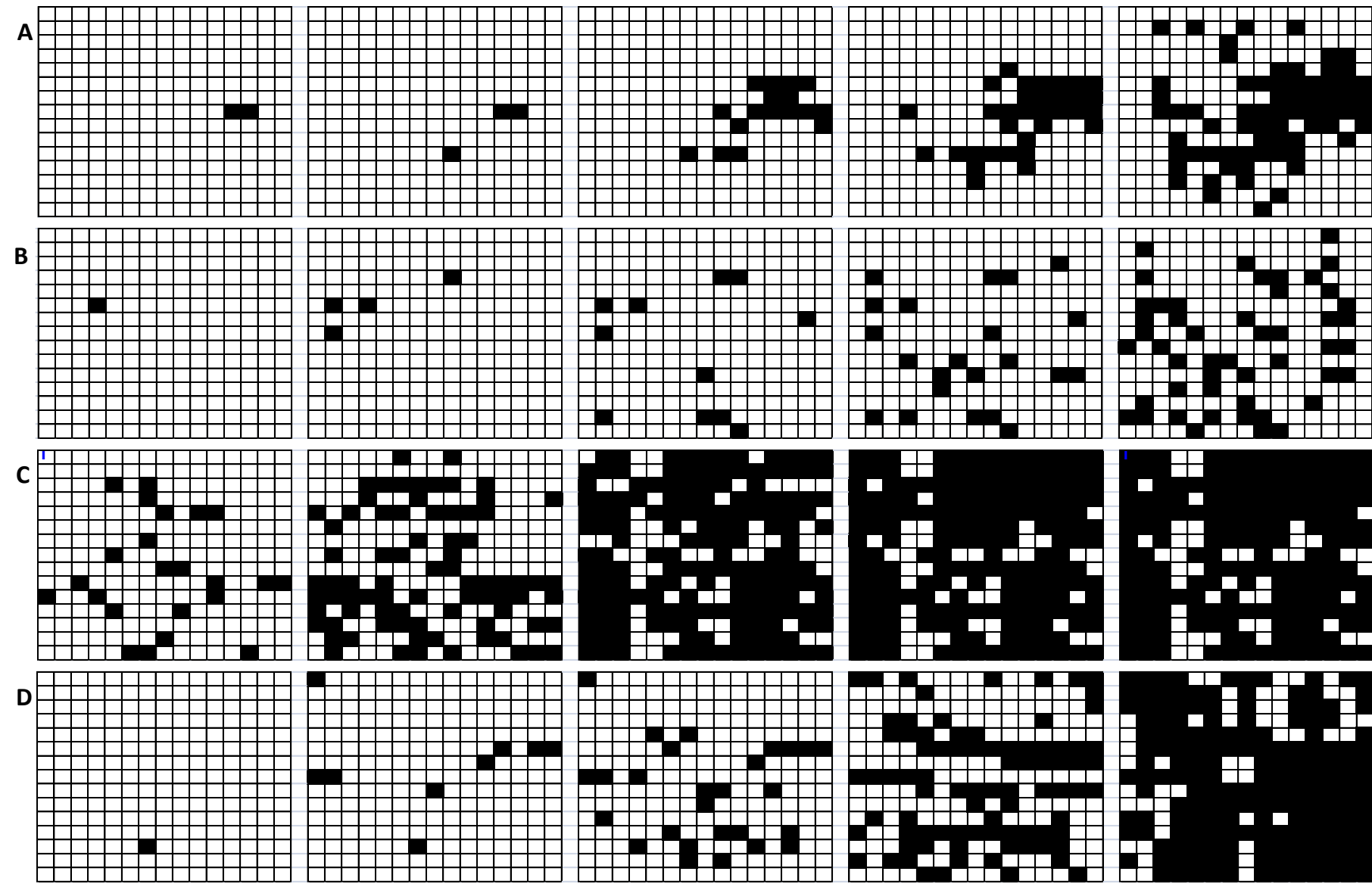

B
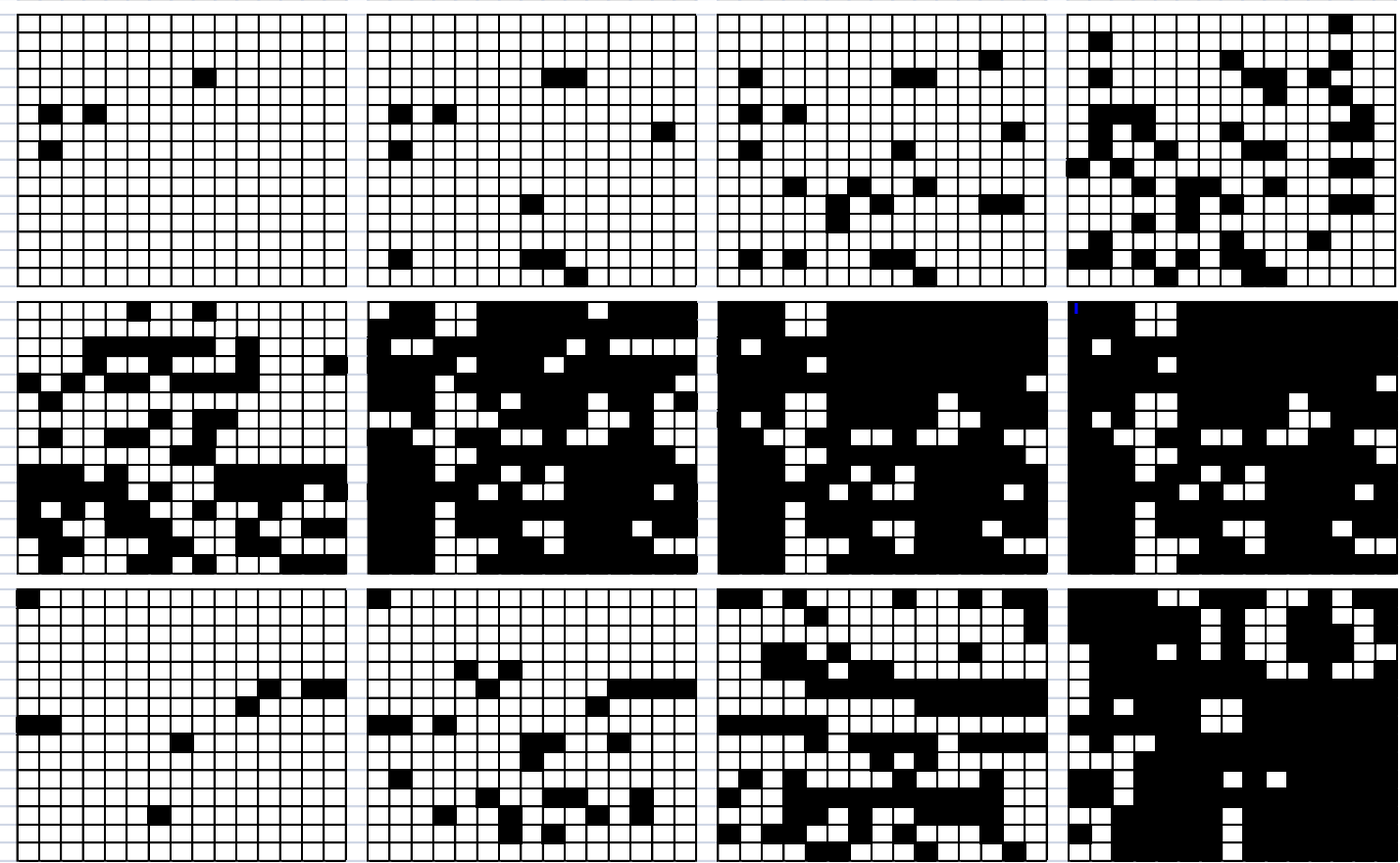

Figure 2. Example of spatial patterns of begomovirus symptomatic plants in tomato fields over time based on weekly evaluations (7 to 35 DAT) in the Luziânia regions. Black squares represent symptomatic tomato plants and white squares represent asymptomatic tomato plants. Spatial progress of symptomatic tomato plants in the Luziânia region, pivot 3, plot 2 (a), and pivot 4, plot 1 (b). 


\section{Temporal analysis}

The incidence of symptomatic tomato plants was assessed weekly in all 24 plots in each of the pivots by visual inspection. The incidence of symptomatic plants $(\mathcal{D})$ in each plot was determined for each evaluation using the following equation (Madden \& Hughes, 1995):

$$
\mathrm{p}=\Sigma\left(X_{i}\right) / \mathrm{nN}
$$

where $X_{i}$ is the total number of symptomatic plants in each quadrat, $\mathrm{n}$ is the number of plants per quadrat, and $\mathrm{N}$ is the total number of quadrats in each plot.

From the disease progress curves, the area under the curve (AUDPC) was calculated by trapezoidal interception according to Campbell and Madden (1990):

$$
\left.\operatorname{AUDPC}=\Sigma\left(\left(y_{i}+y_{i+1}\right) / 2\right)\left(t_{i+1}-t_{i}\right)\right)
$$

where $y_{i}$ and $y_{i+1}$ are incidence values observed in two consecutive assessments $t_{i+1}$ and $t_{i}$.

No attempt was made to fit the disease incidence progress curves to an epidemiological model due to the reduced number of assessments ( 2 to 6) caused by the fast development of infection and the inability to differentiate individual plants by four weeks after transplanting.

\section{Spatial Analysis}

The spatial pattern of the distribution of symptomatic plants was studied based on the ordinary run analysis, dispersion index, modified Taylor's law and dynamic analysis of disease foci. Initially, binary maps (symptomatic and nonsymptomatic plants) were generated. Every new symptomatic plant was plotted in the map in successive assessments. The quadrats of $2 \times 3$ and $3 \times 2$ plants were chosen to determine the spatial parameters of symptomatic plants. 


\section{Ordinary run analysis}

Ordinary run $(\mathrm{OR})$ is a nonparametric and simple test used to detect non-randomness of symptomatic plants within rows (Madden et al., 1982). Rows were combined to form a single row with a length equal to the total number of plants in each plot. A row is considered to have a nonrandom sequence of diseased and asymptomatic plants if the standardized variable $\mathrm{Z}_{\mathrm{u}}$ is lower than -1.64 (Campbell \& Madden, 1990). The ordinary run test was performed for all plots.

\section{Dispersion index}

The dispersion index (D) was calculated for quadrats $2 \times 3$ and $3 \times 2$ from the observed $\left(\mathrm{V}_{\mathrm{obs}}\right)$ and binomial $\left(\mathrm{V}_{\text {bin }}\right)$ variances (Madden \& Hugles, 1995) as follows:

$$
\begin{aligned}
& \mathrm{D}=\mathrm{V}_{\mathrm{obs}} / \mathrm{V}_{\text {bin }} \\
& \mathrm{V}_{\mathrm{obs}}=\Sigma\left(x_{i}-\mathrm{p} \mathrm{n}\right) 2 / \mathrm{n} 2(\mathrm{~N}-1) \text { and } \mathrm{V}_{\text {bin. }}=\mathrm{p}(\mathrm{p}-1) / \mathrm{n}
\end{aligned}
$$

where $x_{i}$ is the total number of symptomatic plants in each quadrat, $p$ is the incidence, $\mathrm{n}$ is the number of plants per quadrat, and $\mathrm{N}$ is the total number of quadrats in each plot.

The significance of $\mathrm{D}$ was verified by the Chi-square test at $5 \%$ probability. $\mathrm{D}$ values statistically equal to 1 were regarded as standard to chance (null hypothesis) and values that differed significantly from 1 were considered aggregates.

\section{Binary power law}

The application of the binary power law was used to characterize the linear relationship between the logarithm of $\mathrm{V}_{\text {bin }}$ and logarithm of $\mathrm{V}_{\text {obs }}$ within each pivot (Madden \& Hugles, 1995) as follows:

$$
\log \left(\mathrm{V}_{\mathrm{bin}}\right)=\log (A)+b \log \left(\mathrm{V}_{\mathrm{obs}}\right)
$$

where $A$ and $b$ are parameters. 
The regressions were performed using Statistica ® 6.0 (Stasoft, Tulsa, OK, USA). The logarithm of binomial variances was considered as the independent variable, whereas the logarithms of variances observed for the maps of each plot were considered as dependent variables. The significance of relationships (linear regression) between $\log \left(\mathrm{V}_{\text {bin }}\right)$ and $\log$ $\left(\mathrm{V}_{\mathrm{obs}}\right)$ was determined by the $\mathrm{F}$ test at $5 \%$ probability. The fitness of the model to the data was determined by calculating the coefficient values $\left(\mathrm{R}^{2}\right)$ and the distribution patterns of the residues (Madden \& Hugles, 1995).

The equality of the parameters $b=1$ and $\log (A)=0$ was evaluated by the t-test at $5 \%$ probability (Madden \& Hugles, 1995) using the estimates of these random parameters and their standard errors. When $b=1$ and $\log (A)=0$, we concluded that the aggregation followed a random distribution pattern. If $b=1$ and $\log (A)>0$, the aggregation level was independent of the incidence. When $b>1$ and $\log (A)>0$, the aggregation varied with the incidence.

\section{Dynamic analysis of disease foci (DADF)}

The focus in a DADF is an area of concentration of infected plants that can become primary sources of infection or coincident with areas originally favourable to the establishment of the disease that tend to influence the pattern of disease dissemination (Laranjeira et al., 2004). The DADF was carried out from the cumulative maps of each plot for each evaluation. Symptomatic plants are in the same focus (disease cluster) if they are present immediately adjacent to symptomatic plants in horizontal, vertical or longitudinal proximity (Nelson 1996, Laranjeira et al., 2004), Maps were constructed by plotting the number of foci and the number of focus units related to the disease incidence for all data sets and fitted to a generalized $\beta$ (beta) function (Hau \& Kranz, 1990) as follows:

$$
Y=b_{1}(x)^{b 2} \times(1-x)^{b 3}
$$

where $Y=$ the number of foci per 225 plants, $x$ is the disease incidence, and $b_{1}, b_{2}$ and $b_{3}$ are the calculated regression constants. 


\section{Estimating the whitefly population}

The whitefly population was monitored weekly by placing eight traps (Bio Controle, Indaiatuba, SP, Brazil) in each plot (except for plots located at the center of the pivot and at pivot 3 in Luziânia). These traps $(12 \times 12 \mathrm{~cm})$ were yellow and sticky on both sides. The traps were placed at plant height, fixed on aluminium wires and left in the field for seven days. The number of adult whiteflies on the traps were counted with a stereomicroscope. A regression approach was performed to verify the relationship between the whitefly population and the begomovirus disease incidence. 


\section{Results}

\section{Detection and identification of begomovirus species}

In all three monitored fields in both locations, Luziânia and PAD-DF, tomato plants with begomovirus infection symptoms were observed. Tomato plants with these symptoms were collected during the course of the study, and begomovirus infection was confirmed by the amplification of the expected $1.1 \mathrm{~kb}$ DNA fragment in PCR assays with a degenerate primer pair. To determine the identity of the begomovirus infecting tomato plants in these fields, 30 samples of plants with begomovirus symptoms were randomly selected, the PCR assay performed and the amplified DNA fragment was directly sequenced. The expected size of $1.1 \mathrm{~kb}$ DNA fragment was amplified from these samples and the approximately 800 nucleotide-long sequences shared the highest nucleotide identity with ToSRV (88 to 98\%, accession FJ824808) in 29 of 30 samples (Table 1). In one of the PCR amplified sample, the sequence had the highest identity (93\%) with Euphorbia yellow mosaic virus (EuYMV, accession JF756676.1) (Table 1). RCA and RFLP (MspI enzyme) analyses of this sample confirmed the typical digestion profile of an EuYMV isolate.

In common beans, the predominant begomovirus species was Bean golden mosaic virus (BGMV, accession KJ939850.1). BGMV was detected in 7 out of 8 samples, with 90 to 93\% nucleotide identity; whereas ToSRV was detected in one bean sample (Table 1). Among the 21 weed samples collected in or around the these fields, begomoviruses were detected in Nicandra physaloides, Sida spp., Sonchus oleraceus, Euphorbia heterophylla and Solanum americanum (Table 1). In Sida spp., Sida micrantha mosaic virus (SiMMV) was predominantly detected (3 of 5), but ToSRV and BGMV were also observed. In $E$. heteroplylla, EuYMV (2 of 3) and ToSRV (1 sample) were detected (Table 1). ToSRV was the only virus detected in $S$. oleraceus and $S$. americanum (Table 1). These results indicate that ToSRV is the predominant begomovirus associated with tomatoes in these two locations, 
whereas BGMV was associated with beans and weed infecting begomoviruses were predominantly associated with weeds.

Table 1. Identification of begomovirus species present in infected tomato, bean and weed plants by direct sequencing of PCR products

\begin{tabular}{lccccc}
\hline & \multicolumn{5}{c}{ Begomovirus $^{1}$} \\
\cline { 2 - 6 } Tested plants & ToSRV & BGMV & EuYMV & SiMMV & Total $^{1}$ \\
\hline Solanum lycopersicum & 29 & 0 & 1 & 0 & 30 \\
Phaseolus vulgaris & 1 & 7 & 0 & 0 & 8 \\
Sida spp. & 1 & 1 & 0 & 3 & 5 \\
Nicandra physaloides & 2 & 0 & 0 & 0 & 2 \\
Sonchus oleraceus & 2 & 0 & 0 & 0 & 2 \\
Euphorbia heterophylla & 1 & 0 & 2 & 0 & 3 \\
Solanum americanum & 1 & 0 & 0 & 0 & 1 \\
\hline PCR directed to the 5' portion of the coat protein gene and the intergenic region. ${ }^{1}$ ToSRV: \\
Tomato severe rugose virus; BGMV: Bean golden mosaic virus; EuYMV: Euphorbia yellow \\
mosaic virus; SiMMV: Sida micrantha mosaic virus; ${ }^{2}$ Total number of collected plants.
\end{tabular}

\section{Temporal analysis}

The mean begomovirus disease incidence in the last evaluation point in all plots and in both regions was 54.97\% (Table 2, Table 3). Begomovirus incidence and AUDPC were invariably higher in plots located at the edge (PE) of the pivot $(58.78 \%, 214.49$, respectively) than in plots located at the center (PC) of the pivot (51.16\% and 168.24, respectively) (Table 2, Table 3). The disease incidence varied from $4 \%$ to $56 \%$ in Luziânia, while from $19.0 \%$ to $100 \%$ in PAD-DF; the AUDPC ranged from 15.0 to 157.8 in Luziânia, and 120.0 to 454.2 in PAD-DF (Table 2, Table 3). The final average of begomovirus incidence in PAD-DF (83.5\%) was more than twice than that of Luziânia (29.54\%) (Table 3).

The symptoms, typical of begomovirus infection such as interveinal chlorosis, leaf rolling, and stunting, could be clearly observed in more than $50 \%$ of the plots two weeks after transplating (Table 3). In plants at PE, symptomatic plants started to appear 7 days after 
transplanting (DAT) in $33.33 \%$ of the experimental plots, however, only $16.66 \%$ of the plots contained symptomatic plants in PC after 7 DAT (Table 3). It was clear that the plants at PC developed infection symptoms later than in plants at PE.

The temporal disease progress was assessed until 6 weeks after transplanting in all plots, though the disease progress in most plots stabilized in the 3rd to the 4th week. This number of assessments was too low to enable a reliable fitting of any epidemiological model (Figure 3).

\section{Spatial analysis}

The spatial pattern of symptomatic plants distribution was analyzed in all plots during the period of six weeks. A slightly aggregated distribution was observed in the plots, though aggregation was stronger in PC than in PE (Figure 4). Whereas a random distribution pattern was observed in a few plots, an aggregated distribution was predominantly observed in the majority of the plots in both evaluated areas. An edge effect could be observed with higher aggregation (Figure 4) and disease incidence (Table 3).

\section{Ordinary run analysis}

In an ordinary run analysis, aggregation of symptomatic plants was observed in only a few rows $(12.3 \%)$ and between rows $(5.7 \%)$ (Table 2, 3). In PC, symptomatic plants were more aggregated (row - 13.4\%; column - 7.7\%) than those in PE (12.0\%; 5.2\%) (Table 3). This suggests that secondary dispersion is more important in the plants located at the center than those in the edge.

\section{Dispersion Index (D)}

In approximately $30 \%$ of the maps, the D value was higher than $1(p>0.05)$ indicating aggregated distribution of the symptomatic plants in the experimental plot (Table 3). An aggregated pattern was observed more frequently (32.65\%) in the quadrat $3 \times 2$ than in quadrat 
$2 \times 3(27.55 \%)$ (Table 2, 3). As expected, in PC, the percentage of aggregated maps was higher (2x3-50.0\%; 3x2 - 40.9\%) than in PE $(21.1 \% ; 30.3 \%)$ (Table 2, 3). 
Table 2. Begomovirus incidence at each evaluation time point and the $\mathrm{D}$ values for quadrats $2 \times 3$ and $3 \times 2$, ordinary run, mean whitefly population and AUDPC for each plot in the Luziânia and PAD-DF regions

\begin{tabular}{|c|c|c|c|c|c|c|c|c|c|}
\hline \multirow[b]{2}{*}{ Plot $^{1}$} & \multirow[b]{2}{*}{ Date $^{2}$} & \multirow[b]{2}{*}{$\mathbf{D A T}^{3}$} & \multirow[b]{2}{*}{ INC $^{4}$} & \multicolumn{2}{|c|}{$D^{5}$} & \multicolumn{2}{|c|}{ ordinary run } & \multirow[b]{2}{*}{$\mathbf{W F}^{8}$} & \multirow[b]{2}{*}{ AUDPC } \\
\hline & & & & (2X3) & (3X2) & Rows $^{6}$ & $\mathrm{~B}$ rows $^{7}$ & & \\
\hline \multirow[t]{4}{*}{ LE1-1 } & 04.02 .12 & 21 & 0.00 & 1.00 & 1.00 & $0 / 1$ & $0 / 1$ & 71.68 & 142.14 \\
\hline & 04.09 .12 & 28 & 0.05 & 0.77 & 0.70 & $0 / 8$ & $2 / 8$ & & \\
\hline & 04.16 .12 & 35 & 0.28 & 1.20 & $1.46^{*}$ & $3 / 14$ & $1 / 15$ & & \\
\hline & 04.23 .12 & 42 & 0.56 & $1.52 *$ & $1.56^{*}$ & $1 / 14$ & $3 / 15$ & & \\
\hline \multirow[t]{3}{*}{ LE1-2 } & 04.09 .12 & 28 & 0.02 & 0.93 & 0.95 & $0 / 14$ & $0 / 14$ & 54.31 & 118.3 \\
\hline & 04.16 .12 & 35 & 0.12 & 1.27 & $1.85^{*}$ & $1 / 10$ & $0 / 12$ & & \\
\hline & 04.23 .12 & 42 & 0.42 & $1.67 *$ & $1.85^{*}$ & $3 / 15$ & $1 / 15$ & & \\
\hline \multirow[t]{4}{*}{ LE1-3 } & 04.02 .12 & 21 & 0.02 & 1.33 & 1.33 & $0 / 4$ & $0 / 2$ & 32.56 & 157.79 \\
\hline & 04.09 .12 & 28 & 0.08 & $2.14 *$ & 0.95 & $1 / 10$ & $0 / 9$ & & \\
\hline & 04.16 .12 & 35 & 0.30 & $1.6^{*}$ & $1.55^{*}$ & $0 / 15$ & $0 / 14$ & & \\
\hline & 04.23 .12 & 42 & 0.57 & 1.24 & 1.37 & $3 / 14$ & $1 / 15$ & & \\
\hline \multirow[t]{3}{*}{ LE1-4 } & 04.09 .12 & 28 & 0.03 & $1.94 *$ & 1.23 & $1 / 4$ & $1 / 4$ & 90.18 & 140.84 \\
\hline & 04.16 .12 & 35 & 0.22 & 0.90 & 0.93 & $1 / 13$ & $0 / 15$ & & \\
\hline & 04.23 .12 & 42 & 0.33 & 1.09 & 1.23 & $0 / 14$ & $0 / 15$ & & \\
\hline \multirow[t]{3}{*}{ LC1-5 } & 04.09 .12 & 28 & 0.05 & 1.34 & $2.04 *$ & $0 / 6$ & $0 / 10$ & $\mathrm{Nc}$ & 150.01 \\
\hline & 04.16 .12 & 35 & 0.20 & $1.83 *$ & $1.43^{*}$ & $2 / 12$ & $1 / 15$ & & \\
\hline & 04.23 .12 & 42 & 0.40 & $1.68 *$ & $2.38^{*}$ & $1 / 14$ & $0 / 15$ & & \\
\hline \multirow[t]{3}{*}{ LE2-1 } & 05.14 .12 & 14 & 0.02 & 0.93 & 0.95 & $0 / 14$ & $0 / 13$ & 39.25 & 69.09 \\
\hline & 05.21 .12 & 21 & 0.07 & 1.37 & 1.24 & $0 / 7$ & $0 / 10$ & & \\
\hline & 05.28 .12 & 28 & 0.23 & $1.49 *$ & $1.49 *$ & $2 / 12$ & $1 / 14$ & & \\
\hline \multirow[t]{5}{*}{ LE2-2 } & 05.07 .12 & 7 & 0.01 & 0.98 & 0.98 & $0 / 1$ & $0 / 1$ & 60.9 & 67.08 \\
\hline & 05.14 .12 & 14 & 0.01 & 0.95 & 0.59 & $0 / 1$ & $0 / 1$ & & \\
\hline & 05.21 .12 & 21 & 0.07 & $2.11 *$ & $2.16^{*}$ & $2 / 3$ & $2 / 3$ & & \\
\hline & 05.28 .12 & 28 & 0.14 & $2.59 *$ & $3.25^{*}$ & $3 / 7$ & $5 / 6$ & & \\
\hline & 05.28 .12 & 35 & 0.31 & $2.35^{*}$ & $2.64 *$ & $4 / 10$ & $2 / 9$ & & \\
\hline \multirow[t]{3}{*}{ LC2-3 } & 05.14 .12 & 14 & 0.00 & 1.00 & 1.00 & $0 / 1$ & $0 / 1$ & $\mathrm{Nc}$ & 22.49 \\
\hline & 05.21 .12 & 21 & 0.03 & $1.76^{*}$ & 1.15 & $0 / 3$ & $0 / 6$ & & \\
\hline & 05.28 .12 & 28 & 0.06 & $1.81 *$ & $2.54 *$ & $0 / 4$ & $0 / 10$ & & \\
\hline \multirow[t]{5}{*}{ LE3-1 } & 07.19 .12 & 7 & 0.00 & 1.00 & 1.00 & $0 / 1$ & $0 / 1$ & $\mathrm{Nc}$ & 69.01 \\
\hline & 07.24 .12 & 14 & 0.02 & 0.93 & 0.93 & $0 / 1$ & $0 / 1$ & & \\
\hline & 07.31 .12 & 21 & 0.05 & 1.14 & 0.99 & $0 / 3$ & $0 / 3$ & & \\
\hline & 08.07 .12 & 28 & 0.10 & 1.05 & 0.78 & $1 / 7$ & $0 / 6$ & & \\
\hline & 08.13 .12 & 35 & 0.23 & 1.22 & 0.85 & $0 / 10$ & $1 / 10$ & & \\
\hline \multirow[t]{3}{*}{ LE3-2 } & 07.31 .12 & 14 & 0.01 & 0.98 & 0.98 & $0 / 2$ & $0 / 2$ & $\mathrm{Nc}$ & 34.18 \\
\hline & 08.07.12 & 21 & 0.04 & $1.75 *$ & 0.74 & $0 / 8$ & $0 / 5$ & & \\
\hline & 08.13 .12 & 28 & 0.10 & $1.55^{*}$ & 1.74 & $3 / 11$ & $0 / 11$ & & \\
\hline \multirow[t]{2}{*}{ LB3-3 } & 07.31 .12 & 21 & 0.00 & 1.00 & 0.98 & $0 / 1$ & $0 / 1$ & $\mathrm{Nc}$ & 15.01 \\
\hline & 08.07.12 & 28 & 0.04 & 0.83 & 0.57 & $0 / 3$ & $0 / 6$ & & \\
\hline \multirow[t]{4}{*}{ PE1-1 } & 03.12 .12 & 7 & 0.00 & 1.00 & 1.00 & $0 / 1$ & $0 / 1$ & 412.4 & 354.38 \\
\hline & 03.19 .12 & 14 & 0.07 & 0.82 & 0.74 & $0 / 4$ & $0 / 9$ & & \\
\hline & 03.26 .12 & 21 & 0.40 & 1.19 & $2.00 *$ & $0 / 14$ & $0 / 15$ & & \\
\hline & 04.02 .12 & 28 & 0.93 & 1.08 & $2.32 *$ & $1 / 9$ & $0 / 10$ & & \\
\hline
\end{tabular}




\begin{tabular}{|c|c|c|c|c|c|c|c|c|c|}
\hline & 04.09 .12 & 35 & 0.94 & 1.03 & $1.85^{*}$ & $0 / 9$ & $0 / 10$ & & \\
\hline \multirow[t]{4}{*}{ PE1-2 } & 03.19 .12 & 14 & 0.00 & 1.00 & 1.00 & $0 / 1$ & $0 / 1$ & 356.16 & 218.73 \\
\hline & 03.26 .12 & 21 & 0.05 & 1.53 & 0.81 & $0 / 8$ & $0 / 4$ & & \\
\hline & 04.02 .12 & 28 & 0.41 & 1.07 & $1.87 *$ & $1 / 14$ & $0 / 15$ & & \\
\hline & 04.09 .12 & 35 & 0.94 & 1.87 & $2.21 *$ & $0 / 4$ & $0 / 10$ & & \\
\hline \multirow[t]{5}{*}{ PE1-3 } & 03.12 .12 & 7 & 0.02 & 0.93 & 0.93 & $0 / 4$ & $0 / 3$ & 418.41 & 441.18 \\
\hline & 03.19 .12 & 14 & 0.25 & $1.44 *$ & $1.87 *$ & $0 / 7$ & $0 / 15$ & & \\
\hline & 03.26 .12 & 21 & 0.78 & $2.20 *$ & $3.41 *$ & $2 / 9$ & $3 / 15$ & & \\
\hline & 04.02 .12 & 28 & 0.99 & 0.98 & 1.00 & $0 / 2$ & $0 / 2$ & & \\
\hline & 04.09 .12 & 35 & 1.00 & 1.00 & --- & $0 / 1$ & $1 / 1$ & & \\
\hline \multirow[t]{4}{*}{ PE1-4 } & 03.19 .12 & 14 & 0.11 & 0.95 & 1.06 & $0 / 11$ & $0 / 13$ & 133.25 & 357.82 \\
\hline & 03.26 .12 & 21 & 0.35 & $1.53 *$ & 1.40 & $0 / 14$ & $0 / 15$ & & \\
\hline & 04.02 .12 & 28 & 0.73 & 0.91 & $1.68 *$ & $0 / 15$ & $1 / 15$ & & \\
\hline & 04.09 .12 & 35 & 0.80 & 1.28 & $1.78 *$ & $0 / 15$ & $1 / 14$ & & \\
\hline \multirow[t]{4}{*}{ PC1-5 } & 03.19 .12 & 14 & 0.02 & 0.93 & 0.95 & $0 / 3$ & $0 / 3$ & $\mathrm{Nc}$ & 206.15 \\
\hline & 03.26 .12 & 21 & 0.08 & 0.97 & 0.70 & $0 / 10$ & $0 / 12$ & & \\
\hline & 04.02 .12 & 28 & 0.37 & $2.19 *$ & 2.40 & $2 / 3$ & $3 / 15$ & & \\
\hline & 04.09 .12 & 35 & 0.85 & $2.63 *$ & $2.79 *$ & $2 / 5$ & $5 / 13$ & & \\
\hline \multirow[t]{3}{*}{ PE2-1 } & 04.10 .12 & 21 & 0.03 & 1.23 & $1.45^{*}$ & $0 / 3$ & $0 / 4$ & 58 & 454.18 \\
\hline & 04.17 .12 & 28 & 0.80 & 1.21 & $1.87 *$ & $4 / 15$ & $0 / 14$ & & \\
\hline & 04.24 .12 & 35 & 0.97 & 1.16 & 1.23 & $0 / 5$ & $0 / 4$ & & \\
\hline \multirow[t]{3}{*}{ PE2-2 } & 04.10 .12 & 21 & 0.03 & 1.23 & 1.23 & $4 / 4$ & $4 / 4$ & 73.08 & 256.66 \\
\hline & 04.17 .12 & 28 & 0.33 & 1.10 & 1.09 & $1 / 15$ & $0 / 15$ & & \\
\hline & 04.24 .12 & 35 & 0.77 & 0.78 & 1.16 & $0 / 11$ & $1 / 15$ & & \\
\hline \multirow[t]{3}{*}{ PE2-3 } & 04.10 .12 & 21 & 0.03 & 1.16 & 1.23 & $0 / 6$ & $0 / 6$ & 40.9 & 422.43 \\
\hline & 04.17 .12 & 28 & 0.71 & $1.44^{*}$ & $2.97 *$ & $4 / 13$ & $2 / 15$ & & \\
\hline & 04.24 .12 & 35 & 0.96 & 0.83 & 1.16 & $0 / 15$ & $0 / 9$ & & \\
\hline \multirow[t]{2}{*}{ PE2-4 } & 04.17 .12 & 28 & 0.15 & 1.24 & $1.68 *$ & $1 / 9$ & $0 / 15$ & 38.5 & 120.02 \\
\hline & 04.24 .12 & 35 & 0.19 & 1.28 & 1.33 & $1 / 12$ & $0 / 15$ & & \\
\hline \multirow[t]{3}{*}{ PC2-5 } & 04.10 .12 & 21 & 0.06 & 0.90 & 1.29 & $1 / 7$ & $0 / 10$ & $\mathrm{Nc}$ & 451.64 \\
\hline & 04.17 .12 & 28 & 0.80 & $1.81^{*}$ & $2.65^{*}$ & $2 / 10$ & $1 / 15$ & & \\
\hline & 04.24 .12 & 35 & 0.93 & $2.08 *$ & $1.45^{*}$ & $2 / 8$ & $0 / 8$ & & \\
\hline \multirow[t]{5}{*}{ PE3-1 } & 04.23 .12 & 7 & 0.01 & $1.65^{*}$ & 0.95 & $1 / 2$ & $1 / 4$ & 34.79 & 172.50 \\
\hline & 04.30 .12 & 14 & 0.02 & $1.45^{*}$ & 0.59 & $1 / 3$ & $1 / 5$ & & \\
\hline & 05.07 .12 & 21 & 0.10 & 1.11 & 1.05 & $2 / 11$ & $2 / 12$ & & \\
\hline & 05.14 .12 & 28 & 0.45 & 1.41 & $1.53 *$ & $0 / 15$ & $0 / 15$ & & \\
\hline & 05.21 .12 & 35 & 0.81 & $1.48 *$ & 1.22 & $8 / 14$ & $3 / 14$ & & \\
\hline \multirow[t]{5}{*}{ PE3-2 } & 04.23 .12 & 7 & 0.04 & 1.36 & $1.52 *$ & $0 / 4$ & $0 / 8$ & 22.25 & 264.57 \\
\hline & 04.30 .12 & 14 & 0.04 & 1.28 & 0.98 & $0 / 5$ & $0 / 9$ & & \\
\hline & 05.07 .12 & 21 & 0.27 & 1.24 & 1.22 & $2 / 15$ & $0 / 15$ & & \\
\hline & 05.14 .12 & 28 & 0.71 & 1.35 & 1.35 & $1 / 14$ & $0 / 15$ & & \\
\hline & 05.21 .12 & 35 & 0.94 & 1.20 & 0.86 & $0 / 9$ & $0 / 9$ & & \\
\hline \multirow[t]{5}{*}{ PC3-3 } & 04.23 .12 & 7 & 0.00 & 1.00 & 1.00 & $0 / 1$ & $0 / 1$ & $\mathrm{Nc}$ & 164.19 \\
\hline & 04.30 .12 & 14 & 0.04 & 1.09 & 0.88 & $1 / 6$ & $0 / 8$ & & \\
\hline & 05.07 .12 & 21 & 0.12 & 0.84 & 1.23 & $1 / 11$ & $0 / 14$ & & \\
\hline & 05.14 .12 & 28 & 0.37 & 0.84 & 1.10 & $4 / 15$ & $0 / 15$ & & \\
\hline & 05.21 .12 & 35 & 0.76 & $2.34 *$ & $1.90 *$ & $1 / 15$ & $4 / 14$ & & \\
\hline
\end{tabular}


${ }^{1}$ Identification of the plots: the first letter identifies the area (L stands for Luziânia and P for PAD-DF); the second letter is the location of the plot ( $\mathrm{E}$ for edge and $\mathrm{C}$ for center); and the first number is the pivot identification followed by the plot number. ${ }^{2}$ Date of evaluation. ${ }^{3}$ DAT: days after transplanting. ${ }^{4} \mathrm{INC}$ : incidence of begomovirus. ${ }^{5} \mathrm{D}$ : dispersion index, $(*)$ values significantly higher than 1 in the Chi-square test $(\mathrm{p}<0.05) .{ }^{6}$ number of aggregated $(\mathrm{Zr}<1.64)$ rows per number of evaluated rows. ${ }^{7}$ number of aggregation $(\mathrm{Zr}<1.64)$ between rows per total evaluated rows. ${ }^{8} \mathrm{WF}$ : average number of whiteflies collected per yellow trap up to two weeks before the last evaluation time; Nc: whitefly data were not collected. ${ }^{9}$ AUDPC: area under disease progress curve.

Table 3. Average begomovirus disease incidence and AUDPC, time of the appearance of the first symptoms of the disease, percentages of aggregated plots by D analyses, and percentages of aggregated rows and between rows

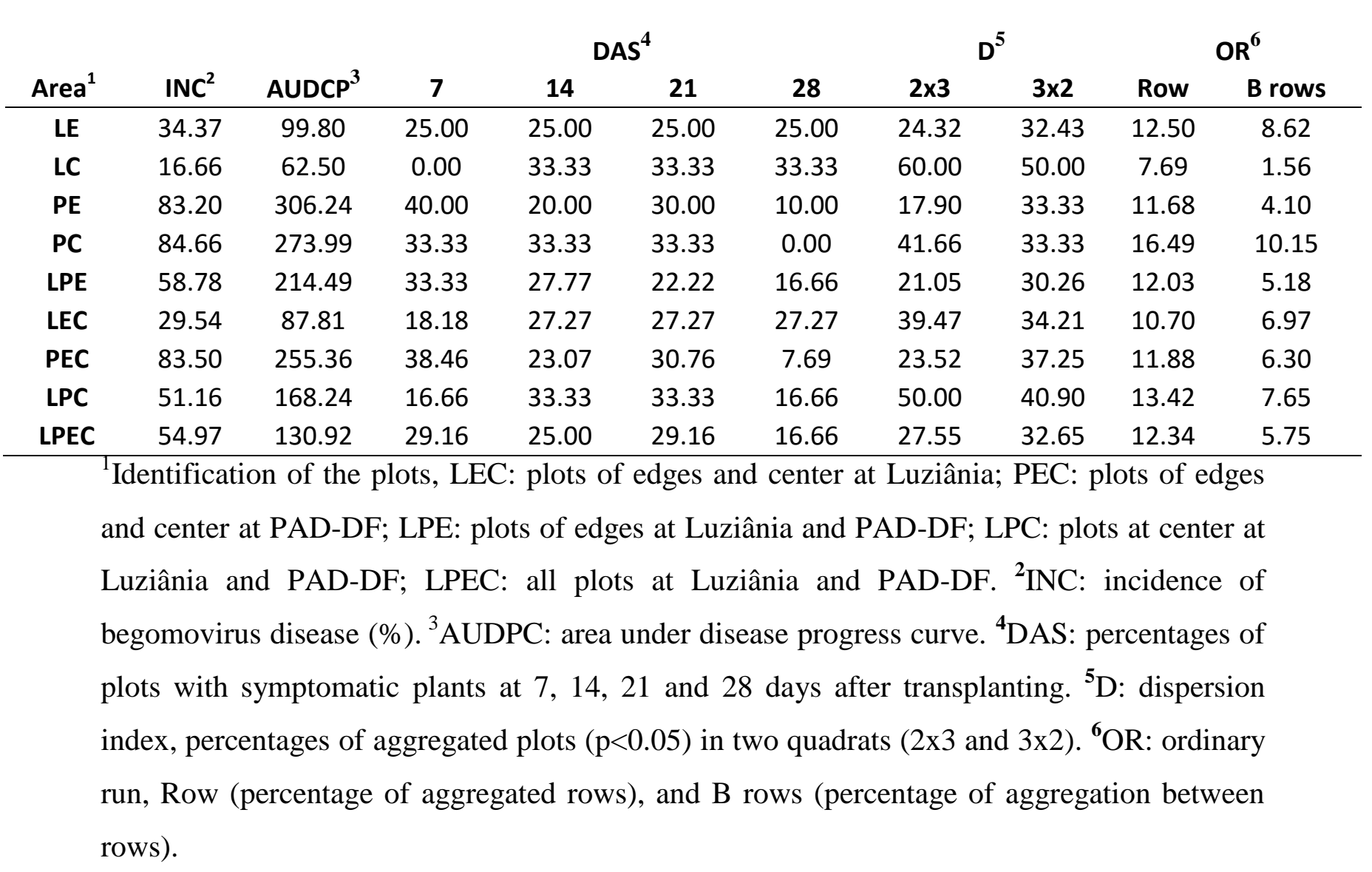




\section{Binary power law}

The estimated slope and intercept parameter were significantly greater than 1 and 0 , respectively, using both quadrats, indicating a slight aggregation pattern of begomovirus symptomatic plants. The estimates of $b$ and $\log (A)$ were 1.10 and $0.31\left(\mathrm{R}^{2}=0.96\right)$ and 1.15 and $0.42\left(\mathrm{R}^{2}=0.94\right)$ for quadrats $2 \times 3$ and $3 \times 2$, respectively. Symptomatic plants in the PC were more aggregated than symptomatic plants analysed in the PE. The estimates of $b$ and $\log$ (A) for quadrats $2 \times 3$ and $3 \times 2$ were equal to 1.16 and $0.47\left(\mathrm{R}^{2}=0.94\right)$ and 1.21 and $0.56\left(\mathrm{R}^{2}=\right.$ 0.92) for PC and 1.09 and $0.26\left(\mathrm{R}^{2}=0.96\right)$ and 1.14 and $0.39\left(\mathrm{R}^{2}=0.94\right)$ for PE, respectively (Fig. 4).

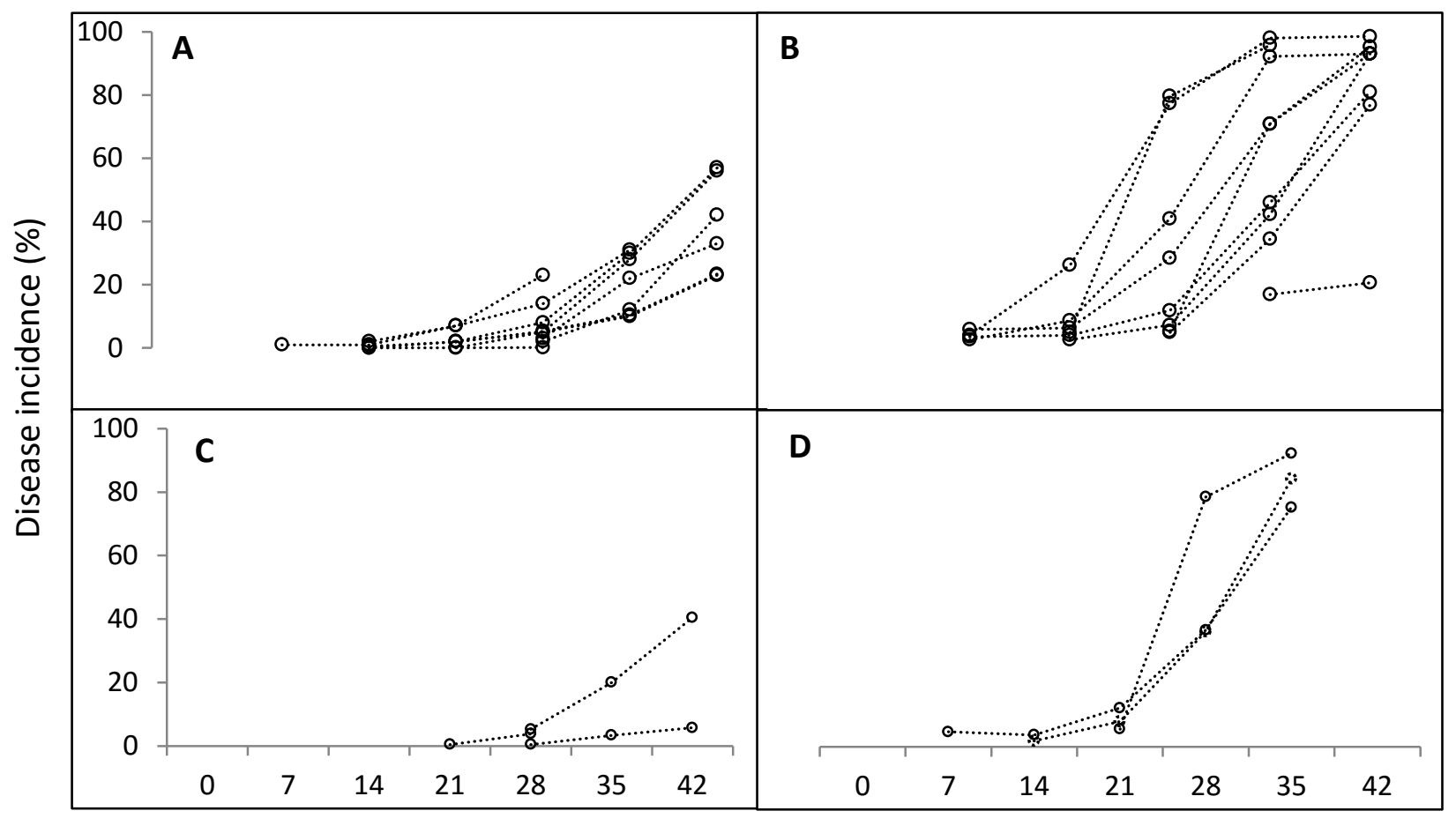

Days after transplanting

Figure 3. Begomovirus disease progression curves from all plots evaluated weekly in tomato fields located at the edge in the Luziânia (A) and PAD-DF (B) regions and those located at the center of the pivot in Luziânia (C) and PAD-DF (D). 

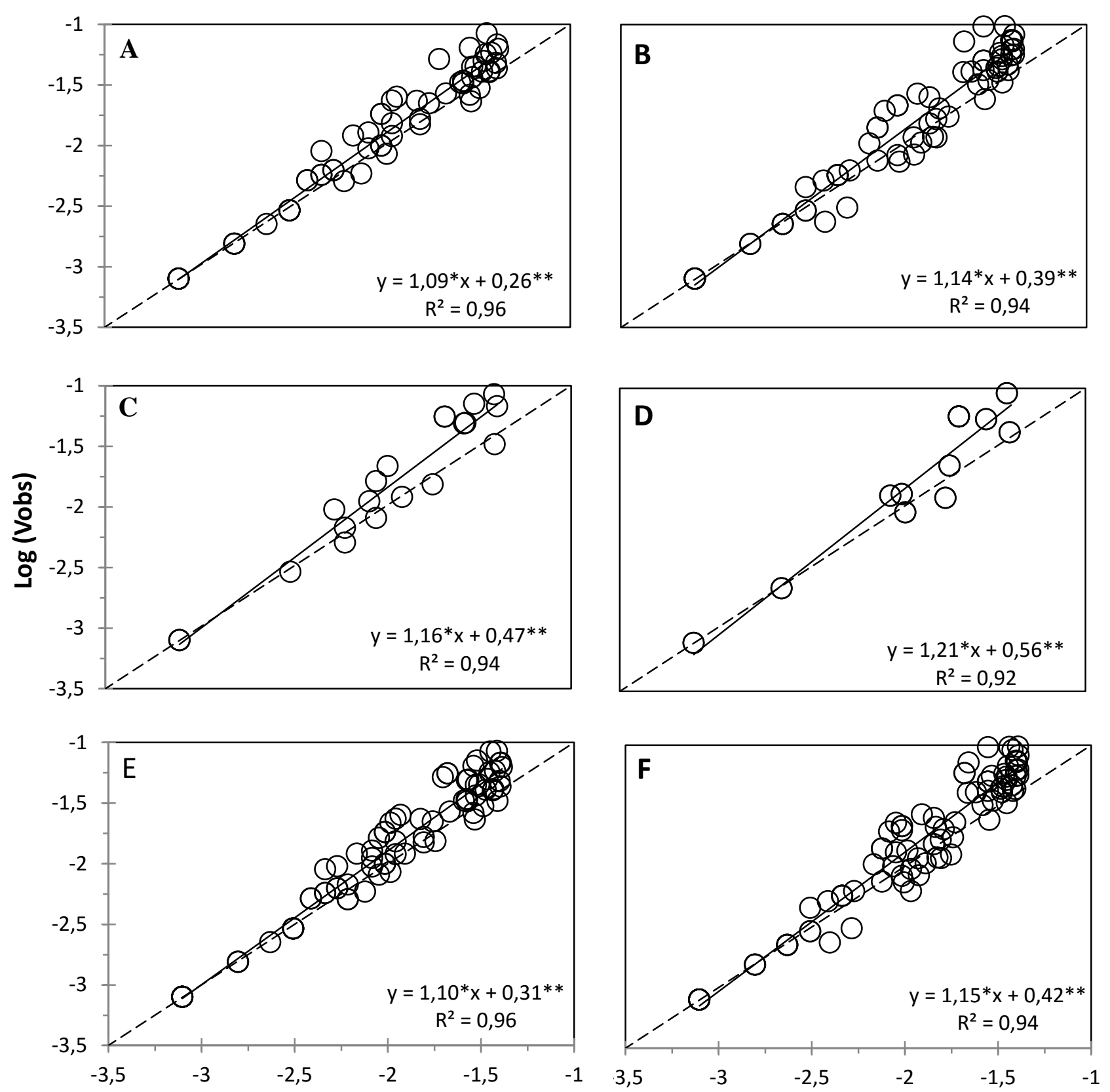

\section{Log (Vbin)}

Figure 4. Relationship between the logarithm of the observed variance $\left[\log \left(\mathrm{V}_{\mathrm{obs}}\right)\right]$ and the logarithm of the binomial variance $\left[\log \left(\mathrm{V}_{\text {bin }}\right)\right]$ for all evaluations in all plots located at the edge of the pivots in the PAD-DF and Luziânia regions using quadrat $2 \times 3$ (A) and quadrat $3 \times 2$ (B). All evaluations of all plots located at the center of the pivots in the PAD-DF and

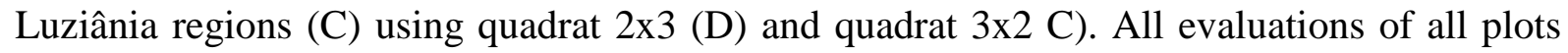
located in the Luziânia and PAD-DF regions using quadrat 2x3 (E) and 3x2 (F). *Values significantly different from 1 . $* *$ Values significantly different from $0(\mathrm{p}<0.05)$. The solid line represents the relationship $\log \left(\mathrm{v}_{\mathrm{obs}}\right)=\log (A)+b \log \left(\mathrm{v}_{\mathrm{bin}}\right)$ fit in the data by ordinary least square regression. The dashed line represents the binomial line (observed variance $=$ binomial variance). 


\section{Dynamic analysis of disease foci (DADF)}

The pattern of curves of the number of clusters was similar for PE and PC. In the PC, the peak of the total disease cluster was observed when the disease incidence was between 7.5-12.5\% (Fig. 5a). However, the PE the peak was observed later when the incidence was approximately $20-25 \%$ (Fig. 5b). Coalescence of the clusters was observed starting from the peak in a slow descending curve (Fig. 5a, 5b). The generalized beta distribution function best fit the data on the number of clusters per disease incidence in the PC areas because their residual values were lower compared to the PE areas. The residual values of the PE and PC data were equal to 16 and 10 , respectively.
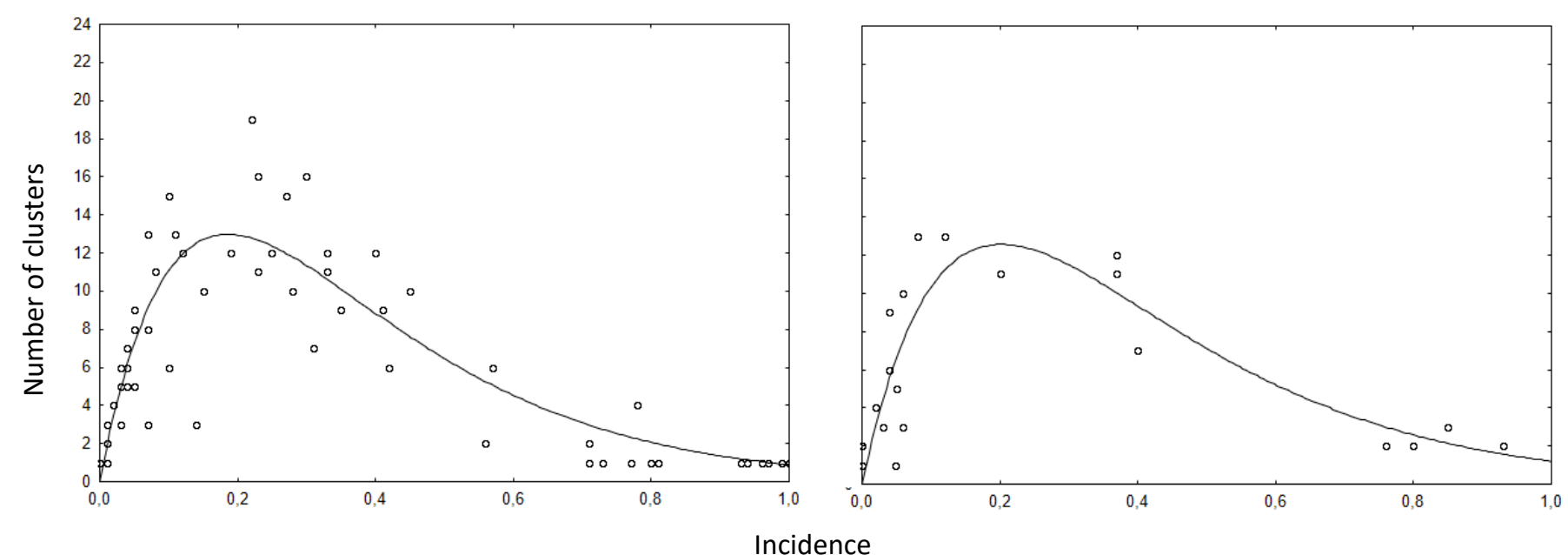

Figure 5. Begomovirus disease evolution as a function of the incidence and the number of clusters per plot in plots located in the center of the pivots (A) and in plots located at the edge of the pivots (B). The continuous line indicates adjustment of the data to the Generalized Beta function. 


\section{Estimating the whitefly population}

The average whitefly population varied considerable. In PAD-DF where the disease incidence reached the highest levels during the monitored period, 22.2 to 418.4 adult whiteflies were counted (average of insects in four traps per plot) (Table 2). In contract, the number of adults on yellow sticky cards was lower in Luziânia (32.6 to 90.2) (Table 2). We observed a tendency for a reduction in the whitefly population over the planting period of monitoring, with the highest populations detected in the earlier and lower populations in the later observation from the first evaluated pivot to the last pivot (March to July, data not shown). Although a high disease incidence was observed to correlate with a high whitefly population (Table 2, PE1-2 and PE1-3), in other areas with high disease incidence the whitefly population was low (PE2-1, PE2-3, and PE3-2). These results suggest that there was no clear positive correlation between whitefly population in these locations and the incidence of begomovirus disease. 


\section{Discussion}

Begomovirus disease outbreaks in processing tomatoes are common in central Brazil, particularly in Goiás state, and can cause substantial economic loss. In the past, the major production areas were concentrated in São Paulo state and in the northeast region of the country. However beginning in the 1990s virus disease outbreaks, especially in the northeast, caused a shift in tomato production to the central region. Today, Goiás is responsible for more than $85 \%$ of processing tomato production in Brazil (IBGE 2012). However, begomovirus disease outbreaks have increased in areas of Goiás, resulting in the implemetantion of TFP. This regulation is only implemented in the state of Goiás. But, in the Federal District, which is geographically located inside Goiás, tomato cultivation is allowed all over the year. Therefore, these two regions were deliberately chosen to exploit their peculiarities to better understand the epidemiological dynamics of begomovirus disease in processing tomatoes.

The results of our study showed that ToSRV predominated in both locations monitored in this study. This is consistent with studies in other regions (Ribeiro et al., 2003, Zerbini et al., 2005, Fernandes et al., 2008, Gonzáles-Aguilera et al., 2012, Macedo et al., 2014). Other begomoviruses were reported in the studied regions, but ToSRV most likely outcompeted the other viruses, such as Tomato golden vein virus (TGVV). One of the hypothesis that could explain the displacement of TGVV by ToSRV is the higher transmission efficiency by the B biotype of ToSRV than TGVV (Macedo et al., 2015). An isolate of Euphorbia yellow mosaic virus was detected in one tomato sample, and its epidemiological importance to tomatoes needs to be further studied.

The presence of ToSRV was observed in neighbouring tomato fields, volunteer tomatoes, beans, and some weeds (Nicandra physaloides, Sida spp., Sonchus oleraceus, Euphorbia heterophylla, and Solanum americanum). Thus, many weeds are potential reservoirs of ToSRV, particularly $N$. physaloides, which is possibly the most important 
alternative host of ToSRV (Barbosa et al., 2009, Barreto et al., 2013). However, during this study we observed that the processing tomato growers did not have problems managing $N$. physaloides and that this species might not play a crucial role in ToSRV epidemiology in processing tomatoes in these two areas. Recently, we observed that common beans are found infected with ToSRV, and that they may have a role as reservoir for the tomato crop (Macedo et al., submitted). Hence, beans, E. heterophylla, S. americanum and tomatoes (neighbouring fields and volunteer plants) may be important and will be the target of future studies.

The incidence and spread of begomovirus disease vary from year to year and field to field and this depends on a complex of many factors, including the time of year, region, climate, neighbouring crops, insecticide spraying regime, location, and planting timing (Bergamin Filho et al., 2016; Inoue-Nagata et al., 2016). The progression of begomovirus disease in tomatoes is still not well understood in Brazil. In this study, the disease incidence and AUDPC were examined at two processing tomato production areas (Luziânia-GO and PAD-DF) in 2012 and we saw a similar pattern, low initial disease incidence followed by rapid disease incidence. Although these regions are located less than $60 \mathrm{~km}$ apart from one another, a relevant difference in the disease incidence was observed, with the incidence in PAD-DF twice as high as that of Luziânia. This may be due to the close proximity of PADDF to fresh market tomato production areas where tomatoes are planted throughout the year, providing virus and whitefly inoculum. Within each field, the disease incidence and AUDPC in the PC were lower than in the PE, indicating that primary spread played an important role in the begomovirus disease epidemic. The results indicated that fewer viruliferous whiteflies arrived at the center than at the border of the pivot.

Disease progress was relatively rapid in both areas (Table 2). Hence only, a few incidence assessments could be used for the analysis, which restrained the attempt to fit an epidemiological model. Because it is well known that yield loss with begomovirus disease is 
greatest when plants are infected early in development, i. e., before flowering, this finding indicated that the measures applied to the control of the disease, such as the chemical control of whiteflies inside the field, were not effective in preventing yield losses. In general, symptomatic plants appeared earlier in the PE than in the PC. Primary spread of the disease is directly related to the migration of viruliferous insects from outside the field. Therefore, viruliferous whiteflies reach the plants and transmit the virus in less than 30 minutes of feeding in a healthy plant. During warm periods (February to May or summer to autumn), begomovirus infection symptoms may appear as soon as seven days after inoculation, and these initially infected plants can be efficient inoculum sources. Thus, for such a rapid disease distribution the primary spread is thought to be more relevant than the secondary spread. This hypothesis may be true because intense spraying in the areas of cultivation reduces the possibility of whitefly acquiring the virus from an infected plant within the field (assuming very efficient spraying), passing through the latent period in the insect and inoculating a healthy plant. Because whitefly migration behaviour varies depending on many external factors (Byrne et al., 1996), the positive correlation between the primary spread with the influx of viruliferous insects consequently leads to curves with different shapes that are often similar to monomolecular model and are sometimes closer to the logistic model.

Interestingly, the curves of epidemics that start very early assume a logistic curve shape (Fig. 3), probably due to the slow influx of vector in the first days of cultivation. The first entry of whiteflies in the field was detected as soon as the transplants were distributed. However, if this initial assessment is neglected, the curves assume a monomolecular shape. The reasons why some progression curves take different forms are not clear, although we have to be aware that in the case of tomato begomovirus disease a disease progress curve with a logistic shape may not result from a process of secondary spread as the main component. The steep line is probably due to the progressive increase in viruliferous whitefly inflows into 
the growing area. Studies on the temporal dynamics of begomoviruses in tomato plants have predominantly shown a monomolecular model associated with the spread of the disease. The disease curve of the bipartite begomovirus Tomato mottle virus (TMoV) in tomatoes in Florida, USA (Polston et al., 1996), and Tomato yellow mottle virus in tomatoes in Costa Rica (Hilje \& Stansly, 2008) also fit better to a monomolecular model. The same finding holds true for monopartite begomoviruses, such as Tomato yellow leaf curl virus (Ioannou \& Iordanou, 1985, Suwwan et al., 1988, Schuster et al., 2011) and Tomato leaf curl virus (Holt et al., 1999), in tomato crops. In the two studies performed in Brazil, the disease progression of Tomato yellow vein streak virus followed a clear linear curve (Della Vecchia et al., 2007), whereas the monomolecular model was the best fit model for ToSRV (Barbosa et al., 2016). Therefore, generally the monomolecular model seems to be the most common model to explain the the temporal dynamics of begomovirus diseases.

In this study, begomovirus-infected plants were distributed in a slightly aggregated pattern. In this regard, no difference was found between the two regions, but a difference was observed in plots located at the edge compared with those in the center of the pivot. In general, symptomatic plants in the PC were more aggregated than those in the PE. In the ordinary run analysis, no significant aggregation was observed within and between rows, indicating that the aggregation pattern detected in other analyses was possibly not due to aggregation in adjacent symptomatic plants. This aggregation pattern is most likely related to a 'block effect' or 'small cluster effect' as described by Poltson et al. (1996), although it is difficult to know how these small clusters are formed. There are two options: either these clusters are produced by the inoculation of a group of viruliferous whiteflies landing at the same time from the primary spread or inoculation that occurs at different times due to secondary spread. Based on the D value analysis, the majority of the PCs, but not the PEs, had values higher than 1 (especially when using quadrat $2 \times 3$ ).. The binary power analysis showed 
aggregation in plots located at the edge and in the center of the pivot, although $b$ and $\log (A)$ were significantly higher in the PC than the PE. In the last spatial analysis (DADF), the number of the disease clusters in the PC with same incidence values in the PE was lower and verified an earlier peak in the curve of the number of clusters and incidence in the PC, indicating earlier coalescence of the clusters in the PC than the PE. These observations indicate that there is a lower number of clusters in the PC, therefore symptomatic plants in the PC were more aggregated than in plots located at the edge. The generalized beta distribution function had a better fit to the data on the number of cluster per disease incidence in the PC compared to the PE, indicating that the disease spread in the PC was ruled out by a low number of spreading mechanisms as verified for citrus variegated chlorosis, which had only one mechanism (Laranjeira et al., 2004). In contrast, a bad fitting to this function suggests that the disease is associated with more than one spread mechanism. This phenomenon was observed in citrus canker, which had at least three mechanisms (Gottwald et al., 2007). In this study, the cluster analysis of begomovirus-infected plant foci confirmed that the primary component acted together with the secondary and the 'false secondary' spread in the PE, whereas the primary component was less relevant in the disease spread in the PC. Thus, the symptomatic plants in the PC are concentrated in a few clusters and consequently exhibit an aggregated distribution. This slightly aggregated pattern that is scattered in small clusters may be typical of diseases associated with whiteflies. Furthermore, the higher aggregation pattern observed in PC suggested that there was a distinct type of predominant spread in plots located at the center and the edge of the pivot as explained in more detail in the paragraph below.

In this study, we observed that symptomatic plants were consistently more aggregated in plots located at the center of the pivot than symptomatic plants in plots located at the edge. The most plausible explanation relies on the existence of three different components of begomovirus disease epidemics. The first component is the primary spread (which is a 
random component): viruliferous whiteflies come from outside of the target field and then the vectors select and feed on plants at random. The second component is the real secondary spread: aviruliferous whiteflies that come from outside the field or are born inside the field acquire the virus and feed on other plants, thereby transmitting the virus to neighbouring plants and producing an aggregated distribution pattern. The third component is the "false" secondary spread, when the same viruliferous whitefly comes from outside the fields and feeds on several nearby plants, producing an aggregated distribution pattern. Therefore, we suggest that the three components are present in the PE, but the first and the third are more important than the second. In this case, the majority of viruliferous whiteflies come from outside of the field and stay at the edge. However, in the PC the first component may be less important because a lower number of whiteflies coming from outside the field reach the center of the pivot. Hence, the second component becomes more relevant in this case. The heavy insecticide spraying regime may also contribute to the reduction of secondary spread. We also observed that the whitefly population was higher at the edge and decreased to the central part and that nymphs were only observed 45 days after transplanting (unpublished results). Thus, viruliferous whiteflies arrive in larger numbers earlier in the edge of the pivot and slowly colonize inside of the plantation with their progeny. Thus, primary spread seems to be the most important mechanism for begomovirus epidemics and disease progression may be accelerated due to the occurrence of primary infection over an extended period of time as theoretically described by Gilligan \& Kleczkowski (1997), Gilligan (2002) and Bergamin Filho et al. (2016).

Large whitefly populations were observed in both regions, especially in PAD-DF and early in the season. For the two monitored areas, the whitefly infestation was high in both areas, although the begomovirus disease incidence was lower in Luziânia. These results suggest that begomovirus disease progression is not directly related to the whitefly population 
in the field and that the most likely explanation is that ToSRV inoculum sources are more abundant in PAD-DF than in Luziânia. This has been previously shown in other studies (Polston et al., 1996; Barbosa et al., 2016). In the fields monitored in this study, the growers apply insecticides on a weekly basis in both regions, which contributes to the decrease in the whitefly population. Viruliferous whiteflies require less than an hour to inoculate the virus (Santos et al., 2003) and the time needed for insecticides to kill an adult whitefly is longer than the inoculation period. Furthermore, the proportion of viruliferous regarding total whiteflies present in the area is not known. The dispersion behaviour of insects is the key to understanding the progress of vectored disease outbreaks in plants. Insect behaviour is highly influenced by the agricultural environment, which is particularly complex in central Brazil. This region has the highest density of central pivots in Brazil, and this complexity hinders a better understanding of begomovirus disease epidemics.

The findings of this study contribute to our understanding of begomovirus disease progression in processing tomatoes. In summary, these results suggest that a begomovirus disease is simply not classifiable as a monocyclic or polycyclic disease because three important components of spread are likely present and primary spread is continuous in this pathosystem. Therefore, it appears that primary spread is the most important component in this begomovirus system. Clearly, there is a need for more effective management and this information provided in this study helps the designing and the application of IPM strategies. Therefore, we suggest the following management recommendations: (i) eliminate weed reservoirs and volunteer tomatoes around fields; (ii) control the whiteflies around tomato fields to reduce populations arriving in the fields; (iii) plan planting locations; (iv) do not plant new fields near old fields; and (v) destroy the tomato crops immediately after harvest. These recommendations should be performed in a wide macro-region because the swarm of vectors may come from distant areas (Bergamin Filho et al., 2016; Inoue-Nagata et al., 2016). 


\section{Conclusions}

$>$ No relevant difference on the temporal and spatial analyses between the tomato field of Luziânia and PAD DF was observed;

Significant difference was observed among plots located at the center and at the edge of the pivots;

$>$ Three different mechanisms of disease dissemination was suggested in the begomovirus disease: a random component (primary spread), and two aggregation components, a real secondary spread, and a "false" secondary spread;

The disease progress is fast when the overall conditions are favorable, especially in plants located in the edge of the pivots, where the population of arriving whiteflies is high;

$>$ In general, a slight aggregation was observed in all plots, especially in PC. It is believed that this aggregation is due to the higher importance of the two aggregation primary spread is less important in PC, and the two others components, aggregated components, become more important;

The primary spread seems to be the more important dissemination component for begomovirus disease in tomato crops;

The management of begomovirus disease should be done on a wide macro-region, because the control only in the target fields seems to be not effective. 


\section{References}

AMBROZEVICIUS, L.P.; CALEGÁRIO, R.F.; FONTES, E.P.B.; CARVALHO, M.G. \& ZERBINI, F.M. 2002. Diversidade genética de begomovirus infetando o tomateiro e plantas daninhas no Sudeste do Brasil. Fitopatologia Brasileira 27: 372-377.

BARBOSA, J.C.; BARRETO, S.S.; INOUE-NAGATA, A.K.; REIS, M.S.; FIRMINO, A.C.; BERGAMIN FILHO, A. \& REZENDE, J.A.M. 2009. Natural infection of Nicandra physaloides by Tomato severe rugose virus in Brazil. Journal of General Plant Pathology 75: 440-443.

BARBOSA, J.C.; REZENDE, J.A.M.; AMORIM, L. \& BERGAMIN FILHO, A. 2016. Temporal Dynamics of Tomato severe rugose virus and Bemisia tabaci in Tomato Fields in São Paulo, Brazil. Journal of Phytopathology 164: 1-10.

BARRETO, S.S.; HALLWASS, M.; AQUINO, O.M. \& INOUE-NAGATA, A.K. 2013. A study of weeds as potential inoculum sources for a tomato-infecting begomovirus in central Brazil. Phytopathology 103: 436-444.

BERGAMIN FILHO, A.; INOUE-NAGATA, A.K.; BASSANEZI, R.B.; BELASQUE, J.J.; AMORIM, L.; MACEDO, M.A.; BARBOSA, J.C.; WILLOCQUET, L. \& SAVARY, S. 2016. The importance of primary inoculum and area-wide disease management to crop health and food security. Food security 8: 1-18.

BYRNE， D.N.; RATHMAN， R.J.; ORUM， T.V. \& PALUMBO， J.C. 1996. Localized migration and dispersal by the sweet potato whitefly, Bemisia tabaci. Oecologia, 105: 320328.

CAMPBELL, C.L. \& MADDEN, L.V. 1990. Introduction to Plant Disease 1 Epidemiology. New York, NY, USA, John Wiley and Sons.

DELlA VECCHIA, M.G.S.; ROSA, D.D.; BERGAMIN FILHO, A.; AMORIM, L.; REZENDE, J.A.M. \& RIBEIRO, A. 2007. Dinâmica temporal e espacial da begomovirose causada por Tomato yellow vein streak virus em tomateiro na regiao de Campinas-SP. Summa Phytopathologica 33: 388-395.

DOYLE, J.J. \& DOYLE, J. 1990. Isolation of plant DNA from fresh tissue. Focus 12: 13-15.

FARIA, J.C. 1994. Mosaico dourado; in: Sartorato, A., and Rava, C. A., eds. Principais doenças do feijoeiro comum e seu controle. EMBRAPA-CNPAF: 262-284.

FERNANDES, F.R.; ALBUQUERQUE, L.C.; GIORDANO, L.B.; BOITEUX, L.S. \& AVILA, A.C. 2008. Diversity and prevalence of Brazilian bipartite begomovirus species associated to tomatoes. Virus Genes 36: 251-258. 
FLORES, E.; SILBERSCHMIDT, K. \& KRAMER, M. 1960. Observações de "clorose infecciosa" das malváceas em tomateiros do campo. Biologico 26: 65-69.

FRANÇA, F.H.; BOAS, G.L.V. \& BRANCO, M.C. 1996. Ocorrência de Bemisia argentifolii Bellows \& Perring (Homoptera:Aleyrodidae) no Distrito Federal. Anais da Sociedade Entomologica do Brasil 25: 369-372.

GHANIM, M.; MORIN, S.; ZEIDAN, M. \& CZOSNEK, H. 1998. Evidence for transovarial transmission of Tomato yellow leaf curl virus by its vector, the whitefly Bemisia tabaci. Virology 240: 295-303.

GILLIGAN, C.A. \& KLECZKOWSKI, A. 1997. Population dynamics of botanical epidemics involving primary and secondary infection. Phil Trans R Soc Lond B 352: 591-608.

GILLIGAN, C.A. 2002. An epidemiological framework for disease management. Advances in Botanical Research 38: 1-64.

GONZALES-AGUILERA, J.; TAVARES, S.S.; SOBRINHO, R.R.; XAVIER, C.A.D.; DUENAS-HURTADO, F.; LARA- RODRIGUES, R.M.; SILVA, D.J.H. \& ZERBINI F.M. 2012. Genetic structure of a Brazilian population of the begomovirus Tomato severe rugose virus (ToSRV). Tropical Plant Pathology 37: 346-353.

GOTTWALD T. R; BASSANEZI, R. B.; AMORIM L. \& BERGAMIN FILHO, A. 2007. Spatial pattern analysis of citrus canker-infected plantings in são paulo, brazil, and augmentation of infection elicited by the asian leafminer. Phytophthology 97:674-683.

HAU, B. \& KRANZ, J. 1990. Mathematics and statistics for analyses in epidemiology. In: Kranz, J. (Ed.) Epidemics of Plant Diseases: mathematical analyses and modeling. Berlin. Springer-Verlag.

HILJE, L. \& STANSLY, P.A. 2008. Living ground covers for management of Bemisia tabaci (Gennadius) (Homoptera: Aleyrodidae) and Tomato yellow mottle virus (ToYMoV) in Costa Rica. Crop Protection 27: 10-16.

HOLT, J.; COLVIN, J.; MUNIYAPPA, V. 1999. Identifying control strategies for tomato leaf curl virus disease using an epidemiological model. Journal of Applied Ecology 36: 625-633.

IBGE, Instituto Brasileiro de Geografia e Estatística. 2012. LEVANTAMENTO SISTEMÁTICO DA PRODUÇÃOO AGRÍCOLA. ftp://ftp.ibge.gov.br/Producao_Agricola/Levantamento_Sistematico_da_Producao_Agricola_[ mensal]/Fasciculo/2012/lspa_201202.pdf. Acessado em 11/05/2013. 
INOUE-NAGATA, A. K.; LIMA, M.F.; GILBERTSON, R. L. 2016. A review of geminivirus diseases in vegetables and other crops in Brazil: current status and approaches for management. Horticultura Brasileira 34(1), 8-18.

IOANNOU, N.; IORDANOU, N. 1985. Epidemiology of Tomato yellow leaf curl virus in relation to the population density of its whitefly vector, Bemisia tabaci (Gennadius). Tech Bull. Agricultural research institute ministry of agriculture and natural resources 71: 1-7.

LARANJEIRA, F. F.; BERGAMIN FILHO, A.; AMORIM, L. \& GOTTWALD, T.R. 2004. Dinâmica espacial da clorose variegada dos citros em três regiões do estado de São Paulo. Fitopatologia Brasileira 29: 056-065.

MACEDO, M.A.; BARRETO, S.S.; HALLWASS, M. \& INOUE-NAGATA, A.K. 2014. High incidence of Tomato chlorosis virus alone and in mixed infection with begomoviruses in two tomato fields in the Federal District and Goiás state, Brazil. Tropical plant pathology 39(6): 449-452.

MACEDO, M.A.; FILHO, M.M.; NAVAS-CASTILLO, J.; INOUE-NAGATA, A.K.; 2015. Host range and whitefly transmission efficiency of Tomato severe rugose virus and Tomato golden vein virus in tomato plants. Tropical plant pathology 40(6): 405-409.

MADDEN, L.V. \& HUGLES, G. 1995. Plant disease incidence: distribution, heterogeneity, and temporal analysis. Annual Review of Phytopathology 33: 529-564.

MADDEN, L.V.; LOUIE, R.; ABT, J.J. \& KNOKE, J.K. 1982. Evaluation of tests for randomness of infected plants. Phytopathology 72: 195-198.

MATYIS, J.C.; SILVA, D.M.; OLIVEIRA, A.R. \& COSTA, A.S. Purificação e morfologia do vírus do mosaico dourado do tomateiro. Summa Phytopathologica 1 (4): 267-27.

MORIN, S.; GHANIM, M.; ZEIDAN, M.; CZOSNEK, H.; VERBEEK, M.; 1999. A GroEL homologue from endosymbiotic bacteria of the whitefly Bemisia tabaci is implicated in the circulative transmission of Tomato yellow leaf curl virus. Virology 256: 75-84.

NELSON, S.C.; 1996. A simple analysis of disease foci. Phytopathology 86: 332-339.

PERRING, T.M.; GRUENHAGEN, N.M. \& FARRAR, C.A. 1999. Management of plant viral diseases through chemical control of insect vectors. Annu. Rev. Entomol. 44: 457-481.

POLSTON, J.E.; CHELLEMI, D.O.; SCHUSTER, D.J.; MCGOVERN, R.J. \& STANSLY, P.A. 1996. Spatial and temporal dynamics of Tomato mottle geminivirus and Bemisia tabaci (Genn.) in Florida tomato fields. Plant Disease 80: 1022-1028.

RIBEIRO, S.G.; AMBROZEVÍCIUS, L.P.; AVILA, A.C.; BEZERRA, I.C.; CALEGARIO, R.F.; FERNANDES, J.J.; LIMA, M.F.; DE MELLO, R.N.; ROCHA, H. \& ZERBINI, F.M. 
2003. Distribution and genetic diversity of tomato-infecting begomovius in Brasil. Archives of Viroogy 148: 281-295.

ROJAS, M.R.; GILBERTSON, R.L.; RUSSEL, D.R. \& MAXWELL, D. 1993. Use of degenerated primers in the polymerase chain reaction to detect whitefly-transmitted geminiviruses. Plant Disease 77: 340-347.

ROSEN, R.; KANAKALA， S.; KLIOT A, C.P.B.; FARICH， B.A.; SANTANA-MAGAL, N.; ElimElECH, M.; KONTSEDAlOV, S.; LEBEDEV, G.; CILIA, M. \& GHANIM, M. 2015. Persistent, circulative transmission of begomoviruses by whitefly vectors. Virology 18 : $15: 1-8$.

RUBINSTEIN, G. \& CZOSNEK, H. 1997. Long-term association of Tomato yellow leaf curl virus with its whitefly vector Bemisia tabaci: effect on the insect transmission capacity, longevity and fecundity. Journal General Virology 78: 2683-2689.

SANTOS, C.D.G.; ÁVILA, S.C. \& RESENDE, R.O. 2003. Estudo da interação de um begomovirus isolado de tomateiro com a mosca branca. Fitopatologia Brasileira 28: 664-673.

SCHUSTER, D.J.; GILREATH, J.P.; CORDERO, R. \& GILREATH, P.R. 2011. Reduced incidence of tomato plants with symptoms of Tomato yellow leaf curl virus infection grown on ultraviolet- reflective soil mulch. Proceedings of the Florida State Horticultural Society 124:162-165.

SUWWAN, M.A.; AKKAWI, M.; AL-MUSA, A.M. \& MANSOUR, A. 1988. Tomato performance and incidence of Tomato yellow leaf curl (TYLC) virus as affected by type of mulch. Sci Hort 37: 39-45.

ZERBINI, F.M.; ANDRADE, E.C.; BARROS, D.R.; FERREIRA, S.S.; LIMA, A.T.M.; ALFENAS, P.F. \& MELLO, R.N. 2005. Traditional and novel strategies for geminivirus management in Brazil. Australasian Plant Pathology 34: 475-480. 


\section{Capítulo 3 - Progresso temporal e espacial de crinivirose e begomovirose em tomateiro}

\section{de crescimento indeterminado}

\section{Resumo}

A begomovirose e a crinivirose são atualmente as doenças de origem viral com maior incidência em tomateiro no Brasil. Os agentes causais dessas doenças são respectivamente espécies de begomovirus e crinivirus, ambos transmitidos por insetos vetores, mosca-branca. O manejo adequado de doenças transmitidas por vetores ainda é um desafio, devido à grande carência de informações sobre os processos epidemiológicos destas doenças sob condições de campo. Com objetivo de entender melhor a epidemiologia dessas duas doenças, parcelas experimentais foram demarcadas e analisadas em quatro regiões produtoras de tomateiro para consumo in natura na região central do Brasil em cultivares com resistência a begomovirose. Nessas áreas é comum o plantio de cultivares com resistência, devido à frequente alta incidência da begomovirose inviabilizando o cultivo de materiais altamente susceptíveis. Dezesseis parcelas com 225 plantas cada uma foram avaliadas semanalmente quanto à presença de plantas com sintomas característicos de infecção por begomovirus e crinivirus. A população de mosca-branca foi monitorada semanalmente a partir da quantificação de indivíduos adultos. Adicionalmente, amostras de tomateiro e outras plantas foram coletadas em todas as parcelas. O begomovirus Tomato severe rugose virus e o crinivirus Tomato chlorosis virus foram as únicas espécies de vírus pertencentes a esses gêneros identificadas em tomateiro neste estudo. Poucas espécies de plantas daninhas coletadas dentro e ao redor das parcelas experimentais estavam infectadas com pelo menos um desses vírus. Esse resultado sugere que possivelmente a principal fonte de inóculo dessas viroses nas áreas avaliadas não eram plantas daninhas. Foi observada uma alta variação de incidência das viroses entre as regiões avaliadas, embora a incidência tenha sido similar entre as parcelas de uma mesma região. Plantas infectadas por crinivirus foram mais abundantes, porém as 
primeiras plantas sintomáticas identificadas foram de begomovirus. Mesmo com a utilização de cultivares com moderada resistência a begomovirose, a incidência foi alta, portanto é provável que essa virose fosse mais crítica com o uso de cultivares susceptíveis. As curvas de progresso de begomovirose e crinivirose obtidas foram bastante similares, sendo que ondas de incidência semelhantes foram observadas nas curvas de ambas as viroses. A presença dessas ondas dificultou o ajuste de modelos epidemiológicos e indicou que são possivelmente resultantes de influxos periódicos de moscas-brancas na área cultivada. Em três das quatro análises espaciais realizadas, a distribuição de plantas sintomáticas foi predominantemente ao acaso tanto para begomovirose como para crinivirose. Leve agregação foi detectada somente pela análise da lei de Taylor modificada para ambas as viroses. Embora begomovirus e crinivirus possuam relação vírus-vetor distintas, a dinâmica temporal e espacial destas viroses foi bastante similar. Isso indica fortemente que para ambas as viroses a disseminação primária seja continua e a principal responsável pela ocorrência das epidemias. A partir dessa premissa, recomenda-se a realização de um manejo regional e integrado para prevenir a entrada de insetos virulíferos provenientes de cultivos ou plantas daninhas infectadas.

\section{Palavras-chaves: Crinivirus, begomovirus, epidemiologia, tomate}




\section{Abstract}

The begomovirus and crinivirus diseases are today the viral diseases with the highest incidence in tomatoes in Brazil, Both begomovirus and crinivirus disease are transmitted by the whitefly Bemisia tabaci. An efficient management of vector-borne diseases remains a challenge due to the great lack of information on the epidemiological processes of these diseases under field conditions. In order to better understand the epidemiology of the two viral diseases, experimental plots were demarcated and analyzed in four fresh market production areas in central Brazil in begomovirus resistant cultivars. It is common to cultivate begomovirus resistant plants, as the high incidence of begomovirus is frequent and thus preventing the use of highly susceptible cultivars. Sixteen plots with 225 plants each were weekly evaluated for the presence of plants with typical symptoms of begomovirus and crinivirus infection. The whitefly population was weekly monitored for quantification of adult insects. In addition, samples of tomato and uncultivated plants were collected from all plots. Tomato severe rugose virus and Tomato chlorosis virus were the only begomovirus and crinivirus species, respectively, identified in the plots. Few weed species collected inside and around of the experimental plots were infected with at least one of these viruses. This result suggests that most possibly the primary sources of these viruses in the evaluated areas were not those weeds. High variation in virus disease incidence between the areas was observed, although the incidence was similar between plots of the same region. Plants infected by crinivirus were more abundant, but the first symptomatic plants were infected by begomovirus. Even with the use of cultivars with moderate resistance to begomovirus, the disease incidence was high, hence most likely this disease would be more critical if using susceptible cultivars. The begomovirus and crinivrus disease progress curves were very similar, and identical waves were observed in the disease curves of both viruses. The presence of these waves hampered the attempts to fit epidemiological models to the curves, and 
indicated that they are possibly caused by whitefly periodic inflows in the target fields. In three of four spatial analyzes, the distribution of symptomatic plants was predominantly at random for begomovirus and crinivirus diseases. Slight aggregation was detected only when using the modified Taylor law for both viral diseases. Although begomovirus and crinivirus disease have distinct virus-vector relationship, the temporal and spatial dynamics of the disease they cause was essentially similar. This results strongly indicates that the virus primary inoculum spread is continuous, and thus responsible for the occurrence of epidemics for the two virus diseases. From this premise, it is recommended to perform a regional and integrated pest management to prevent the entry of viruliferous insects from the neighboring infected weeds and crops.

Key-words: Crinivirus, begomovirus, epidemiology, tomato 


\section{Introdução}

A begomovirose é atualmente considerada a principal doença de origem viral em tomateiro no Brasil. Isso se deve à alta incidência nas lavouras, reduzida oferta de cultivares resistentes de tomateiro (principalmente de crescimento determinado) aos begomovirus, à presença de grande número de hospedeiras alternativas suscetíveis em campo e à dificuldade de controle do inseto vetor, a mosca-branca. A partir de 2008, outra virose, a crinivirose, cujo agente etiológico também é transmitido por mosca-branca, foi identificada infectando plantas de tomate no Estado de São Paulo (Barbosa et al., 2008). A partir de então foi observada a presença desse vírus infectando tomateiros em outros cinco estados do País (Barbosa et al., 2011). Uma alta taxa de incidência de ambas as viroses tem sido observada nas principais regiões produtoras, como por exemplo, no Distrito Federal e entorno (Macedo et al., 2014).

A begomovirose em tomateiro é causada por diversas espécies do gênero Begomovirus. No Brasil, Tomato severe rugose virus (ToSRV) é a espécie predominante na cultura na maioria dos estados produtores (Ribeiro et al., 2003, Zerbini et al., 2005, Fernandes et al., 2008, Gonzáles-Aguilera et al., 2012, Macedo et al., 2014). A crinivirose é causada por duas espécies do gênero Crinivirus, porém apenas a Tomato chlorosis virus (ToCV) já foi relatado no País. Os begomovirus pertencem à família Geminiviridae e possuem genoma composto de DNA fita simples circular encapsidados em partículas gemininadas e icosaédricas (Brown et al., 2015). Os crinivirus pertencem à família Closteroviridae e possuem genoma composto por RNA fita simples positiva (Wisler et al., 1998). Ambos os vírus são transmitidos naturalmente pela mosca-branca Bemisia tabaci. A inter-relação vírusvetor dessas viroses é distinta. Begomovirus são transmitidos de maneira circulativapersistente por diversos biótipos de B. tabaci (Ghanim et al., 1998; Morin et al., 1999; Rubinstein \&Czosnek1997, Rosen et al., 2015). Crinivirus são transmitidos de maneira não 
circulativa semi-persistente por B. tabaci e duas espécies de Trialeurodes, T. vaporariorum e T. abutilonea (Wisler et al., 1998). A última espécie ainda não foi relatada no Brasil.

Prejuízos causados pela begomovirose afetam a tomaticultura brasileira desde a década de 90 (França et al., 1996). A recente introdução de crinivirose no País e a alta população do inseto vetor em campo aumentaram a preocupação dos produtores (França et al., 1996). Atualmente, no cultivo de tomateiro estaqueado o uso de cultivares resistentes é frequente, sendo mandatório em determinadas regiões, devido aos altos níveis de incidência e de perdas na produção. O gene $T y$-1 é muito provavelmente o gene de resistência a begomovirus mais utilizado, sendo que esse gene não confere imunidade à infecção por begomovirus. Esse gene de resistência possibilita uma resistência parcial que leva a uma menor taxa de infecção e indução de sintomas mais leves, se comparada a cultivares susceptíveis (Inoue-Nagata et al., 2012). O controle de doenças transmitidas por insetos vetores ainda é um grande desafio para os agricultores devido às diversas lacunas existentes na compreensão dos principais componentes epidemiológicos que levam ao desenvolvimento da doença. A grande dificuldade está em avaliar estes componentes de forma integrada e relativamente precisa retratando as condições reais de um cultivo comercial. Por isso, estudos nesta área ainda são raros e dificilmente conseguem explicar o funcionamento do patossistema como um todo. O objetivo deste trabalho é tentar preencher algumas destas lacunas, gerando informações que levem à melhor compreensão desses dois patossistemas. $\mathrm{O}$ trabalho foi realizado a partir do estudo do progresso temporal e espacial simultâneo de begomovirose e crinivirose em tomateiro de crescimento indeterminado, visando obter informações importantes sobre o processo epidemiológico dessas doenças que possam ser utilizadas para a elaboração de estratégias de controle das mesmas. 


\section{Material e Métodos}

\section{Descrição das áreas avaliadas}

As parcelas experimentais foram localizadas em quatro áreas de produção comercial de tomate de crescimento indeterminado na região central do País: duas áreas no Estado de Goiás, Goianápolis (parcelas G1 a G4; localizadas a 16 30' 21.3" ao sul, 48 57' 29.9" a oeste e a 984 metros de altitude) e Distrito Agro-Industrial de Anápolis - DAIA (parcelas D1 a D4; localizadas a $16^{\circ} 31^{\prime} 48.9^{\prime \prime}$ ao sul e $48^{\circ} 48^{\prime} 14.4^{\prime \prime}$ a oeste e a 968 metros de altitude) e duas no Distrito Federal, Boa Esperança (parcelas B1 a B4; localizadas a 15 49' 18.4" ao sul, 48 $14^{\prime}$ 43.9" a oeste e a 1104 metros de altitude) e Taquara (parcelas T1 a T4; localizadas a $15^{\circ} 39^{\prime} 31.11^{\prime \prime}$ ao sul, $47^{\circ} 33^{\prime} 12.79 "$ a oeste e a 1110 metros de altitude) entre setembro de 2012 a outubro de 2014. Essas áreas pertenciam a produtores de pequeno porte com moderado nível de tecnificação. As mudas foram provenientes de viveiros comerciais com alto padrão de qualidade. A forma de condução foi feita por tutoramento à base de bambu ou fitilho com espaçamento entre plantas de $0,7 \mathrm{~m}$ e entre linhas de $1,5 \mathrm{~m}$, com a condução de duas hastes por planta.

Em cada área foram selecionadas parcelas de 225 plantas (15 por 15 plantas) para avaliação semanal (Parcelas G1-G4, D1-D4, B1-B4) ou a cada três dias (T1-T4) da incidência de crinivirose e begomovirose. Devido ao tamanho reduzido das áreas de produção, parcelas consideradas no centro do cultivo não foram possíveis de serem demarcadas (apenas parcelas na borda do cultivo foram demarcadas). Os dados de número de parcelas, a cultivar, o período de avaliação e outras informações a respeito das parcelas encontram-se na Tabela 1. Devido à dificuldade de diagnose da begomovirose e crinivirirose, a avaliação da incidência foi realizada com a utilização de ferramentas moleculares nas duas primeiras parcelas. Todas as plantas com sintoma de viroses foram coletadas e a detecção viral foi realizada semanalmente para cada virose até que ambas as viroses fossem detectadas em cada planta sintomática ou 
até o final das avaliações. Uma vez que foi confirmado que o resultado da avaliação visual foi idêntico à avaliação por testes de detecção, nas parcelas seguintes a avaliação da incidência foi baseada na análise dos sintomas de forma visual. Adicionalmente, nessas parcelas, amostras de plantas sintomáticas foram coletadas em cada data de avaliação e analisadas para confirmação do diagnóstico visual. Um total de 177 e 187 amostras com sintomas característicos de begomovirus e crinivirus, respectivamente, foram coletadas.

Tabela 1: Características das parcelas em todas as áreas avaliadas, Goianápolis, DAIA e Boa esperança, 2012-2013.

\begin{tabular}{cccccc}
\hline \multirow{2}{*}{ Área } & NP & cultivar & Período & \\
& & & mês & ano & irrigação \\
\hline Goianápolis $^{1}$ & 2 & Dominador $^{3}$ & Set-out & 2012 & Sulco \\
Goianápolis $^{\mathbf{1}}$ & 2 & Dominador $^{3}$ & Set-nov & 2012 & Sulco \\
DAIA $^{\mathbf{1}}$ & 4 & Dominador $^{3}$ & Out-dez & 2012 & Sulco \\
Boa Esperança $^{2}$ & 4 & Predador $^{4}$ & Jun-ago & 2013 & Gotejamento \\
Taquara $^{2}$ & 4 & Dominador $^{3}$ & Jun-out & 2014 & Gotejamento \\
\hline
\end{tabular}

${ }^{1}$ Região localizada no estado de Goiás; ${ }^{2}$ Região localizada no Distrito Federal; ${ }^{3}$ Cultivar resistente a begomovirus, ${ }^{4}$ Cultivar resistente à infecção por begomovirus e crinivirus. NP: número de parcelas.

\section{Coleta de plantas daninhas}

Em todas as parcelas foram coletadas plantas daninhas na última avaliação. As plantas foram coletadas aleatoriamente, com ou sem sintomas de infecção viral, em um total de 184 amostras. DNA e RNA totais destas plantas foram extraídos e submetidos a PCR e RT-PCR com primers específicos para detecção de begomovirus e crinivirus de acordo com os métodos descritos a seguir. 


\section{Extração de DNA e RNA total e detecção viral}

O DNA total das plantas foi extraído a partir do método desenvolvido por Doyle e Doyle (1990). Esse foi submetido à amplificação por PCR utilizando Taq DNA polimerase (Invitrogen) com o par de primers universais para begomovirus PAR1c496/PAL1v1978, gerando um fragmento de aproximadamente 1100 pares de bases (Rojas et al., 1993). Em amostras positivas para begomovirus, primers espécie-específicos para ToSRV (Fernandes et al., 2010) foram utilizados. Vinte amostras positivas com os primers espécie-específicos para ToSRV foram selecionadas e o DNA total utilizado para amplificação por círculo rolante (TempliPhi Amplification Kit; GE Healthcare), segundo método descrito por Inoue-Nagata et al. (2004). O produto de RCA obtido foi parcialmente sequenciado com o primer PAR1c496 correspondente à parte da ORF AV1 (CP) e à região intergênica para confirmação dos resultados da PCR específica.

O RNA total das plantas foi extraído com Trizol ® (Invitrogen), o cDNA foi sintetizado com a transcriptase reversa M-MLV (Invitrogen) e o primer Toc-6 e PCR realizada para amplificação de parte do genoma do ToCV com o par de primersToc-5/Toc-6 (Dovas et al., 2002), amplificando um fragmento de 463 pares de bases. Um total de 20 produtos de PCR obtidos foi utilizado para sequenciamento com o primer ToC-5 que corresponde à região HSP70.

\section{Análises epidemiológicas}

Os dados de incidência no tempo e espaço ao longo das avaliações em todas as áreas foram utilizados para plotagem cumulativa e não-cumulativa da incidência das doenças e realização das análises epidemiológicas. Mapas representando as parcelas (225 plantas) foram criados para cada avaliação em todas as regiões para serem usados nas análises temporais e 
espaciais. Plantas sintomáticas foram colocadas em mapas na mesma posição em que estas se encontravam nas parcelas reais (exemplo na Figura 1).

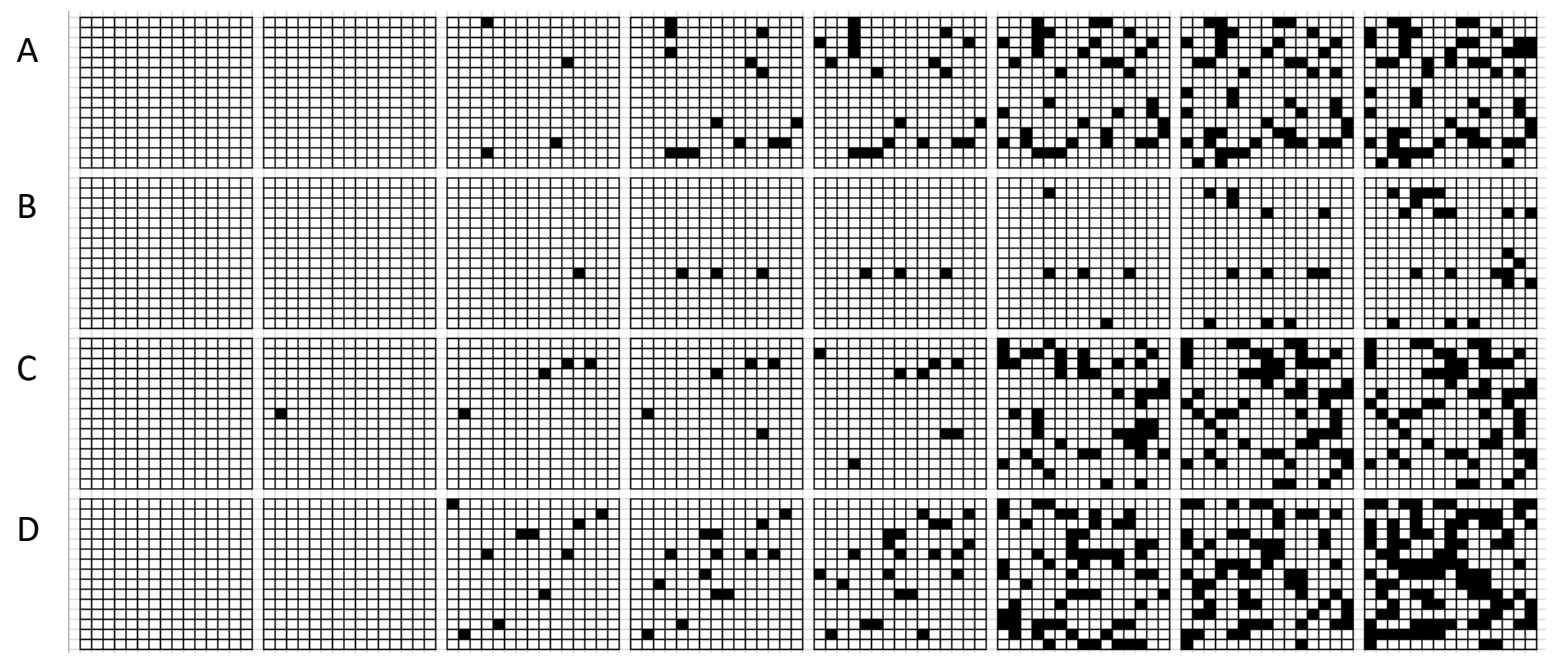

Figura 1: Padrão espacial de begomovirose em quatro parcelas localizadas na região de Goianápolis (GO). Cada quadrado representa uma avaliação (a cada 7 dias após o transplantio). Quadrados pretos representam plantas sintomáticas e brancos assintomáticas. A: Parcela G1, B, parcela G2. C: parcela G3 e D: parcela G4.

\section{Análise temporal}

A incidência de plantas de tomate sintomáticas foi avaliada em 16 parcelas, as 12 primeiras foram avaliadas semanalmente (parcelas G1-G4, D1-D4 e B1-B4). Devido à rápida evolução e estabilidade das epidemias nas parcelas experimentais, a frequência de avaliação semanal levou a um número reduzido de avaliações. Por isso, nas quatro últimas parcelas a frequência de avaliação da incidência da doença foi aumentada, passando a ser a duas avaliações semanais (parcelas T1-T4).

A incidência de plantas doentes $(\mathcal{P})$ foi determinada em cada avaliação por meio da equação (Madden \& Hughes, 1995): $\mathrm{p}=\Sigma\left(X_{i}\right) / \mathrm{nN}$, onde $X i$ é o número total de plantas sintomáticas em cada quadrat, $\mathrm{n}$ é o número de plantas de cada quadrat e $\mathrm{N}$ é o número total de quadrats em cada parcela. 
A área abaixo da curva de progresso (AACPD) foi calculada pelo método da integralização trapezoidal (AACPD) de acordo com Campbell e Madden (1990):

$$
\left.\mathrm{AACPD}=\Sigma\left(\left(y_{i}+y_{i+1}\right) / 2\right)\left(t_{i+1}-t_{i}\right)\right)
$$

onde $y_{i \text { e }} y_{i+1}$ são valores de incidência observados em duas avaliações consecutivas, $t_{i+1}$ e $t_{i}$.

\section{Análise espacial}

Quatro métodos foram utilizados para estudar o padrão espacial das viroses em todas as parcelas avaliadas: análise de sequências ordinárias, índice de dispersão, a lei de Taylor modificada e dinâmica de focos de doença. Inicialmente, mapas binários (plantas sintomáticas ou não sintomáticas) foram gerados para cada avaliação de cada parcela. Quadrats com dois tipos de tamanho foram utilizados, $2 \times 3$ (duas plantas na linha e três entre linhas) e 3x2 (três plantas na linha e duas entre linhas).

\section{Análise de sequências ordinárias}

Análise de sequências ordinárias é um teste não paramétrico simples que utiliza dados binários para detectar agregação de plantas sintomáticas imediatamente adjacentes dentro das linhas de plantio ou transversalmente a elas (Madden et al., 1982). O número esperado de "runs" E (U) sob a hipótese nula de aleatoriedade é dado por $E(U)=1+[2 m(N-m) / N]$, onde $m$ é o número de plantas com sintomas e $N$ é o número total de plantas por linhas combinadas. O desvio padrão de U, sob a hipótese de nulidade, é dado por $S(U)=\{[(2 m(N-m))(2 m(N-m)$ $N)] /(N 2(N-1)\} 0,5$. Utilizando o teste normal padrão $\mathrm{Z}$, onde $Z(U)=[U-E(U)] / S(U)]$, foi utilizado para determinar a significância da agregação de plantas sintomáticas, sendo que valores de $Z$ menores que -1,64 $(\mathrm{P}=0,05)$ indicam rejeição à hipótese de nulidade (arranjo aleatório), em favor da hipótese alternativa (arranjo agregado) (Campbell \& Madden, 1990). 


\section{Índice de dispersão (D)}

O índice de dispersão (D) foi calculado para todas as parcelas com dois tamanhos de quadrat $(2 \times 3$ e $3 \times 2)$ a partir da variância observada $\left(\mathrm{V}_{\mathrm{obs}}\right)$ e binomial $\left(\mathrm{V}_{\text {bin }}\right)$ através da equação (Madden \& Hugles, 1995):

$$
\begin{aligned}
& \mathrm{D}=\mathrm{V}_{\text {obs }} / \mathrm{V}_{\text {bin }} \\
& \mathrm{V}_{\text {obs }}=\Sigma\left(x_{i}-\mathrm{p} \mathrm{n}\right) 2 / \mathrm{n} 2(\mathrm{~N}-1) \text { e } \mathrm{V}_{\text {bin. }}=\mathrm{p}(\mathrm{p}-1) / \mathrm{n}
\end{aligned}
$$

onde $x_{i}$ é o número total de plantas sintomáticas em cada quadrat, $\mathrm{p}$ é a incidência, $\mathrm{n}$ é o número de plantas por quadrat e $\mathrm{N}$ é o número total de quadrats em cada parcela.

A significância do índice de dispersão foi verificada por meio do teste de qui-quadrado ao nível de 5\% de probabilidade. Valores de D estatisticamente iguais a 1 foram considerados como padrão ao acaso (hipótese nula), já valores que diferiram estatisticamente de 1 foram considerados como agregados.

\section{Aplicação da lei de Taylor modificada}

A aplicação da Lei de Taylor modificada foi realizada utilizando a relação linear entre o logaritmo da $\mathrm{V}_{\text {bin }}$ e o logaritmo da $\mathrm{V}_{\text {obs }}$ (Madden \& Hugles, 1995), da seguinte forma: Log $\left(\mathrm{V}_{\text {bin }}\right)=\log (A)+b \log \left(\mathrm{V}_{\mathrm{obs}}\right)$, onde $A$ e $b$ são parâmetros.

As regressões foram realizadas utilizando o programa Statistica ${ }^{\circledR} 6.0$ (Statsoft, Tulsa, OK, EUA). Como variável independente foi considerada o logaritmo das variâncias binomiais e como variável dependente o logaritmo das variâncias observadas para os mapas de cada parcela, para os dados de todas as parcelas de cada experimento e os dados de todas as mesmas em conjunto. A significância das relações (regressão linear) entre $\log \left(\mathrm{V}_{\text {bin }}\right)$ e $\log$ $\left(\mathrm{V}_{\text {obs }}\right.$ ) foi determinada pelo teste $\mathrm{F}$ ao nível de $5 \%$ de probabilidade. A adequação do ajuste do modelo aos dados foi determinada por meio dos valores de coeficiente de determinação $\left(\mathrm{R}^{2}\right)$ e pelos padrões de distribuição dos resíduos (Madden \& Hughes, 1995). 
A igualdade dos parâmetros $b=1$ e $\log (A)=0$ foi avaliada através do teste $\mathrm{t}$ ao nível de 5\% de probabilidade (Madden \& Hugles, 1995), utilizando as estimativas destes parâmetros de aleatoriedade e seus erros padrões. Quando $b=1$ e $\log (A)=0$, os dados seguem um padrão de distribuição ao acaso. Se $b=1$ e $\log (A)>0$, existe um nível de agregação que independe da incidência. Enquanto que quando $b>1$ e $\log (A)>0$ existe agregação e esta varia de acordo com a incidência.

\section{Análise da dinâmica de focos da doença (ADFD)}

O conceito de foco para ADFD foi considerado como sendo uma área de concentração de plantas infectadas, podendo ser fontes primárias de infecção ou coincidentes com áreas originalmente favoráveis ao estabelecimento da doença e que tendem a influenciar no padrão de transmissão da doença (Laranjeira, 1997). A ADFD foi realizada a partir dos mapas cumulativos de cada parcela em cada avaliação, sendo consideradas plantas sintomáticas do mesmo foco apenas aquelas plantas sintomáticas imediatamente adjacentes no padrão de proximidade horizontal, vertical ou longitudinal (Nelson, 1996 e Laranjeira, 1997). A partir de então, para cada mapa foi quantificado o número de focos para o total de plantas em cada parcela. Mapas com a representação gráfica do número de focos relacionados com a incidência da doença foram gerados para todos os conjuntos de dados e esses foram ajustados à função beta generalizada (Hau \& Kranz, 1990):

$$
Y=b_{1}(x)^{b 2} \times(1-x)^{b 3}
$$

Em que $Y=$ é o número de focos por 225 plantas, $x$ é a incidência da doença, e as constantes de regressão B1, B2 e B3 são calculados. 


\section{Associação entre begomovirose e crinivirose}

A associação entre begomovirose e crinivirose foi quantificada a partir do cálculo do índice de Jaccard (Ludwig \& Reynolds 1988; Turecheck \& Madden 2000). Para cada parcela experimental o índice de Jaccard foi calculado a partir da seguinte fórmula:

$$
\mathrm{J}=a /(a+b+c)
$$

onde $a$ representa a quantidade de plantas onde ambas as viroses foram observadas, $b$ representa a quantidade de plantas sintomáticas com vírus 1 e $c$ representa a quantidade de plantas sintomáticas com o vírus 2 . Os valores do índice variam entre 0 e 1 , sendo que quanto mais próximo de 1 maior a associação, enquanto que quanto mais próximo de 0 menor a associação entre as viroses.

\section{Monitoramento dos adultos de mosca-branca}

Em todas as parcelas avaliadas foi realizado semanalmente o monitoramento da população de moscas-brancas. O monitoramento foi realizado colocando-se oito armadilhas (armadilha amarela, BioControle) em cada parcela. Essas armadilhas eram quadradas $(12 \times 12 \mathrm{~cm})$, com dupla face amarela e recobertas com cola, onde os insetos ficavam aderidos. No campo, essas armadilhas foram instaladas na altura das plantas, fixadas em estacas de alumínio, onde permaneciam em campo por sete dias. Após este período as armadilhas eram levadas ao laboratório de Entomologia da Embrapa Hortaliças para contagem dos adultos (com auxílio de um microscópio estereoscópico). 


\section{Resultados}

\section{Diagnóstico sintomático visual}

O estudo epidemiológico foi realizado durante os anos de 2012 a 2014 em 16 parcelas localizadas em quatro áreas de produção de tomateiro para consumo in natura com duas cultivares híbridas: Dominador (TopSeed) e Predador (TopSeed). Ambos os cultivares apresentam resistência moderada à infecção por begomovirus, isto é, apresentam casos de escapes de infecção e em plantas infectadas, os sintomas são amenos. Plantas infectadas com begomovirus apresentavam manchas cloróticas suaves, principalmente nas folhas superiores da planta. Com o avanço do progresso da epidemia os sintomas passaram a ser observados em outras partes da planta, mas de forma pouco severa (Figura 2 A, B e C). Os sintomas causados por crinivirus foram observados mais tardiamente, somente após pelo menos três semanas do transplante das mudas. Plantas infectadas com crinivirus apresentaram mosqueado, manchas cloróticas, clorose e enrolamento foliar inicialmente nas folhas mais velhas e mais tarde atingindo quase toda a planta (Figura 2 D, E e F). Plantas infectadas com ambas as viroses apresentaram sintomas típicos de begomovirose na parte superior da planta e de crinivirose na parte inferior da mesma (Figura 2 G, H e I). Os sintomas de begomovirose observados em ambas as cultivares foram evidentes, porém suaves se comparados com os sintomas apresentados por cultivares suscetíveis ao begomovirus. A análise molecular confirmou a presença de begomovirus e/ou crinivirus em $100 \%$ das plantas coletadas com sintomas característicos de begomovirus e/ou crinivirus. A análise visual das plantas sintomáticas foi precisa e confiável para este estudo. Poucos casos de outras doenças de origem viral foram observados além dessas duas viroses nas parcelas. Entretanto, algumas plantas fora das parcelas apresentavam sintomas característicos de vira-cabeça do tomateiro. Esses sintomas eram facilmente distinguíveis, como por exemplo, arroxeamento das folhas, pontuações necróticas e necrose nas folhas e caule e distorção do ápice. Doenças de origem não viral 
também foram observadas, principalmente bactérias (do gênero Pseudomonas

Xanthomonas) causando perda de área foliar, porém ocorrendo de forma uniforme nas parcelas e não prejudicando as avaliações.

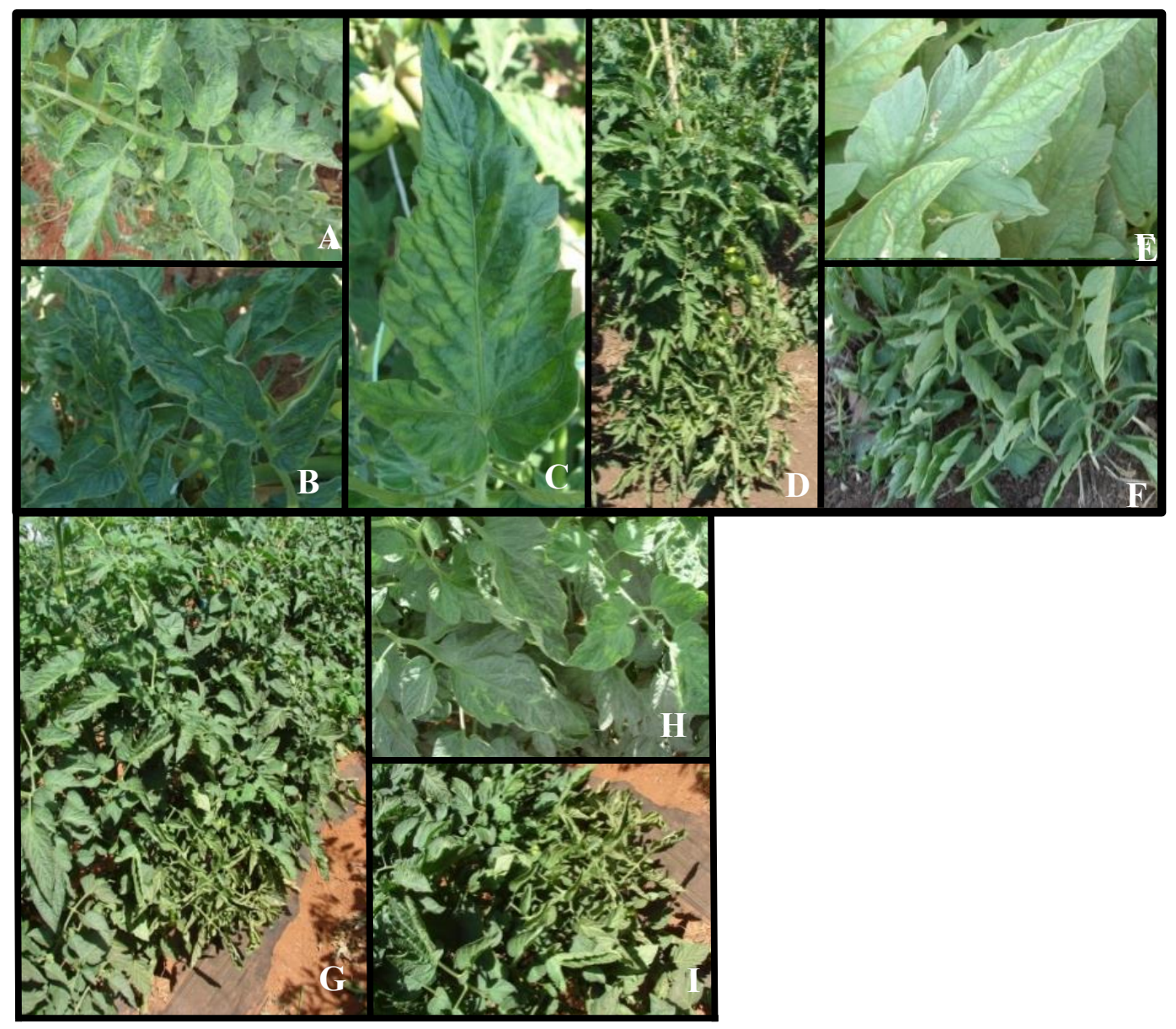

Figura 2. Folhas de tomateiro apresentando clorose internerval e enrolamento foliar das folhas mais novas, causados por infecção por begomovirus (A, B, C); tomateiro apresentando clorose internerval e enrolamento foliar das folhas mais velhas, causados por infecção por crinivirus (D, E, F); tomateiros infetados por begomovirus e crinivirus $(\mathrm{G}, \mathrm{H}, \mathrm{I})$. 


\section{Detecção e identificação das espécies virais em campo}

Durante as avaliações em todas as parcelas das quatro áreas avaliadas foram coletadas um total de 317 amostras de plantas sintomáticas. Essas amostras foram inicialmente analisadas via PCR. O DNA total das 177 plantas com sintomas de begomovirus amplificaram um fragmento de $\sim 1100$ pares de bases utilizando os primers universais a begomovirus, confirmando a infecção. O cDNA de todas as 187 amostras coletadas com sintomas de crinivirus amplificaram um fragmento de aproximadamente 500 pares de bases, utilizando os primers (ToC 5 e ToC 6), confirmando a infecção por ToCV. Os dois vírus estavam presentes simultaneamente em 95 amostras sintomáticas coletadas. O resultado do sequenciamento parcial do produto da PCR confirmou a presença de apenas ToSRV e ToCV nas amostras analisadas, indicando que essas são as espécies de begomovirus e crinivirus predominantes na região.

Em todas as parcelas foram coletadas plantas daninhas na última avaliação, em um total de 184 amostras de plantas. Dezessete espécies de plantas daninhas diferentes foram coletadas e cinco destas espécies estavam infectadas com begomovirus (Nicandra physaloides e Sida spp.) ou crinivirus (Amaranthus viridis, Solanum americanum, Sida spp. e Commelina benghalensis) (Tabela 2). 
Tabela 2: Detecção molecular de begomovirus e crinivirus em plantas daninhas coletadas nas regiões de Goianápolis, DAIA, Boa Esperança e Taquara.

\begin{tabular}{|c|c|c|}
\hline & ToSRV* & ToCV* \\
\hline Curcubita spp. & $0 / 1$ & $0 / 1$ \\
\hline Euphorbia heterophylla & $0 / 15$ & $0 / 15$ \\
\hline Alternanthera tenella & $0 / 7$ & $0 / 7$ \\
\hline Portulaca oleracea & $0 / 4$ & $0 / 4$ \\
\hline Galinsoga parviflora & $0 / 4$ & $0 / 4$ \\
\hline Brachiaria spp. & $0 / 3$ & $0 / 3$ \\
\hline Amaranthus viridis & $0 / 38$ & $1 / 38$ \\
\hline Crotalaria spp. & $0 / 6$ & $0 / 6$ \\
\hline Euphorbia brasiliensis & $0 / 1$ & $0 / 1$ \\
\hline Emilia sonchifolia & $0 / 1$ & $0 / 1$ \\
\hline Phaseolus vulgaris & $0 / 12$ & $0 / 12$ \\
\hline Solanum americanum & $0 / 30$ & $4 / 30$ \\
\hline Nicandra physaloides & $1 / 7$ & $1 / 7$ \\
\hline Bidens pilosa & $0 / 1$ & $0 / 1$ \\
\hline Sonchus oleraceus & $0 / 5$ & $0 / 5$ \\
\hline Sida spp. & $4 / 42$ & $3 / 42$ \\
\hline Commelina benghalensis & $0 / 9$ & $1 / 9$ \\
\hline Total & $5 / 184$ & $10 / 184$ \\
\hline
\end{tabular}

*Total de plantas infectadas pelo total de plantas coletadas. ToSRV: Tomato severe rugose virus; ToCV: Tomato chlorosis vírus. 


\section{Análise temporal}

\section{Incidência da doença}

A incidência de begomovirose e crinivirose foi avaliada em 16 parcelas contendo 225 plantas cada, em quatro áreas de produção comercial de tomate para consumo in natura em diferentes épocas do ano (Tabelas 3 e 4). Em geral, sintomas característicos de begomovirose foram primeiramente observados para a maioria das parcelas. Aos 14 DAT, plantas de tomate começaram a exibir sintomas característicos de infecção por begomovirus, enquanto sintomas característicos de crinivirus foram observados mais tardiamente, aos 21 dias.

Alta variação de incidência e de AACPD para ambas as viroses entre as parcelas e as áreas avaliadas foram observadas, embora uma pequena variação de incidência e AACPD tenham sido verificadas entre as parcelas de uma mesma área de produção. As duas regiões com maior incidência final média de ambas as viroses foram Taquara $(67,5 \%$ de begomovirose e $76 \%$ de crinivirose) e Goianápolis (29\% e 57,8\%, respectivamente). Apresentaram baixa incidência as regiões de DAIA com 6,3\% de begomovirose e 1,6\% de crinivirose e Boa Esperança com 19,8\% e 25,3\%, respectivamente. As incidências finais e a AACPD, respectivamente, variaram de 0,9 - 71\% e 4,18 - 224,21 para begomovirus e de 4,9 $87 \%$ e 12,08 - 218,43 para crinivirus. Mesmo o sintoma de crinivirose ficando visível mais tardiamente, a incidência e a AACPD para esta doença apresentaram maiores valores em todas as parcelas avaliadas. 


\section{Curvas de progresso}

As curvas de progresso obtidas refletem os diferentes períodos de incubação das viroses, mostrando o aparecimento um pouco mais tardio de plantas sintomáticas para crinivirose. As curvas de progresso de crinivirose estão defasadas no tempo em relação às curvas de begomovirose no período inicial, especialmente para as parcelas localizadas em Taquara. Mais tarde, a incidência de crinivirose aumenta e supera os valores de begomovirose em todas as parcelas avaliadas. A forma das curvas de progresso de begomovirose e crinivirose apresentou certa similaridade entre as regiões, mas especialmente entre parcelas da mesma localidade (Figura 3). Devido principalmente à quantidade reduzida de avaliações nas 12 primeiras parcelas avaliadas, não foi possível fazer um ajuste adequado das curvas a nenhum modelo estatístico. Nas quatro últimas parcelas, onde o número de avaliações foi aumentado, ondas de incidência foram observadas ao longo das curvas de progresso, especialmente para crinivirose, fato esse que mais uma vez dificultou um ajuste adequado. Optou-se, então, por não realizar ajuste das curvas de progresso e explicar as ondas observadas a partir de aspectos biológicos dos patossistemas estudados. 

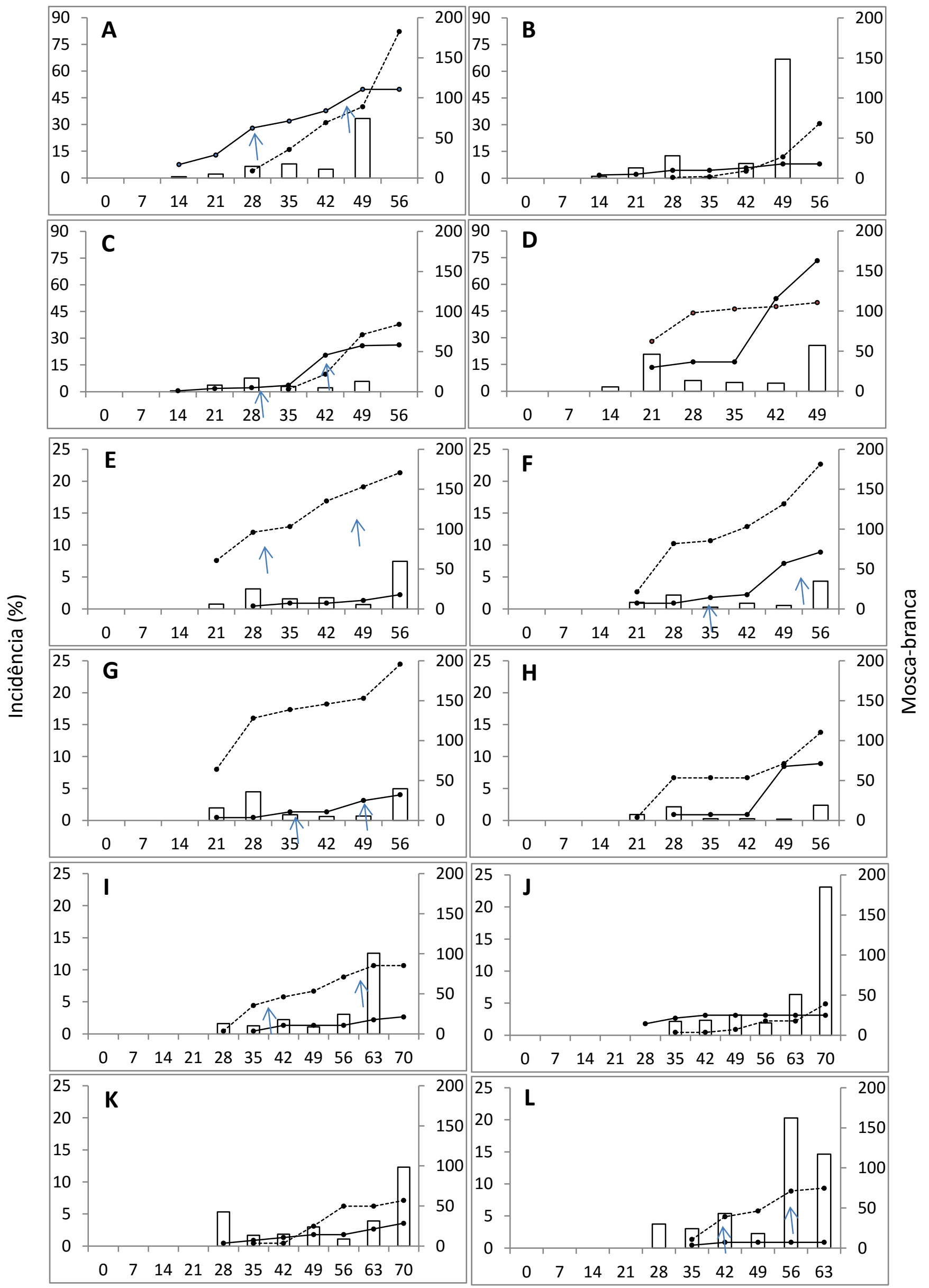

Dias após o transplantio 


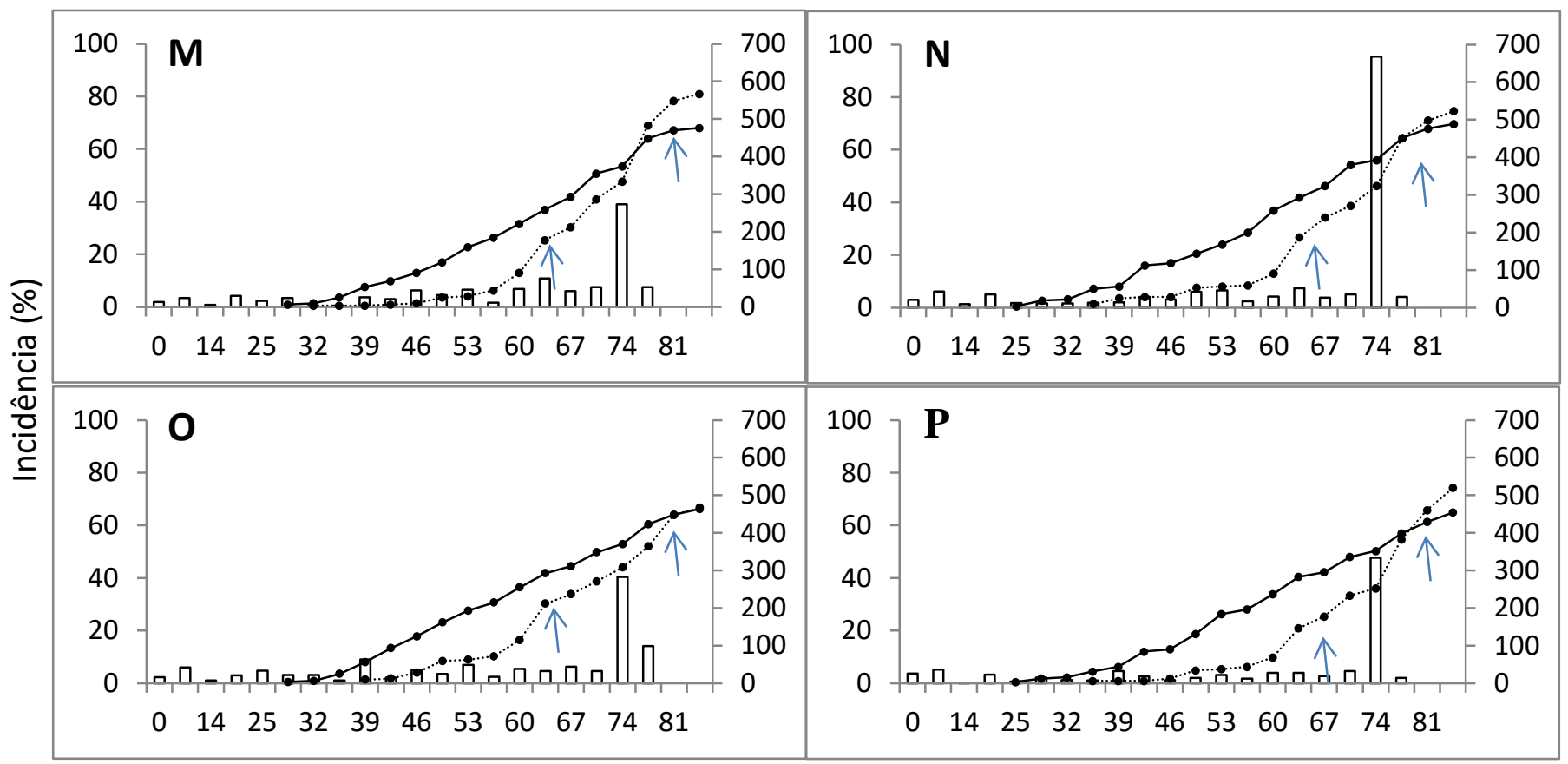

Dias após o transplantio

Figura 3: Curvas de progresso de begomovirose (linha contínua) e crinivirose (linha pontilhada) e população de mosca-branca (barras). Setas indicam a presença de ondas de incidência. Quatro regiões produtoras de tomateiro avaliadas. A: parcela G1, B: G2, C: G3 D: G4 (localizadas em Goianápolis); E: D1, F: D2, G: D3, H: D4 (localizadas no DAIA); I: B1, J: B2, K: B3, L: B4 (localizadas em Boa Esperança); e M: T1, N: T2, O: T3 E P: T4 (localizadas em Taquara). 
Tabela 3: Incidência de begomovirose, valor de D (quadrat 2x3 e 3x2), valores da análise de sequências ordinárias, população média de mosca-branca e valores da AACPD em 12 parcelas localizadas nas regiões de Goianápolis (GO), DAIA (GO), Boa Esperança (DF) e Taquara (DF).

\begin{tabular}{|c|c|c|c|c|c|c|c|c|c|}
\hline \multirow{2}{*}{ Parcela } & \multirow{2}{*}{ Data } & \multirow{2}{*}{ DAT } & \multirow{2}{*}{ INC } & \multicolumn{2}{|c|}{ D } & \multicolumn{2}{|c|}{ Seq. ordinárias } & \multirow{2}{*}{ MB } & \multirow{2}{*}{ AACPD } \\
\hline & & & & $2 \times 3$ & $3 \times 2$ & row & columns & & \\
\hline \multirow{6}{*}{ G1 } & 13.09 .12 & 14 & 0,08 & 0,84 & 1,10 & $0 / 9$ & $0 / 12$ & \multirow{6}{*}{9,56} & \multirow{6}{*}{154,01} \\
\hline & 20.09 .12 & 21 & 0,13 & 0,71 & 0,95 & $0 / 12$ & $2 / 14$ & & \\
\hline & 27.09 .12 & 28 & 0,27 & $1,46 *$ & $1,47 *$ & $0 / 15$ & $1 / 15$ & & \\
\hline & 04.09.12 & 35 & 0,20 & 0,79 & 0,85 & $0 / 14$ & $0 / 15$ & & \\
\hline & 11.10 .12 & 42 & 0,26 & 1,38 & 0,97 & $0 / 15$ & $0 / 15$ & & \\
\hline & 16.10 .12 & 49 & 0,40 & $1,64 *$ & 1,35 & $0 / 15$ & $0 / 15$ & & \\
\hline \multirow{5}{*}{ G2 } & 13.09 .12 & 14 & 0,10 & 0,09 & 0,93 & $0 / 2$ & $0 / 4$ & \multirow{5}{*}{11} & \multirow{5}{*}{34,48} \\
\hline & 20.09 .12 & 21 & 0,02 & 0,90 & 0,90 & $0 / 2$ & $0 / 5$ & & \\
\hline & 27.09 .12 & 28 & 0,05 & 0,77 & 0,77 & $0 / 5$ & $0 / 7$ & & \\
\hline & 04.09 .12 & 35 & 0,05 & 0,99 & 0,99 & $0 / 5$ & $0 / 9$ & & \\
\hline & 11.10 .12 & 42 & 0,06 & 0,90 & 0,75 & $0 / 7$ & $0 / 10$ & & \\
\hline \multirow{6}{*}{ G3 } & 27.09 .12 & 14 & 0,02 & 0,93 & 0,93 & $0 / 3$ & $0 / 4$ & \multirow{6}{*}{8,18} & \multirow{6}{*}{92,99} \\
\hline & 04.09 .12 & 21 & 0,02 & 0,90 & 0,00 & $0 / 4$ & $0 / 5$ & & \\
\hline & 11.10 .12 & 28 & 0,04 & 0,83 & 1,09 & $0 / 5$ & $0 / 7$ & & \\
\hline & 16.10 .12 & 35 & 0,20 & 1,27 & 1,41 & $1 / 15$ & $1 / 14$ & & \\
\hline & 25.10 .12 & 42 & 0,26 & 1,10 & 1,09 & $1 / 15$ & $0 / 15$ & & \\
\hline & 01.11 .12 & 49 & 0,26 & 1,03 & 1,02 & $1 / 15$ & $0 / 15$ & & \\
\hline \multirow{6}{*}{ G4 } & 27.09 .12 & 14 & 0,05 & 0,99 & 0,99 & $0 / 7$ & $0 / 10$ & \multirow{6}{*}{8,56} & \multirow{6}{*}{136,67} \\
\hline & 04.09 .12 & 21 & 0,07 & 1,13 & 0,98 & $0 / 10$ & $0 / 11$ & & \\
\hline & 11.10 .12 & 28 & 0,10 & 1,37 & 1,05 & $0 / 11$ & $0 / 14$ & & \\
\hline & 16.10 .12 & 35 & 0,28 & 1,17 & 1,31 & $1 / 15$ & $1 / 15$ & & \\
\hline & 25.10 .12 & 42 & 0,29 & 0,70 & 1,27 & $1 / 15$ & $1 / 15$ & & \\
\hline & 01.11 .12 & 49 & 0,44 & 0,96 & 1,23 & $1 / 15$ & $0 / 15$ & & \\
\hline \multirow{5}{*}{ D1 } & 07.11 .12 & 28 & 0,00 & 1,00 & 0,03 & $0 / 1$ & $0 / 1$ & \multirow{5}{*}{14,37} & \multirow{5}{*}{5,42} \\
\hline & 14.11 .12 & 35 & 0,00 & 1,00 & 1,00 & $0 / 2$ & $0 / 2$ & & \\
\hline & 21.11 .12 & 42 & 0,00 & 1,00 & 1,00 & $0 / 2$ & $0 / 2$ & & \\
\hline & 27.11 .12 & 49 & 0,01 & 0,98 & 0,98 & $0 / 3$ & $0 / 3$ & & \\
\hline & 05.12 .12 & 56 & 0,02 & 0,93 & 0,93 & $0 / 5$ & $0 / 5$ & & \\
\hline \multirow{6}{*}{ D2 } & 31.10 .12 & 21 & 0,00 & 1,00 & 0,03 & $0 / 1$ & $0 / 1$ & \multirow{6}{*}{15,87} & \multirow{6}{*}{12,67} \\
\hline & 07.11 .12 & 28 & 0,00 & 1,00 & 0,03 & $0 / 1$ & $0 / 1$ & & \\
\hline & 14.11 .12 & 35 & 0,01 & 0,95 & 0,67 & $0 / 3$ & $0 / 3$ & & \\
\hline & 21.11 .12 & 42 & 0,01 & 0,95 & 0,67 & $0 / 3$ & $0 / 3$ & & \\
\hline & 27.11 .12 & 49 & 0,03 & 0,85 & 0,76 & $0 / 5$ & $0 / 6$ & & \\
\hline & 05.12 .12 & 56 & 0,04 & 1,04 & 1,22 & $0 / 6$ & $0 / 8$ & & \\
\hline
\end{tabular}




\begin{tabular}{|c|c|c|c|c|c|c|c|c|c|}
\hline \multirow{6}{*}{ D3 } & 07.11 .12 & 21 & 0,00 & 0,98 & 0,52 & $0 / 2$ & $0 / 2$ & \multirow{6}{*}{8,68} & \multirow{6}{*}{31,46} \\
\hline & 14.11 .12 & 28 & 0,00 & 0,98 & 0,98 & $0 / 2$ & $0 / 2$ & & \\
\hline & 21.11 .12 & 35 & 0,09 & 0,93 & 0,73 & $0 / 3$ & $0 / 4$ & & \\
\hline & 27.11 .12 & 42 & 0,02 & 0,90 & 0,75 & $0 / 4$ & $0 / 4$ & & \\
\hline & 05.12 .12 & 49 & 0,07 & 1,29 & $1,48^{*}$ & $0 / 9$ & $0 / 9$ & & \\
\hline & 11.12 .12 & 56 & 0,09 & 1,55 & $1,55^{*}$ & $0 / 11$ & $0 / 10$ & & \\
\hline \multirow{5}{*}{ D4 } & 07.11 .12 & 28 & 0,01 & 0,98 & 0,98 & $0 / 2$ & $0 / 2$ & \multirow{5}{*}{7,125} & \multirow{5}{*}{28,32} \\
\hline & 14.11 .12 & 35 & 0,01 & 0,98 & 0,98 & $0 / 2$ & $0 / 2$ & & \\
\hline & 21.11 .12 & 42 & 0,01 & 0,98 & 0,98 & $0 / 2$ & $0 / 2$ & & \\
\hline & 27.11 .12 & 49 & 0,09 & 1,11 & 1,24 & $0 / 10$ & $0 / 10$ & & \\
\hline & 05.12 .12 & 56 & 0,10 & 1,17 & 1,24 & $0 / 10$ & $0 / 10$ & & \\
\hline \multirow{5}{*}{ B1 } & 17.07 .13 & 35 & 0,00 & 1,00 & 1,00 & $0 / 1$ & $0 / 1$ & \multirow{5}{*}{12,31} & \multirow{5}{*}{7,49} \\
\hline & 24.07 .13 & 42 & 0,01 & 0,98 & $1,44^{*}$ & $0 / 2$ & $0 / 3$ & & \\
\hline & 31.07 .13 & 49 & 0,01 & 0,98 & $1,44^{*}$ & $0 / 2$ & $0 / 3$ & & \\
\hline & 07.08 .13 & 56 & 0,01 & 0,98 & $1,44^{*}$ & $0 / 2$ & $0 / 3$ & & \\
\hline & 14.08 .13 & 63 & 0,02 & 0,90 & 0,90 & $0 / 5$ & $0 / 5$ & & \\
\hline \multirow{3}{*}{ B2 } & 03.07 .13 & 28 & 0,02 & 0,93 & 0,93 & $0 / 4$ & $0 / 3$ & \multirow{3}{*}{19,12} & \multirow{3}{*}{19,16} \\
\hline & 10.07 .13 & 35 & 0,03 & 0,88 & 0,88 & $0 / 5$ & $0 / 5$ & & \\
\hline & 17.07 .13 & 42 & 0,03 & 0,85 & 0,85 & $0 / 5$ & $0 / 6$ & & \\
\hline \multirow{7}{*}{ B3 } & 03.07 .13 & 28 & 0,00 & 1,00 & 1,00 & $0 / 1$ & $0 / 1$ & \multirow{7}{*}{23,56} & \multirow{7}{*}{11,04} \\
\hline & 17.07 .13 & 35 & 0,01 & 0,98 & 0,98 & $0 / 2$ & $0 / 2$ & & \\
\hline & 24.07 .13 & 42 & 0,01 & 0,95 & 0,95 & $0 / 3$ & $0 / 3$ & & \\
\hline & 31.07 .13 & 49 & 0,02 & 0,93 & 0,93 & $0 / 4$ & $0 / 4$ & & \\
\hline & 07.08 .13 & 56 & 0,02 & 0,93 & 0,93 & $0 / 4$ & $0 / 4$ & & \\
\hline & 14.08 .13 & 63 & 0,03 & 1,23 & 0,88 & $0 / 4$ & $0 / 4$ & & \\
\hline & 21.08 .13 & 70 & 0,00 & 1,36 & 0,83 & $0 / 7$ & $0 / 6$ & & \\
\hline \multirow{3}{*}{ B4 } & 10.07 .13 & 35 & 0,00 & 1,00 & 1,00 & $0 / 1$ & $0 / 1$ & \multirow{3}{*}{28,75} & \multirow{3}{*}{4,18} \\
\hline & 17.07 .13 & 42 & 0,00 & 1,00 & 1,00 & $0 / 1$ & $0 / 1$ & & \\
\hline & 24.07 .13 & 49 & 0,01 & 0,98 & 0,98 & $0 / 2$ & $0 / 2$ & & \\
\hline \multirow{14}{*}{ T1 } & 14.08 .14 & 28 & 0,01 & 0,98 & 1,00 & $0 / 2$ & $0 / 2$ & \multirow{14}{*}{41,95} & \multirow{14}{*}{209,78} \\
\hline & 18.08 .14 & 32 & 0,01 & 0,95 & 0,98 & $0 / 3$ & $0 / 2$ & & \\
\hline & 21.08 .14 & 35 & 0,04 & 0,83 & 0,88 & $0 / 6$ & $0 / 7$ & & \\
\hline & 25.08 .14 & 39 & 0,08 & 0,97 & 0,78 & $0 / 11$ & $0 / 11$ & & \\
\hline & 28.08 .14 & 42 & 0,10 & 0,85 & 0,94 & $0 / 12$ & $0 / 13$ & & \\
\hline & 01.09 .14 & 46 & 0,14 & 0,62 & 0,88 & $0 / 12$ & $0 / 14$ & & \\
\hline & 04.00 .14 & 49 & 0,18 & 0,88 & 0,99 & $0 / 13$ & $0 / 14$ & & \\
\hline & 08.09 .14 & 53 & 0,24 & 0,99 & 0,95 & $0 / 13$ & $0 / 15$ & & \\
\hline & 11.09 .14 & 56 & 0,27 & 1,11 & 1,06 & $4 / 14$ & $0 / 15$ & & \\
\hline & 15.09 .14 & 60 & 0,31 & 1,17 & 1,05 & $3 / 15$ & $1 / 15$ & & \\
\hline & 18.09 .14 & 63 & 0,36 & 1,12 & 1,14 & $3 / 15$ & $0 / 15$ & & \\
\hline & 22.09 .14 & 67 & 0,41 & 1,27 & 1,21 & $2 / 15$ & $0 / 15$ & & \\
\hline & 25.09 .14 & 70 & 0,50 & 1,33 & 1,37 & $3 / 15$ & $0 / 15$ & & \\
\hline & 29.09 .14 & 74 & 0,52 & 1,32 & 1,37 & $4 / 15$ & $0 / 15$ & & \\
\hline
\end{tabular}




\begin{tabular}{|c|c|c|c|c|c|c|c|c|c|}
\hline & 02.10 .14 & 77 & 0,63 & 1,22 & 1,20 & $1 / 14$ & $1 / 15$ & & \\
\hline & 06.10 .14 & 81 & 0,66 & 1,24 & 1,25 & $0 / 14$ & $1 / 15$ & & \\
\hline & 10.10 .14 & 84 & 0,67 & 1,18 & 1,33 & $0 / 14$ & $1 / 15$ & & \\
\hline \multirow{17}{*}{$\mathbf{T} 2$} & 14.08 .14 & 28 & 0,00 & 1,00 & 1,00 & $0 / 1$ & $0 / 1$ & \multirow{17}{*}{45,13} & \multirow{17}{*}{224,21} \\
\hline & 18.08 .14 & 32 & 0,01 & 0,98 & 0,98 & $0 / 2$ & $0 / 2$ & & \\
\hline & 21.08 .14 & 35 & 0,04 & 1,09 & 1,09 & $0 / 6$ & $0 / 8$ & & \\
\hline & 25.08 .14 & 39 & 0,09 & 0,92 & 0,92 & $0 / 11$ & $0 / 11$ & & \\
\hline & 28.08 .14 & 42 & 0,14 & 1,03 & 0,97 & $0 / 13$ & $0 / 15$ & & \\
\hline & 01.09 .14 & 46 & 0,18 & 0,87 & 1,09 & $0 / 13$ & $0 / 15$ & & \\
\hline & 04.00 .14 & 49 & 0,23 & 0,89 & 1,12 & $0 / 13$ & $0 / 15$ & & \\
\hline & 08.09 .14 & 53 & 0,28 & 1,01 & 1,28 & $1 / 14$ & $0 / 15$ & & \\
\hline & 11.09 .14 & 56 & 0,30 & 1,04 & 1,22 & $1 / 14$ & $0 / 15$ & & \\
\hline & 15.09 .14 & 60 & 0,37 & 1,30 & $1,52 *$ & $3 / 14$ & $0 / 15$ & & \\
\hline & 18.09 .14 & 63 & 0,42 & 1,34 & 1,30 & $1 / 14$ & $0 / 15$ & & \\
\hline & 22.09 .14 & 67 & 0,45 & 1,26 & 1,26 & $2 / 14$ & $0 / 15$ & & \\
\hline & 25.09 .14 & 70 & 0,50 & 1,02 & 1,13 & $1 / 14$ & $0 / 15$ & & \\
\hline & 29.09 .14 & 74 & 0,53 & 1,13 & 1,09 & $0 / 14$ & $1 / 15$ & & \\
\hline & 02.10 .14 & 77 & 0,61 & 1,19 & 0,69 & $0 / 15$ & $2 / 15$ & & \\
\hline & 06.10 .14 & 81 & 0,65 & 1,19 & 0,67 & $0 / 15$ & $2 / 15$ & & \\
\hline & 10.10 .14 & 84 & 0,67 & 1,27 & 0,79 & $0 / 15$ & $2 / 15$ & & \\
\hline \multirow{18}{*}{ T3 } & 11.08 .14 & 25 & 0,00 & 1,00 & -- & $0 / 1$ & $0 / 1$ & \multirow{18}{*}{58,16} & \multirow{18}{*}{219,36} \\
\hline & 14.08 .14 & 28 & 0,03 & 0,88 & 0,90 & $0 / 5$ & $0 / 5$ & & \\
\hline & 18.08 .14 & 32 & 0,03 & 1,16 & 1,23 & $1 / 5$ & $0 / 5$ & & \\
\hline & 21.08 .14 & 35 & 0,07 & 1,13 & 0,93 & $1 / 11$ & $1 / 11$ & & \\
\hline & 25.08 .14 & 39 & 0,08 & 1,16 & 0,88 & $1 / 12$ & $1 / 12$ & & \\
\hline & 28.08 .14 & 42 & 0,15 & 1,01 & 1,11 & $0 / 14$ & $2 / 14$ & & \\
\hline & 01.09 .14 & 46 & 0,16 & 1,05 & 1,05 & $0 / 14$ & $2 / 15$ & & \\
\hline & 04.00 .14 & 49 & 0,20 & 0,97 & 1,03 & $0 / 14$ & $0 / 15$ & & \\
\hline & 08.09 .14 & 53 & 0,23 & 1,11 & 1,05 & $0 / 14$ & $0 / 15$ & & \\
\hline & 11.09 .14 & 56 & 0,28 & 1,06 & 1,15 & $1 / 15$ & $1 / 15$ & & \\
\hline & 15.09 .14 & 60 & 0,37 & 1,01 & 1,12 & $1 / 15$ & $1 / 15$ & & \\
\hline & 18.09 .14 & 63 & 0,42 & 0,98 & 0,82 & $0 / 15$ & $0 / 15$ & & \\
\hline & 22.09 .14 & 67 & 0,47 & 1,24 & 0,79 & $0 / 15$ & $0 / 15$ & & \\
\hline & 25.09 .14 & 70 & 0,55 & $1,5^{*}$ & 1,06 & $0 / 15$ & $0 / 15$ & & \\
\hline & 29.09 .14 & 74 & 0,57 & $1,45^{*}$ & 1,02 & $0 / 15$ & $0 / 15$ & & \\
\hline & 02.10 .14 & 77 & 0,66 & $1,55^{*}$ & 1,17 & $1 / 15$ & $0 / 15$ & & \\
\hline & 06.10 .14 & 81 & 0,69 & $1,7 *$ & 1,27 & $2 / 15$ & $1 / 15$ & & \\
\hline & 10.10 .14 & 84 & 0,71 & $1,49 *$ & 1,15 & $3 / 15$ & $0 / 15$ & & \\
\hline \multirow{5}{*}{ T4 } & 14.08 .14 & 28 & 0,01 & 0,95 & 1,00 & $0 / 4$ & $0 / 4$ & \multirow{5}{*}{34,01} & \multirow{5}{*}{213,4} \\
\hline & 18.08 .14 & 32 & 0,02 & 0,93 & 0,93 & $0 / 5$ & $0 / 4$ & & \\
\hline & 21.08 .14 & 35 & 0,04 & 0,80 & 0,90 & $0 / 8$ & $0 / 9$ & & \\
\hline & 25.08 .14 & 39 & 0,06 & 1,03 & 0,77 & $0 / 9$ & $0 / 12$ & & \\
\hline & 28.08 .14 & 42 & 0,12 & $1,48 *$ & 0,82 & $0 / 13$ & $0 / 14$ & & \\
\hline
\end{tabular}




$\mid$\begin{tabular}{lllllll}
01.09 .14 & 46 & 0,13 & $1,59^{*}$ & 0,57 & $0 / 13$ & $0 / 14$ \\
04.00 .14 & 49 & 0,20 & 1,34 & 0,66 & $0 / 14$ & $1 / 15$ \\
08.09 .14 & 53 & 0,27 & 1,24 & 0,84 & $0 / 15$ & $0 / 15$ \\
11.09 .14 & 56 & 0,29 & 1,35 & 0,78 & $0 / 15$ & $1 / 15$ \\
15.09 .14 & 60 & 0,35 & 1,41 & 0,85 & $0 / 15$ & $1 / 15$ \\
18.09 .14 & 63 & 0,42 & 1,26 & 0,85 & $0 / 15$ & $0 / 15$ \\
22.09 .14 & 67 & 0,43 & 1,25 & 0,90 & $0 / 15$ & $0 / 15$ \\
25.09 .14 & 70 & 0,50 & 1,27 & 0,89 & $0 / 15$ & $0 / 15$ \\
29.09 .14 & 74 & 0,51 & 1,15 & 0,90 & $0 / 15$ & $0 / 15$ \\
02.10 .14 & 77 & 0,58 & 1,14 & 0,80 & $1 / 15$ & $0 / 15$ \\
06.10 .14 & 81 & 0,62 & 1,31 & 0,82 & $0 / 14$ & $0 / 15$ \\
10.10 .14 & 84 & 0,65 & $1,49^{*}$ & 0,81 & $0 / 14$ & $0 / 15$ \\
\hline
\end{tabular}

G: Goianápolis, D: DAIA, B: Boa Esperança, T: Taquara. DAT: Dias após o transplantio, INC: incidência da doença, D: índice de dispersão, MB: média da população de mosca-branca coletada em cada parcela até duas semanas antes do final das avaliações, AACPD: área abaixo da curva de progresso da doença por parcela; (*) valores significativamente maiores do que 1 pelo teste do qui-quadrado $(\mathrm{p}<0,05)$.

\section{Análise espacial}

\section{Análise de sequências ordinárias}

A agregação de plantas com sintomas de begomovirus e crinivirus foi primeiramente examinada pela proximidade de plantas sintomáticas entre plantas adjacentes (Tabela 3 e 4 ). Em um total de 134 (begomovirus) e 124 (crinivirus) mapas de plantas sintomáticas, 30,6 e 34,7\% apresentaram agregação, respectivamente para begomovirus e crinivirus (Tabela 3 e 4). Em um total de 1249 linhas para begomovirus e 1257 para crinivirus avaliadas, apenas 56 (4,40\% - begomovirus) e 61 (4,85\% - crinivirus) apresentam agregação de plantas sintomáticas. A porcentagem de agregação de plantas sintomáticas entre linhas foi mais baixa que dentro da linha. De um total de 1291 (begomovirus) e 1276 (crinivirus) entrelinhas avaliadas apenas 27 (2,1\% - begomovirus) e 23 (1,8\% - crinivirus) apresentavam plantas sintomáticas distribuídas de forma agregada. 
Tabela 4: Incidência de crinivirose, valor de D (quadrat $2 \times 3$ e 3x2), valores da análise de sequências ordinárias, população média de mosca-branca e valores da AACPD em 12 parcelas localizadas nas regiões de Goianápolis (GO), DAIA (GO), Boa Esperança (DF) e Taquara (DF).

\begin{tabular}{|c|c|c|c|c|c|c|c|c|c|}
\hline \multirow{2}{*}{ Parcela } & \multirow{2}{*}{ Data } & \multirow{2}{*}{ DAT } & \multirow{2}{*}{ INC } & \multicolumn{2}{|c|}{$\mathbf{D}$} & \multicolumn{2}{|c|}{ Seq. ordinárias } & \multirow{2}{*}{ MB } & \multirow{2}{*}{ AACPD } \\
\hline & & & & $2 \times 3$ & $3 \times 2$ & row & columns & & \\
\hline \multirow{6}{*}{ G1 } & 27.09 .12 & 28 & 0,08 & 0,84 & 1,10 & $0 / 9$ & $0 / 12$ & \multirow{6}{*}{9,56} & \multirow{6}{*}{209,98} \\
\hline & 04.09 .12 & 35 & 0,13 & 0,92 & 1,00 & $0 / 4$ & $0 / 14$ & & \\
\hline & 11.10 .12 & 42 & 0,20 & 1,40 & $1,72 *$ & $1 / 13$ & $4 / 15$ & & \\
\hline & 16.10 .12 & 49 & 0,32 & 0,83 & 0,89 & $2 / 15$ & $0 / 15$ & & \\
\hline & 25.10 .12 & 56 & 0,40 & $1,44^{*}$ & 1,32 & $1 / 15$ & $0 / 15$ & & \\
\hline & 31.10 .12 & 63 & 0,82 & 1,08 & 1,38 & $4 / 15$ & $0 / 14$ & & \\
\hline \multirow{6}{*}{ G2 } & 27.09 .12 & 28 & 0,01 & 0,98 & 0,98 & $0 / 2$ & $0 / 2$ & \multirow{6}{*}{11} & \multirow{6}{*}{52,00} \\
\hline & 04.09 .12 & 35 & 0,01 & 0,98 & 0,98 & $0 / 2$ & $0 / 2$ & & \\
\hline & 11.10 .12 & 42 & 0,01 & 0,95 & 0,95 & $0 / 3$ & $0 / 3$ & & \\
\hline & 16.10 .12 & 49 & 0,05 & 0,77 & 0,82 & $0 / 8$ & $0 / 9$ & & \\
\hline & 25.10 .12 & 56 & 0,14 & 0,65 & 0,89 & $0 / 14$ & $0 / 14$ & & \\
\hline & 31.10 .12 & 63 & 0,30 & 0,90 & 0,79 & $0 / 15$ & $1 / 15$ & & \\
\hline \multirow{4}{*}{ G3 } & 11.10 .12 & 35 & 0,01 & 0,95 & 0,95 & $0 / 3$ & $0 / 3$ & \multirow{4}{*}{8,18} & \multirow{4}{*}{129,07} \\
\hline & 16.10 .12 & 42 & 0,10 & 0,89 & 1,11 & $1 / 13$ & $2 / 11$ & & \\
\hline & 25.10 .12 & 49 & 0,33 & 1,27 & 1,22 & $1 / 15$ & $0 / 15$ & & \\
\hline & 31.10 .12 & 56 & 0,38 & 1,27 & 1,28 & $2 / 15$ & $0 / 15$ & & \\
\hline \multirow{5}{*}{ G4 } & 04.10 .12 & 28 & 0,01 & 0,98 & 0,98 & $0 / 2$ & $0 / 2$ & \multirow{5}{*}{8,56} & \multirow{5}{*}{168,33} \\
\hline & 11.10 .12 & 35 & 0,06 & $1,7 *$ & 1,20 & $0 / 9$ & $0 / 8$ & & \\
\hline & 16.10 .12 & 42 & 0,10 & 1,26 & 0,95 & $0 / 15$ & $0 / 15$ & & \\
\hline & 25.10 .12 & 49 & 0,62 & 1,14 & 0,79 & $0 / 14$ & $0 / 13$ & & \\
\hline & 31.10 .12 & 56 & 0,81 & 1,15 & 0,98 & $0 / 14$ & $0 / 13$ & & \\
\hline \multirow{6}{*}{ D1 } & 31.10 .12 & 21 & 0,08 & $1,5^{*}$ & 1,23 & $2 / 9$ & $0 / 7$ & \multirow{6}{*}{14,37} & \multirow{6}{*}{106,66} \\
\hline & 07.11 .12 & 28 & 0,12 & $1,64^{*}$ & $1,76^{*}$ & $2 / 12$ & $0 / 9$ & & \\
\hline & 14.11 .12 & 35 & 0,15 & $1,62 *$ & $2,06^{*}$ & $2 / 12$ & $0 / 11$ & & \\
\hline & 21.11 .12 & 42 & 0,16 & $1,84^{*}$ & $2,09 *$ & $2 / 13$ & $0 / 12$ & & \\
\hline & 27.11 .12 & 49 & 0,19 & $2,06 *$ & $1,98 *$ & $3 / 13$ & $2 / 12$ & & \\
\hline & 05.12 .12 & 56 & 0,20 & $2,11 *$ & $1,98 *$ & $3 / 13$ & $3 / 13$ & & \\
\hline \multirow{6}{*}{ D2 } & 31.10 .12 & 21 & 0,07 & 1,29 & 1,18 & $0 / 14$ & $0 / 10$ & \multirow{6}{*}{15,87} & \\
\hline & 07.11 .12 & 35 & 0,14 & 1,05 & 1,39 & $0 / 15$ & $0 / 12$ & & \\
\hline & 14.11 .12 & 42 & 0,15 & 1,01 & $1,54^{*}$ & $0 / 15$ & $0 / 13$ & & 10834 \\
\hline & 21.11 .12 & 49 & 0,16 & 1,05 & $1,53^{*}$ & $1 / 15$ & $0 / 13$ & & 108,34 \\
\hline & 27.11 .12 & 56 & 0,17 & 1,07 & $1,58^{*}$ & $1 / 15$ & $0 / 13$ & & \\
\hline & 05.12 .12 & 63 & 0,22 & 0,90 & 1,39 & $1 / 15$ & $0 / 15$ & & \\
\hline & 31.10 .12 & 21 & 0,03 & 0,88 & 0,88 & $0 / 5$ & $0 / 5$ & & \\
\hline D3 & 07.11 .12 & 35 & 0,10 & 0,85 & 0,85 & $0 / 13$ & $0 / 10$ & 8,68 & 90,99 \\
\hline & 14.11 .12 & 42 & 0,11 & 0,80 & 0,80 & $0 / 13$ & $0 / 12$ & & \\
\hline
\end{tabular}




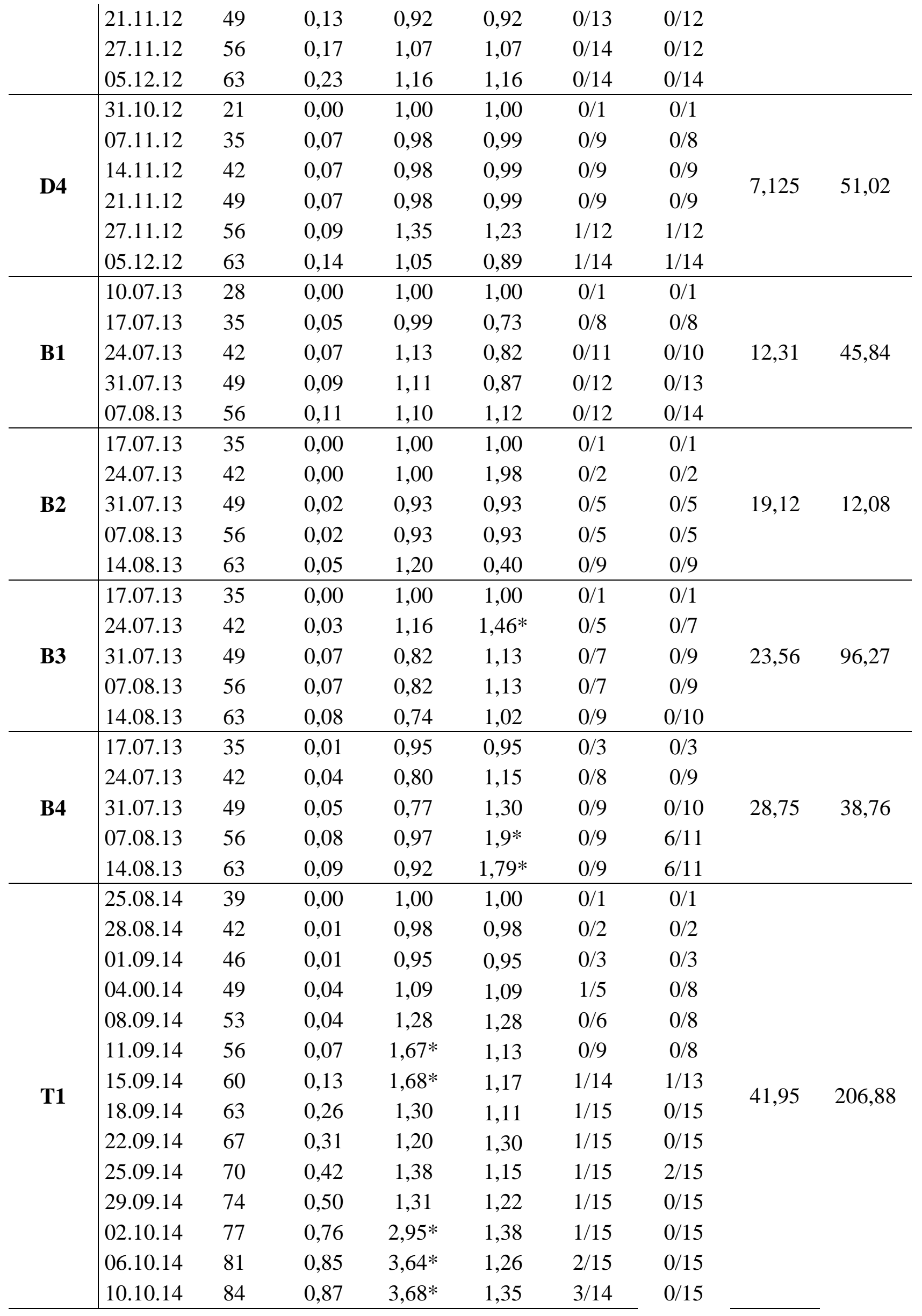




\begin{tabular}{|c|c|c|c|c|c|c|c|c|c|}
\hline \multirow{15}{*}{$\mathbf{T} 2$} & 21.08 .14 & 35 & 0,01 & 0,95 & $1,65^{*}$ & $0 / 3$ & $0 / 3$ & \multirow{15}{*}{45,13} & \multirow{15}{*}{175,13} \\
\hline & 25.08 .14 & 39 & 0,01 & 0,95 & $1,65^{*}$ & $0 / 3$ & $0 / 3$ & & \\
\hline & 28.08 .14 & 42 & 0,02 & 0,93 & $1,45^{*}$ & $0 / 4$ & $0 / 4$ & & \\
\hline & 01.09 .14 & 46 & 0,04 & 0,80 & 1,04 & $0 / 8$ & $0 / 8$ & & \\
\hline & 04.00 .14 & 49 & 0,09 & 1,35 & $1,83 *$ & $0 / 11$ & $0 / 11$ & & \\
\hline & 08.09 .14 & 53 & 0,10 & 1,28 & $1,74 *$ & $0 / 11$ & $0 / 11$ & & \\
\hline & 11.09 .14 & 56 & 0,11 & 1,40 & $1,8 *$ & $0 / 11$ & $0 / 12$ & & \\
\hline & 15.09 .14 & 60 & 0,17 & 1,14 & $1,69 *$ & $2 / 13$ & $0 / 14$ & & \\
\hline & 18.09 .14 & 63 & 0,30 & 1,04 & 1,18 & $3 / 15$ & $0 / 15$ & & \\
\hline & 22.09 .14 & 67 & 0,33 & 1,01 & 0,85 & $2 / 15$ & $0 / 15$ & & \\
\hline & 25.09 .14 & 70 & 0,38 & 0,98 & 0,82 & $1 / 15$ & $0 / 15$ & & \\
\hline & 29.09 .14 & 74 & 0,44 & 0,92 & 0,70 & $0 / 15$ & $0 / 15$ & & \\
\hline & 02.10 .14 & 77 & 0,52 & 0,95 & 0,85 & $0 / 15$ & $0 / 15$ & & \\
\hline & 06.10 .14 & 81 & 0,65 & 1,15 & 0,82 & $0 / 15$ & $0 / 15$ & & \\
\hline & 10.10 .14 & 84 & 0,67 & 1,31 & 0,90 & $0 / 15$ & $1 / 15$ & & \\
\hline \multirow{15}{*}{ T3 } & 21.08 .14 & 35 & 0,02 & 0,93 & 0,98 & $0 / 3$ & $0 / 4$ & \multirow{15}{*}{58,16} & \multirow{15}{*}{218,43} \\
\hline & 25.08 .14 & 39 & 0,03 & 0,85 & 0,88 & $0 / 6$ & $0 / 4$ & & \\
\hline & 28.08 .14 & 42 & 0,04 & 0,83 & 0,85 & $0 / 7$ & $0 / 8$ & & \\
\hline & 01.09 .14 & 46 & 0,04 & 0,83 & 0,85 & $0 / 7$ & $0 / 8$ & & \\
\hline & 04.00 .14 & 49 & 0,71 & 0,78 & 0,93 & $0 / 12$ & $0 / 9$ & & \\
\hline & 08.09 .14 & 53 & 0,08 & 0,74 & 0,88 & $0 / 13$ & $0 / 10$ & & \\
\hline & 11.09 .14 & 56 & 0,09 & 0,84 & 0,84 & $0 / 13$ & $0 / 11$ & & \\
\hline & 15.09 .14 & 60 & 0,13 & 0,80 & 0,71 & $0 / 14$ & $0 / 14$ & & \\
\hline & 18.09 .14 & 63 & 0,28 & 0,93 & $1,62 *$ & $0 / 15$ & $0 / 15$ & & \\
\hline & 22.09 .14 & 67 & 0,35 & 0,81 & 0,81 & $0 / 15$ & $0 / 15$ & & \\
\hline & 25.09 .14 & 70 & 0,40 & 0,95 & 0,86 & $1 / 15$ & $0 / 15$ & & \\
\hline & 29.09 .14 & 74 & 0,47 & 1,04 & 0,80 & $1 / 15$ & $0 / 15$ & & \\
\hline & 02.10 .14 & 77 & 0,65 & 1,14 & 0,56 & $1 / 15$ & $0 / 15$ & & \\
\hline & 06.10 .14 & 81 & 0,72 & 1,17 & 0,75 & $1 / 15$ & $1 / 15$ & & \\
\hline & 10.10 .14 & 84 & 0,75 & 1,23 & 0,91 & $1 / 15$ & $1 / 15$ & & \\
\hline \multirow{12}{*}{ T4 } & 21.08 .14 & 35 & 0,01 & 0,98 & 0,98 & $0 / 2$ & $0 / 1$ & \multirow{12}{*}{34,01} & \multirow{12}{*}{155,53} \\
\hline & 25.08 .14 & 39 & 0,01 & 0,98 & 0,98 & $0 / 2$ & $0 / 1$ & & \\
\hline & 28.08 .14 & 42 & 0,01 & 0,98 & 0,98 & $0 / 2$ & $1 / 1$ & & \\
\hline & 01.09 .14 & 46 & 0,02 & $1,45^{*}$ & 1,45 & $0 / 4$ & $0 / 2$ & & \\
\hline & 04.00 .14 & 49 & 0,05 & $1,53 *$ & $1,53^{*}$ & $0 / 8$ & $0 / 6$ & & \\
\hline & 08.09 .14 & 53 & 0,06 & $1,45^{*}$ & $1,99 *$ & $0 / 8$ & $0 / 7$ & & \\
\hline & 11.09 .14 & 56 & 0,07 & $1,45^{*}$ & $2,04 *$ & $0 / 9$ & $0 / 8$ & & \\
\hline & 15.09 .14 & 60 & 0,10 & 1,26 & $1,47 *$ & $0 / 11$ & $0 / 10$ & & \\
\hline & 18.09 .14 & 63 & 0,22 & 1,08 & 1,21 & $0 / 14$ & $0 / 15$ & & \\
\hline & 22.09 .14 & 67 & 0,27 & 0,96 & 1,37 & $0 / 14$ & $0 / 15$ & & \\
\hline & 25.09 .14 & 70 & 0,35 & 1,23 & $1,63^{*}$ & $1 / 15$ & $1 / 15$ & & \\
\hline & 29.09 .14 & 74 & 0,37 & 1,18 & $1,71^{*}$ & $1 / 15$ & $1 / 15$ & & \\
\hline
\end{tabular}




\begin{tabular}{|lllllll}
02.10 .14 & 77 & 0,54 & 0,88 & 1,21 & $0 / 15$ & $0 / 15$ \\
06.10 .14 & 81 & 0,66 & 0,59 & 1,12 & $0 / 15$ & $0 / 15$ \\
10.10 .14 & 84 & 0,75 & 0,64 & 0,95 & $0 / 15$ & $0 / 15$
\end{tabular}

G: Goianápolis, D: DAIA, B: Boa Esperança, T: Taquara. DAT: Dias após o transplantio, INC: incidência da doença, D: índice de dispersão, MB: média da população de mosca-branca coletada em cada parcela até duas semanas antes do final das avaliações, AACPD: área abaixo da curva de progresso da doença por parcela; * (*) valores significativamente maiores do que 1 pelo teste do qui-quadrado $(\mathrm{p}<0,05)$.

\section{Índice de dispersão (D)}

Os valores do índice de dispersão (D) variaram de acordo com a parcela e com o quadrat para ambas as viroses (Tabela 3 e 4). A maioria das avaliações tanto para begomovirose quanto para crinivirose utilizando ambos os quadrats apresentaram valores de D estatisticamente menores que $1(\mathrm{p}>0,05)$, indicando maior tendência à aleatoriedade da distribuição das plantas sintomáticas dentro da parcela. Foi verificado um maior número de avaliações com valores de D superiores a 1 para crinivirus para ambos os quadrats, sugerindo que plantas com sintomas de crinivirus possuem maior tendência a estarem em agregação do que plantas com sintomas de begomovirus.

\section{Aplicação da Lei de Taylor modificada}

A agregação de plantas infectadas com begomovirus e crinivirus foi também analisada utilizando a significância da relação entre o $\log \left(\mathrm{V}_{\mathrm{obs}}\right)$ e $\log \left(\mathrm{V}_{\mathrm{bin}}\right)$ que indicou agregação das plantas sintomáticas para begomovirus e crinivirus apenas quando foi utilizado o quadrat $2 \times 3$. Os valores de $b$ e A para begomovirus e crinivirus foram respectivamente igual a 1,06 e 0,15 $\left(R^{2}=0,99\right)$ e 1,05 e $0,14\left(R^{2}=0,94\right)$ para o quadrat $2 \times 3$ e de 1,04 e $0,06\left(R^{2}=0,88\right)$ e 1,02 e $0,09\left(R^{2}=0,95\right)$ para o quadrat $3 \times 2($ Figura 4$)$. 


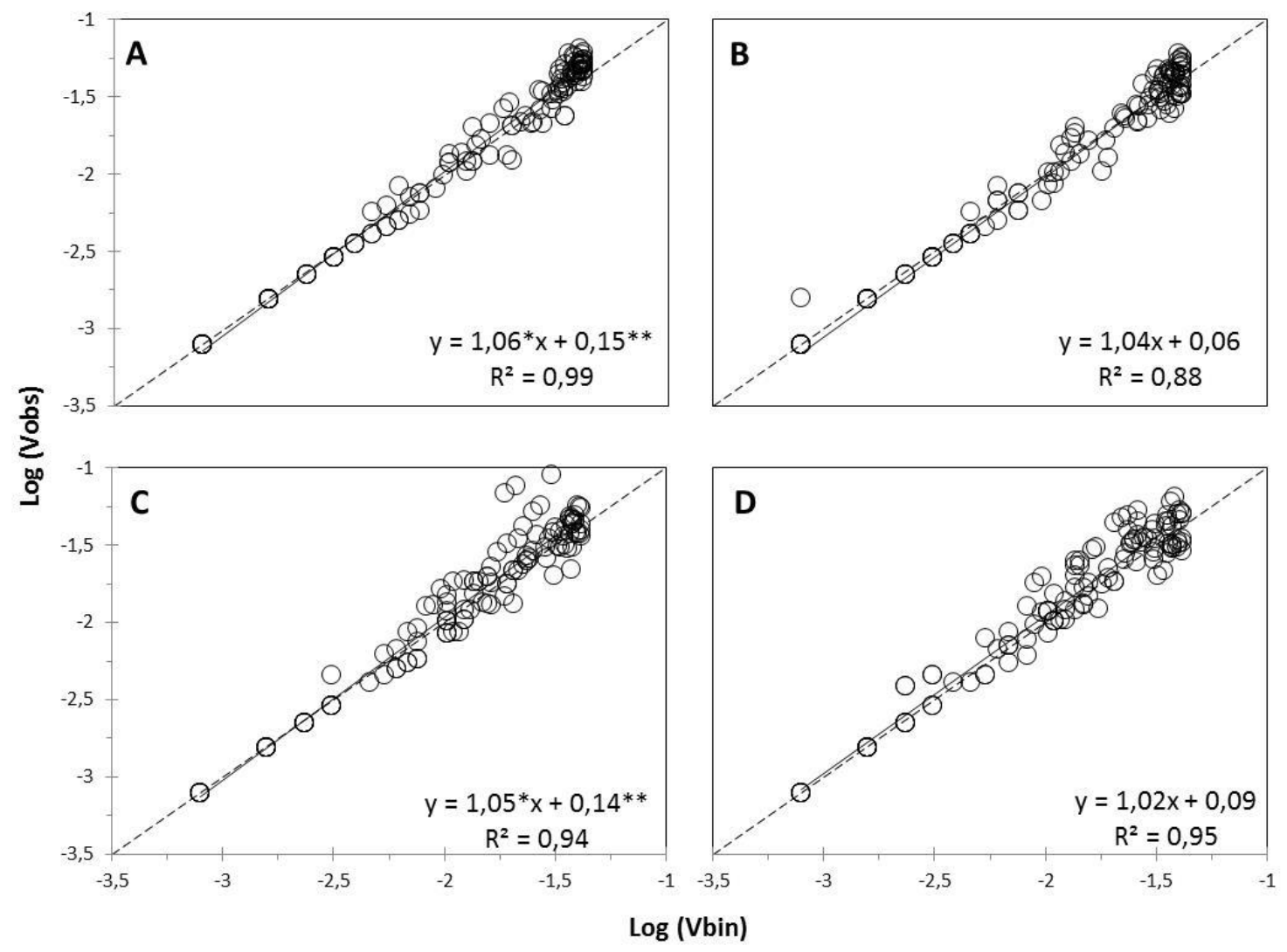

Figura 4: Relação entre o logaritmo da variância observada [log (Vobs)] e o logaritmo da variância binomial $\left[\log \left(\mathrm{V}_{\text {bin }}\right)\right]$ de begomovirus (A e B) e crinivirus (C e D) em áreas de produção comercial de tomate localizados nas regiões de Goianápolis, DAIA, Boa Esperança e Taquara. (A) Begomovirus e (C) crinivirus utilizando quadrat 2x3, (B) begmovirus e (D) crinivirus utilizando quadrat $3 \times 2$. *Valores estatisticamente diferentes de 1 e ** valores estatisticamente diferentes de $0(\mathrm{P}<0,05)$.

\section{Análise de dinâmica de focos da doença (ADFD)}

O padrão das curvas do número de focos para begomovirose e crinivirose foi semelhante, diferindo basicamente apenas os valores brutos (Figuras 5A, 5B). O pico do número de focos foi alto para ambas as viroses, respectivamente, begomovirus (19) e crinivirus (21) (Figura 5A e 5B). O pico do número total de focos para ambas as viroses foi observado em situações de incidência similar (Figura 5A e 5B). A coalescência dos focos foi 
observada a partir da ocorrência do pico do número de focos, que levou a crescente redução dos mesmos. Os valores de $\mathrm{R}^{2}$ e a amplitude dos resíduos obtidos no ajuste do gráfico de número de focos pela incidência da doença mostrou que os dados referentes à epidemia de crinivirus e begomovirus se ajustaram similarmente a função Beta Generalizada. Os valores de $\mathrm{R}^{2}$ e a amplitude dos resíduos de begomovirus e crinivirus foram respectivamente iguais a $(0,90$ e 0,95$)$ e $(18$ e 14$)$.
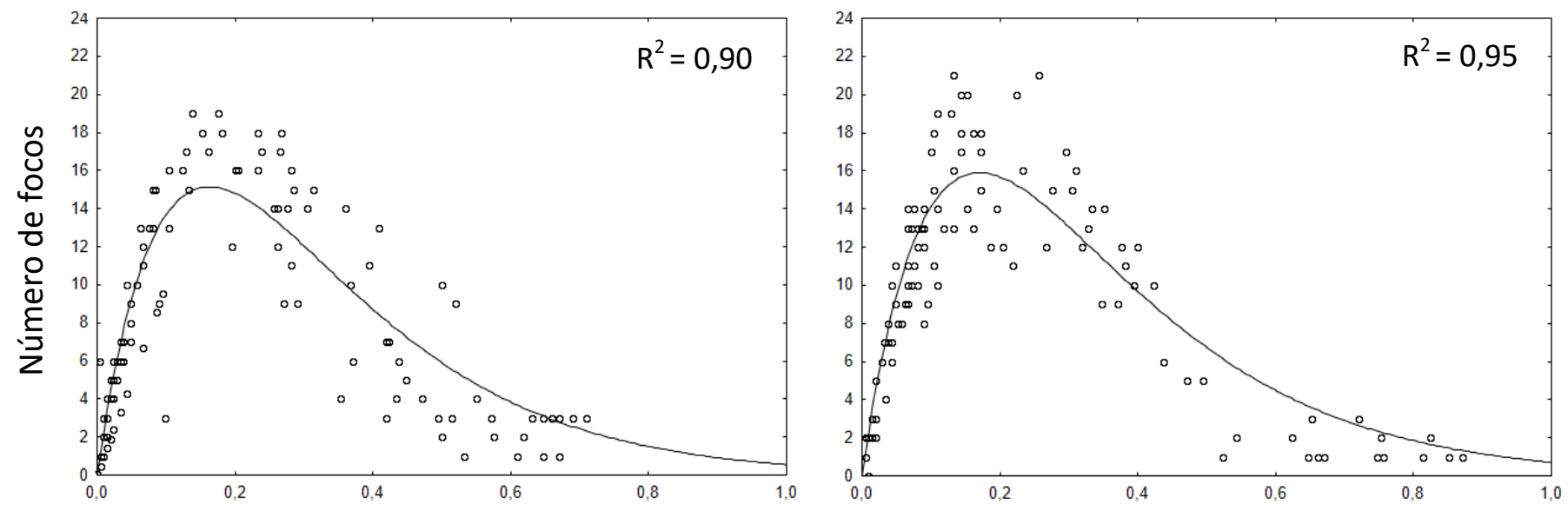

Incidência

Figura 5: Evolução de begomovirose e crinivirose em função da incidência, do número de focos por 225 plantas (A) para begomovirus, (B) para crinivirus para os dados de todas as parcelas avaliadas das regiões de Goianápolis, DAIA, Boa Esperança e Taquara. Linha continua indica o ajuste dos pontos à função Beta generalizada. 


\section{Associação entre begomovirose e crinivirose}

Uma baixa associação entre begomovirose e crinivirose foi observada na maioria das parcelas. As parcelas localizadas nas regiões de DAIA e Boa Esperança apresentaram valores de associação muito baixos, respectivamente em intervalos iguais a 0,06 - 0,08 e 0 - 0,04. Na região de Goianápolis o índice de associação entre as viroses foi intermediário, entre 0,14 a 0,43. Taquara foi a região com maior índice de associação, apresentando intervalo igual a 0,52 a 0,59 .

\section{Monitoramento de mosca-branca}

Mesmo com elevada frequência de pulverizações com inseticidas, insetos adultos de mosca-branca foram observados e capturados em armadilhas adesivas em todas as avaliações em todas as parcelas. Alta variação na quantidade de adultos de B. tabaci coletados semanalmente foi observada em todas as regiões avaliadas. A região com maior média de adultos de mosca-branca por parcela foi Taquara $(34-58,2)$, seguido de Boa Esperança $(12,3$ - 28,8), DAIA $(7,1$ - 15,9) e Goianápolis $(8,18$ - 11,0) (Tabelas 3 e 4). Uma tendência de crescimento do número médio de indivíduos coletados ao longo do período (Figura 3) foi verificada, embora não tenha sido observado um pico populacional constante entre as parcelas. Não foi verificada correlação positiva entre a incidência de virose e a população de mosca-branca presente no campo. 


\section{Discussão}

Begomovirose e tospovirose sempre preocuparam os tomaticultores brasileiros. Embora a tospovirose apresente maior severidade de sintomas, perdas provocadas por begomovirose são maiores devido à alta incidência dessa doença desde a introdução do biótipo B de B. tabaci (França et al., 1996). A alta incidência de begomovirose vem impossibilitando o uso de cultivares suscetíveis de tomateiro para consumo in natura (estaqueado) nas principais regiões produtoras. Atualmente, mesmo com o uso de cultivares moderadamente resistentes a begomovirus, surtos de begomovirose em cultivo de tomate estaqueado ainda são frequentemente observados (Macedo et al., 2014). A crinivirose detectada no País a partir de 2006 (Barbosa et al., 2008) vem ganhando importância, em termos de disseminação e incidência em regiões produtoras importantes (Barbosa et al., 2011; Macedo et al., 2014). Hoje, a begomovirose e a crinivirose são as doenças de origem viral com maior incidência na produção de tomate no Brasil.

A produção de tomate para consumo in natura é comumente realizada em pequenas áreas de produção por agricultores com baixo a moderado nível de tecnificação. Em geral, as áreas de produção de tomateiro estaqueado para processamento são localizadas relativamente longe das áreas de produção de tomate rasteiro. Duas das regiões avaliadas são tradicionalmente produtoras de tomate para consumo in natura, Goianápolis (GO) e Taquara (DF). Já as regiões de Boa Esperança (DF) e DAIA (DF) são áreas de produção que iniciaram o cultivo mais recentemente. Nas quatro regiões avaliadas a ocorrência de begomovirose e crinivirose em tomateiro é constante. Assim, em todas as parcelas experimentais foi verificada a presença de ambas as viroses. A escolha das regiões estudadas foi fundamental para o estudo epidemiológico simultâneo de begomovirose e crinivirose.

Apenas uma espécie de begomovirus e uma de crinivirus foram detectadas nas amostras coletadas, respectivamente Tomato severe rugose virus e Tomato chorosis virus. 
Estudos apontam essas espécies como sendo as predominantes em tomateiro também em outras regiões do Brasil (Ribeiro et al., 2003, Fernandes et al., 2008, Barbosa et al., 2011, Macedo et al., 2014). A presença de ToSRV e ToCV foram examinadas em amostras de diversas espécies de plantas voluntárias presentes dentro e nas proximidades das áreas de cultivo. Apenas em cinco espécies de plantas foi detectada a presença de pelo menos uma das espécies virais predominantes em tomateiro. Amostras de plantas das espécies Amaranthus viridis, Solanum americanum e Commelina benghalensis foram coletadas e avaliadas como positivas para ToCV e Nicandra physaloides e Sida spp. positivas para ambas as espécies. Resultados similares foram obtidos em estudos realizados por Barbosa et al. (2009) confirmando a susceptibilidade de $N$. physaloides à ToSRV e por Barreto et al. (2013) que demonstraram que as espécies Crotalaria spp., Euphorbia heterophylla, N. physaloides e Sida spp. são também hospedeiras de ToSRV e podem ser potenciais fontes de inóculo para o tomateiro. Para crinivirus apenas a espécie S. americanum já foi relatada como potencial fonte de inóculo de crinivirus (Eui-Joon et al., 2015). Com relação às espécies A. viridis e $C$. benghalensis, testes adicionais de transmissão precisam ser realizados para confirmação dessas espécies como hospedeiras desse vírus. Todas as espécies de plantas daninhas hospedeiras de begomovirus e crinivirus encontradas neste estudo são frequentemente encontradas nas regiões produtoras de tomateiro no Brasil e podem representar um importante reservatório de inóculo destas viroses em campo. Por outro lado, apesar destas espécies ocorrerem normalmente em alta população em campo, apenas uma pequena porção de plantas infectadas dessas espécies foram observadas. Esses resultados sugerem que a principal fonte de inóculo para ambas as viroses, especialmente em parcelas com elevada incidência de doença, parece não ser as plantas daninhas presentes dentro e ao redor das áreas de cultivo, como também sugerido no capítulo anterior. 
No presente estudo, altas taxas de incidência de begomovirus e crinivirus foram observadas entre os anos de 2012 e 2014, nas regiões de Goianápolis (GO) e Taquara (DF). Entretanto, nas outras duas regiões estudadas, DAIA (GO) e Boa Esperança, a incidência de ambas as viroses foi relativamente baixa. As diferenças de incidência observadas entre as regiões estudadas devem-se provavelmente a alguns fatores como histórico da área de produção, época de plantio, população de mosca-branca, diferenças na quantidade e qualidade de fonte de inóculo, além de peculiaridades no manejo da cultura. Esses dados levam a dois importantes questionamentos: a incidência de begomovirus e crinivirus é alta por que há outros cultivos de tomateiro na região e o tomateiro infectado é a principal fonte de vírus aos cultivos vizinhos? ou por que o longo período de cultivo de tomateiro na região possibilitou o estabelecimento dos vírus (ambos) em plantas daninhas ou silvestres (ou em eventuais plantas voluntárias de tomateiro) presentes na região que sobrevivem durante o período sem o tomateiro? Ainda não é possível responder a essas perguntas e trabalhos específicos necessitam ser realizados.

Altas incidências e AACPD foram observadas para crinivirus em todas as parcelas, sendo sempre maiores que as apresentadas para begomovirus. Diversos fatores podem ter levado a este cenário: as cultivares presentes na área estudada eram moderadamente resistentes apenas a begomovirus, diferença na eficiência de transmissão desses vírus por mosca-branca, diferenças na fonte de inóculo e distinta inter-relação vírus-vetor. Estudos anteriores mostram que a eficiência de transmissão de ToSRV para tomateiro por B. tabaci biótipo B é de aproximadamente $70 \%$ utilizando três insetos vetores por planta (Macedo et al., 2015). Por outro lado, a eficiência de transmissão média de ToCV utilizando a mesma quantidade de insetos por planta de tomate foi aproximadamente 40\% (Dalmo et al., 2009). Portanto, aparentemente ToSRV possui maior eficiência de transmissão que ToCV o que sugere que a maior incidência de crinivirus nas plantas das parcelas avaliadas não se deve à 
diferença na eficiência de transmissão destes vírus pela mosca-branca. Acredita-se que o uso de plantas com moderada resistência a ToSRV e a possível presença mais abundante de fonte de inóculo de crinivirus sejam os fatores principais da alta ocorrência desse vírus.

A incidência de ambas as viroses com valores similares nas parcelas analisadas sugere ainda que as moscas-brancas que chegaram ao cultivo-alvo provavelmente se alimentaram em plantas infectadas com ambos os vírus. Vale a pena destacar que na região de maior incidência avaliada, Taquara, havia, ao lado das parcelas experimentais, uma área de tomateiro em fase final de produção, com incidência de begomovirose e crinivirose acima de 90\% e com relativamente alta quantidade de moscas-brancas. Esses dados sugerem que a principal fonte de inóculo para as plantas nas parcelas experimentais em Taquara foram provenientes dessa área. Nas demais áreas não foram observados cultivos próximos que pudessem servir como principal fonte de inóculo para as parcelas experimentais. Esse fato indica que o plantio consecutivo com grande diferença entre a idade de plantas entre os cultivos deve ser evitado para que cultivos anteriores não sirvam como fonte de inóculo para novos cultivos.

Em geral, sintomas característicos de begomovirose foram observados primeiramente, provavelmente devido ao maior período de incubação de crinivirus em plantas de tomate (Tzanetakis et al., 2013). As curvas de progresso de begomovirus e crinivirus obtidas neste trabalho apresentaram formas similares e são aproximadamente paralelas, embora a curva de crinivirose esteja um pouco defasada no tempo em relação à begomovirose, mais uma vez devido principalmente ao maior período de incubação de crinivirus. Mesmo em parcelas com maiores números de avaliações, não foi possível um ajuste adequado de modelos epidemiológicos às curvas de progresso obtidas nesse trabalho. A dificuldade de ajuste devese principalmente à presença de ondas de incidência de doença nas curvas de progresso para ambas as viroses. Resultados similares de ausência de ajuste foram obtidos com as curvas de 
progresso de begomovirose em tomateiro rasteiro (capítulo anterior) e com as curvas de progresso de Cucumber yellow stunting disorder virus (CYSDV), espécie de crinivirus, em cultivo de melancia na Flórida (EUA) (Turechek et al., 2014). Em outro estudo de análise temporal realizado com o crinivirus CYSDV em cultivo de pepino em Almeria (Espanha), as curvas de progresso ajustaram-se adequadamente ao modelo Gompertz (Ruiz et al., 2006). Até o momento, devido ao número reduzido de estudos de análise temporal de doenças causadas por espécies do gênero Crinivirus, não existe um consenso sobre o modelo que melhor se ajuste a epidemias causadas por esse vírus. Por outro lado, o modelo monomolecular tem sido predominantemente o modelo com melhor ajuste para curvas de progresso de begomovirus em tomateiro (Ioannou \& Iordanou 1985; Suwwam et al., 1988; Polston et al., 1996, Della Vecchia et al., 2007, Schuster et al., 2011; Barbosa et al., 2016). Ondas de incidência foram observadas em todas as curvas de progresso do presente trabalho, algumas de forma clara (Figura 3N e 3P - crinivirus) e outras com ondas mais suaves (Figura 3I e 3L - crinivirus). Ondas de incidência similares foram observadas em um estudo temporal de begomovirose em áreas comerciais de tomateiro em Sumaré-SP (Barbosa et al., 2016). Essas ondas de incidência podem ser resultantes de influxos de insetos vetores em determinados períodos nas áreas de cultivo. Pode-se relacionar a presença de ondas de incidência com doenças cujo componente primário de disseminação é contínuo (Bergamin Filho et al., 2016). Portanto, esses dados indicam que begomoviroses e criniviroses possuem disseminação primária continua, como também sugerido em begomovirose em tomateiro rasteiro no capítulo anterior.

Neste estudo, provavelmente devido ao uso de cultivares moderadamente resistentes a begomovirus, a incidência de crinivirus foi maior em todas as parcelas avaliadas, no entanto alta taxa de incidência de begomovirose foi observada em algumas parcelas. Isso sugere que apenas o uso de cultivares moderadamente resistentes aliado ao intenso controle químico do 
inseto vetor não são suficientes para o controle das begomoviroses em tomateiro estaqueado. Outro importante ponto observado foi a ocorrência de uma baixa taxa de infecção mista na maioria das parcelas. Quando essas estavam presentes não foram observadas sinergismos de sintomas evidentes entre as viroses. A baixa taxa de infecção mista também pode sugerir que as fontes de inóculo dos vírus são distintas.

Em geral, a distribuição de plantas sintomáticas tanto para begomovirus como para crinivirus foi ao acaso. A análise da Lei de Taylor modificada foi o único método que detectou uma leve agregação das plantas sintomáticas. Uma porcentagem muito pequena de linhas e entrelinhas significativamente agregadas foi observada pela análise de sequências ordinárias. $\mathrm{O}$ índice de dispersão também apresentou pequena porcentagem de mapas com indicativo de agregação de plantas sintomáticas. Observação semelhante foi realizada em outros estudos de begomovirose em tomateiro (Polston et al., 1996, Barbosa et al., 2016) e em crinivirose em melancia (Turechek et al., 2014) e em pepino (Ruiz et al., 2006).

Outra análise espacial realizada, a análise da dinâmica de focos foi informativa e evidenciou um grande número de focos tanto para begomovirose quanto para crinivirose, indicando que as plantas sintomáticas estavam distribuídas mais aleatoriamente na parcela experimental. Ao comparar esses dados de dinâmica de focos com os dados do capítulo anterior, verifica-se que os picos de focos tanto para begomovirose quanto para crinivirose são similares com aqueles observados nas parcelas localizadas na borda do cultivo (onde a distribuição das plantas sintomáticas foi mais ao acaso que em parcelas localizadas no centro do pivô). Um melhor ajuste dos dados de focos de doença pela incidência à função beta generalizada indica que a doença possui menor número de modos de disseminação da doença, como verificado para Clorose Variegada dos Citrus, que possui apenas um mecanismo (Laranjeira et al., 2004). Já um ajuste inadequado está relacionado a doenças que possuem mais de um mecanismo de disseminação como foi relatado para Cancro Cítrico, que possui 
pelo menos três mecanismos (Gottwald et al., 2007). A função de distribuição beta generalizada teve um bom ajuste para os dados do número de focos pela incidência tanto para begomovirus quanto para crinivirus, apresentando valor de amplitude residual semelhante ao obtido com begomovirose nas parcelas localizadas na borda do pivô no capítulo anterior, no entanto obtendo um pior ajuste ao observado para parcelas centrais. Esses dados sugerem que o peso dos três mecanismos de disseminação que atuam nos patossistemas begomovirose e crinivirose em tomateiro estaqueado e begomovirose em parcelas na borda do cultivo em tomateiro rasteiro foi similar, mas diferem levemente do peso atribuído aos componentes de disseminação em parcelas localizadas longe da borda do cultivo. Um melhor ajuste dos dados à função Beta Generalizada indica que a doença é governada por um menor número de mecanismos de propagação, como verificado para Clorose Variegada dos Citros, que tem apenas um mecanismo (Laranjeira et al., 2004). Por outro lado, um mau ajuste para este modelo sugere que a doença está associada a mais mecanismos de propagação, como foi observado, em Cancro Cítrico, o qual tem pelo menos três mecanismos (Gottwald et al., 2007). Esses dados indicam mais uma vez que o componente primário age em conjunto com o secundário e o "falso secundário" em parcelas localizadas na borda, enquanto o componente primário de disseminação é menos relevante para a disseminação da doença em áreas localizadas no centro do cultivo.

Os valores obtidos com a análise das sequências ordinárias, índice de dispersão, lei de Taylor e dinâmicas de focos se assemelham muito aos valores obtidos com o estudo de begomovirose em parcelas localizadas na borda do pivô obtidos no capitulo anterior. A distribuição de plantas sintomáticas nas parcelas da borda no capítulo anterior apresentaram um padrão espacial levemente mais agregada que em parcelas de tomateiro estaqueado. Esse fato provavelmente deve-se à existência de diferenças no tipo de espaçamento e no porte da planta entre os dois tipos de cultivo. No cultivo do tomateiro estaqueado, a distância entre 
plantas e linhas permanece mais ou menos constante durante todo o cultivo, no entanto, cultivos para tomateiro rasteiro, o espaçamento dentro e entre linhas vai diminuindo progressivamente com a idade do cultivo, consequentemente aproximando plantas infectadas das plantas sadias, o que possivelmente facilita a disseminação do vírus e agregação das plantas infectadas.

O progresso espacial e temporal dessas duas doenças foi bastante similar, o que não era esperado, uma vez que mesmo as duas espécies virais sendo transmitidas pelo mesmo inseto vector, a inter-relação vector-vírus é distinta. A ausência de período de latência na transmissão de crinivirus pelo vetor poderia levar a uma maior agregação de plantas sintomáticas de crinivirus, uma vez que ao adquirir o vírus o vetor está imediatamente apto a inocular o vírus em plantas sadias (Wisler \& Duffus, 2001). Além disso, a mosca-branca virulífera deixa de ter a capacidade de transmitir o vírus após certo período (1-3 dias) de alimentação em plantas sadias (Wintermantel \& Wisler, 2006). Para begomovirus, o inseto ao se alimentar em uma planta infectada precisa ainda de um período de aproximadamente $16 \mathrm{~h}$ para que o vetor esteja apto a inocular plantas sadias. A compreensão de todos esses processos é complexa, principalmente levando-se em conta o comportamento alimentar do inseto em diferentes condições de cultivo. Por exemplo, pulverizações constantes na área de cultivo podem ocasionar mudanças relevantes na seleção das plantas e alimentação dos insetos, influenciando de forma significativa a eficiência de transmissão de cada vírus.

No presente estudo não foi possível comparar o padrão espacial e temporal de begomovirose e crinivirose em parcelas centrais e localizadas dentro da área de cultivo. No entanto, os resultados obtidos corroboram com os encontrados para begomovirose em tomateiro rasteiro em parcelas localizadas na borda do pivô (capítulo anterior). Mais uma vez o componente primário de disseminação parece ser o principal no desenvolvimento das epidemias, uma vez que, como sugerido no capítulo anterior, altos níveis de aleatoriedade de 
distribuição de plantas sintomáticas em campo estão associados a forte influência do componente primário.

A associação entre a begomovirose e a crinivirose foi baixa. Somente em quatro das 16 parcelas avaliadas essa associação foi relativamente alta, de acordo com o índice de Jaccard. Resultados similares, de baixa associação entre vírus transmitidos por mosca-branca, foram obtidos entre o ipomovírus Cucumber vein yellow virus e o crinivirus, CYDSV, em cultivo de pepino em Almeria, na Espanha (Ruiz et al., 2006) e entre um begomovirus (Curcubit leaf crumple virus) e outro ipomovirus (Squash vein yellow virus) em cultivo de melancia na Flórida, EUA (Turechek et al., 2014). As doenças apresentaram alta associação apenas nas parcelas localizadas em Taquara, o que mais uma vez fortalece a ideia de que a fonte de inóculo dos vírus em Taquara realmente era o cultivo de tomate em fase final de produção mantido próximo às parcelas experimentais.

A média da população de mosca-branca foi relativamente constante entre parcelas de uma mesma região, mas grande variação na quantidade de indivíduos adultos foi observada entre as regiões avaliadas. Nenhuma correlação positiva entre a quantidade de mosca-branca presente na área e a incidência de begomovirose ou crinivirose foi observada. Parcelas com baixa população de mosca-branca atingiram alta incidência, como observado nas parcelas localizadas em Goianápolis. Resultados similares foram obtidos em estudo de begomovirose em tomateiro rasteiro (capítulo anterior) e begomovirose em tomateiro de mesa em SumaréSP (Barbosa et al., 2016) e na Flórida (EUA) (Polston et al., 1996).

As informações obtidas nesse estudo são importantes para a melhor compreensão da epidemiologia de begomovirose e crinivirose em tomateiro para consumo in natura. Até o momento, não existem trabalhos publicados que mostrem o progresso temporal e espacial de crinivirose em tomateiro. Alguns trabalhos estudaram a dinâmica da distribuição de 
begomovirose em tomateiro. No caso dos estudos realizados no Brasil (Della Vecchia et al., 2007, Barbosa et al., 2016), a baixa incidência da doença compromete em parte as conclusões epidemiológicas. Nesse trabalho, foi possível realizar o estudo simultâneo das duas principais viroses que ocorrem em tomateiro no País. Conclui-se que a dinâmica epidemiológica de crinivirose e begomovirose em tomateiro estaqueado e de begomovirose em tomateiro rasteiro (capítulo anterior) são similares. Embora a epidemia dessas viroses seja resultado de três mecanismos de disseminação distintos (descritos no capítulo anterior), o componente primário de infecção parece ser crucial no desenvolvimento dessas epidemias. A chave do manejo de begomovirose e crinivirose em tomateiro parece ser a prevenção da chegada de insetos virulíferos na área de cultivo. Tentativas de controle dos insetos vetores apenas no cultivo alvo são pouco eficazes no controle dessas viroses. Um manejo regional e integrado não só para a cultura do tomateiro, mas para culturas que possam servir de hospedeiras alternativas dos vírus e/ou do inseto vetor das viroses é essencial (Bergamin Filho et al., 2016). Todas as demais recomendações sugeridas no capitulo anterior para begomoviroses em tomateiro rasteiro são adequadas e podem ser sugeridas para o controle de begomovirose e crinivirose em tomateiro estaqueado. 


\section{Conclusões}

A incidência de begomovirose e crinivirose variou com a área de produção avaliada;

A incidência de crinivirose foi maior em todas as parcelas experimentais avaliadas;

A diversidade de espécies de begomovirus e crinivirus é baixa nas áreas de produção de tomateiro estudadas;

$>$ A incidência de ToCV e ToSRV em plantas daninhas presentes nas regiões produtoras estudadas é baixa;

As curvas de progresso de begomovirose e crinivirose foram similares embora a observação da crinivirose tenha sido um pouco defasada no tempo devido provavelmente ao maior período de incubação desse vírus;

$>$ O padrão espacial de plantas infectadas com begomovirus e crinivirus é levemente agregado e essa agregação é observada em clusters e não necessariamente em plantas adjacentes;

A fonte de inóculo das parcelas experimentais provavelmente não foram plantas daninhas presentes nos arredores das áreas de produção;

A disseminação primária é a principal responsável pelas epidemias de begomovirose e crinivirose em tomateiro estaqueado;

$>\mathrm{O}$ manejo de begomovirose e crinivirose deve ser realizado de forma integrada e regional para a eficiência do controle dessas viroses; 


\section{Referências Bibliográficas}

BARBOSA, J. C.; BARRETO, S.S.; INOUE-NAGATA, A.K.; REIS, M.S.; FIRMINO, A. C; BERGAMIN FILHO, A. \& REZENDE, J. A. M. 2009. Natural infection of Nicandra physaloides by Tomato severe rugose virus in Brazil. Journal of General Plant Pathology 75: 440-443.

BARBOSA, J. C.; COSTA, H.; GIORIA, R. \& REZENDE, J. A. M. 2011.Occurrence of Tomato chlorosis virus in tomato crops in five brazilian states. TROPICAL PLANT PATHOLOGY 36(4): 256-258.

BARBOSA, J. C.; REZENDE, J. A. M.; AMORIM, L. \& BERGAMIN FILHO, A. 2016. Temporal Dynamics of Tomato severe rugose virus and Bemisia tabaci in Tomato Fields in São Paulo, Brazil. Journal of Phytopathology 164: 1-10.

BARbOSA, J. C.; TEIXEIRA, A. P. M.; MOREIRA, A. G.; CAMARGO, L. E. A.; BERGAMIN FILHO, A.; KITAJIMA, E. W. \& REZENDE, J. A. M. 2008. First report of Tomato chlorosis virus infecting tomato crops in Brazil. Plant Disease 92: 1709.

BARRETO, S. S; HALLWASS, M.; AQUINO, O. M. \& INOUE-NAGATA, A. K. 2013. A study of weeds as potential inoculum sources for a tomato-infecting begomovirus in central Brazil. Phytopathology 103: 436-444.

BERGAMIN FILHO, A.; INOUE-NAGATA, A. K.; BASSANEZI, R. B.; BELASQUE JR, J.; AMORIM, L.; MACEDO, M. A.; BARBOSA, J.C.; WILLOCQUET, L. \& SAVARY, S. 2016. The importance of primary inoculum and area-wide disease management to crop health and food security. Food security 8: 1-18.

BROWN, J. K.; ZERBINI， F. M; NAVAS-CASTILLO, J.; MORIONES, E.; RAMOSSOBRINHO, R.; SILVA, J. C.; FIALLO-OLIVÉ, E.; BRIDDON, R. W.; HERNÁNDEZZEPEDA, C.; IDRIS, A.; MALATHI, V. G.; MARTIN, D. P.; RIVERA-BUSTAMANTE, R.; UEDA, S.; VARSANI, A. 2015. Revision of Begomovirus taxonomy based on pairwise sequence comparisons.Archives of Virology160(6):1593-619.

CAMPBELL, C. L. \& MADDEN, L. V. 1990. Introduction to plant disease 1 epidemiology.NEW YORK, NY, USA, JOHN WILEY AND SONS.

DALMO, A.; FABRE, F.; GUILBAUD, L.; LECOQ, H. \& JACQUEMOND, M. 2009 comparative whitefly transmission of Tomato chlorosis virus and Tomato infectious chlorosis virus from single or mixed infections. Plant Pathology, 58 (2): 221-227.

DELlA VECCHIA, M. G. S.; ROSA, D. D.; BERGAMIN FILHO, A.; AMORIM, L.; REZENDE, J. A. M. \& RIBEIRO, A. 2007. Dinâmica temporal e espacial da begomovirose 
causada por Tomato yellow vein streak virus em tomateiro na região de Campinas-SP. Summa Phytopathol 33: 388-395.

DOVAS, C. I.; KATIAS, N. I. \& AVGELIS, A. D. 2002. Multiplex detection of criniviruses associated with epidemics of yellowing disease of tomato in greece. PLANT DISEASE 86: 1345-1349.

DOYLE, J. J. \& DOYLE, J. 1990. Isolation of plant DNA from fresh tissue. Focus 12: 13-15. EUI-JOON， KIL.; YE-JI， L.; SEUNGCHAN， C.; CHUNG-KYOON， A.; DONGGIUN, KIM.; KYEONG-YEOLL， L.; MI-KYEONG， K.; HONG-SOO， C.; ,CHANG-SEOK， K. \& SUKCHAN, L. 2015. Identification of natural weed hosts of Tomato chlorosis virus in Korea by RT-PCR with root tissues. European journal of plant pathology 142 (2): 419-426.

FERNANDES, F. R.; ALBUQUERQUE, L. C. \& INOUE-NAGATA, A. K. 2010. Development of a species-specific detection method for three Brazilian tomato begomoviruses. Tropical Plant Pathology 35:43-47.

FERNANDES, F. R.; ALBUQUERQUE, L. C.; BRITTO GIORDANO, L.; BOITEUX, L. S. \& AVILA, A. C. 2008. Diversity and prevalence of Brazilian bipartite begomovirus species associated to tomatoes. Virus Genes 36: 251-258.

FRANÇA, F. H.; BOAS, G. L. V. \& BRANCO, M. C. 1996. Ocorrência de Bemisia argentifolii bellows \& perring (homoptera: aleyrodidae) no distrito federal. ANAIS DA SOCIEDADE ENTOMOLOGICA DO BRASIL 25: 369-372.

GHANIM, M.; MORIN, S.; ZEIDAN, M. \& CZOSNEK, H. 1998. evidence for transovarial transmission of Tomato yellow leaf curl virus by its vector, the whitefly Bemisia tabaci.VIROLOGY 240: 295-303.

GONZALES-AGUILERA, J.; TAVARES, S. S.; SOBRINHO, R. R.; XAVIER, C. A. D.; DUENAS-HURTADO, F.; LARA-RODRIGUES, R. M.; SILVA, D. J. H. \& ZERBINI, F. M. 2012. Genetic structure of a Brazilian population of the begomovirus Tomato severe rugose virus (ToSRV). Tropical Plant Pathology 37: 346-353.

GOTTWALD T. R; BASSANEZI, R. B.; AMORIM L. \& BERGAMIN FILHO, A. 2007. Spatial pattern analysis of citrus canker-infected plantings in são paulo, brazil, and augmentation of infection elicited by the asian leafminer. Phytophthology 97:674-683.

HAU, B. \& KRANZ, J. 1990. Mathematics and statistics for analyses in epidemiology. In: Kranz, J. (Ed.) Epidemics of Plant Diseases: mathematical analyses and modeling. Berlin. Springer-Verlag.

INOUE-NAGATA, A. K.; ALBUQUERQUE, L. C.; ROCHA, W. B. \& NAGATA, T. 2004. A simple method for cloning the complete begomovirus genome using the bacteriophage phi 
29 DNA polymerase. Journal of Virology Methods 116: 209-211. INOUE-NAGATA, A. K. 2012. Doenças causadas por vírus. In: Flávia M.V.T. Clemente; Leonardo S. Boiteux. (Org.). Produção de tomate para processamento industrial. $1^{\mathrm{a} e d .}$ Brasília, DF: Embrapa, 2012.

IOANNOU, N. \& IORDANOU, N. 1985. Epidemiology of Tomato yellow leaf curl virus in relation to the population density of its whitefly vector, Bemisia tabaci (Gennadius). Tech Bull. Agricultural research institute ministry of agriculture and natural resources 71: 1-7.

LARANJEIRA, F. F.; BERGAMIN FILHO, A.; AMORIM, L. \& GOTTWALD, T.R. 2004. Dinâmica espacial da clorose variegada dos citros em três regiões do estado de São Paulo. Fitopatologia Brasileira 29: 056-065.

LUDWIG, J. A. \& REYNOLDS, F. J. 1988. Statistical Ecology. John Wiley \& Sons, New York.

MACEDO, M. A.; BARRETO, S. S.; HALLWASS, M. \& INOUE-NAGATA, A. K. 2014. High incidence of Tomato chlorosis virus alone and in mixed infection with begomoviruses in two tomato fields in the Federal District and Goiás state, Brazil. Tropical plant pathology 39(6): 449-452.

MACEDO, M.A.; MICHEREFF FILHO, M.; NAVAS-CASTILLO, J. \& INOUE-NAGATA, A.K. 2015. Host range and whitefly transmission efficiency of Tomato severe rugose virus and Tomato golden vein virus in tomato plants. Tropical plant pathology 40(6): 405-409.

MADDEN, L. V. \& HUGLES, G. 1995. Plant disease incidence: distribution, heterogeneity, and temporal analysis. Annual Review of Phytopathology.Palo Alto 33: 529-564.

MADDEN, L.V.; LOUIE, R.; ABT, J. J. \& KNOKE, J. K. 1982. Evaluation of tests for randomness of infected plants. Phytopathology 72: 195-198.

MORIN, S.; GHANIM, M.; ZEIDAN, M.; CZOSNEK, H.; VERBEEK, M. 1999. A GroEL homologue from endosymbiotic bacteria of the whitefly Bemisia tabaci is implicated in the circulative transmission of tomato yellow leaf curl virus. Virology 256: 75-84.

NELSON, S.C. 1996. A simple analysis of disease foci. Phytopathology 86:332-339.

POLSTON, J. E.; CHELLEMI, D. O.; SCHUSTER, D. J.; MCGOVERN, R. J. \& STANSLY, P. A. 1996. Spatial and temporal dynamics of Tomato mottle geminivirus and Bemisia tabaci (Genn.) in Florida tomato fields. Plant Disease 80: 1022-1028.

RIBEIRO, S. G.; AMBROZEVÍCIUS, L. P.; AVILA, A. C.; BEZERRA, I. C.; CALEGARIO, R. F.; FERNANDES, J. J.; LIMA, M. F.; DE MELLO, R. N.; ROCHA, H. 
\& ZERBINI F. M. 2003. Distribution and genetic diversity of tomato-infecting begomovius in Brasil. Archives of Virology 148: 281-295.

ROJAS, M. R.; GILBERTSON, R. L.; RUSSEL D. R. \& MAXWELL, D. 1993. Use of degenerated primers in the polymerase chain reaction to detect whitefly-transmitted geminiviruses. Plant Disease 77: 340-347.

ROSEN, R.; KANAKALA, S.; KLIOT, A.; PAKKIANATHAN B. C.; FARICH B. A.; SANTANA-MAGAL， N.; ELIMELECH， M.; KONTSEDALOV， S.; LEBEDEV, G.; CILIA, M. \& GHANIM, M. 2015. Persistent, circulative transmission of begomoviruses by whitefly vectors. Virology $18: 15: 1-8$.

RUBINSTEIN, G. \& CZOSNEK, H. 1997. Long-term association of tomato yellow leaf curl virus with its whitefly vector Bemisia tabaci: effect on the insect transmission capacity, longevity and fecundity. Journal General Virology 78: 2683-2689.

RUIZ, L.; JANSSEN, D.; MARTÍN, G.; SEGUNDO E. \& CUADRADO, I. M. 2006. Analysis of the temporal and spatial disease progress of Bemisia tabaci-transmitted Curcubit yellow stunting disorder virus and Cucumber vein yellowing virus in cucumber. Plant pathology 55: 264-275.

SCHUSTER, D. J.; GILREATH J. P.; CORDERO, R. \& GILREATH, P. R. 2011. Reduced incidence of tomato plants with symptoms of Tomato yellow leaf curl virus infection grown on ultraviolet- reflective soil mulch. Proc Fla State Hort Soc 124:162-165.

SUWWAN, M.A.; AKKAWI, M.; AL-MUSA, A. M. \& MANSOUR, A. 1988. Tomato performance and incidence of Tomato yellow leaf curl (TYLC) virus as affected by type of mulch. Sci Hort 37:39-45. Wisler GC, Duffus JE, Liu HY, Li RH (1998) Ecology and epidemiology of whitefly-transmitted. closteroviruses. Plant Disease 82: 270.

TURECHEK, W. W. \& MADDEN, L. V. 2000. Analysis of association between the incidence of two spatially aggregated foliar disease of strawberry. Phytopathology 90: 157170.

TURECHEK, W. W.; ROBERTS, P. D.; STANSLY, P. A.; WEBSTER, C. G; KOUSIK, C. S. \& ADKINS, S. 2014. Spatial and temporal analysis of Squash vein yellowing virus infections in Watermelon. Plant Disease 98(12): 1671-1680.

TZANETAKIS, I. E.; MARTIN, R. R. \& WINTERMANTEL, W. N. 2013. Epidemiology of criniviruses: an emerging problem in world agriculture. Front Microbiology 4: 1-14.

WINTERMANTEL, W. M. \& WISLER, G. C. 2006. Vector specificity host range, and genetic diversityof Tomato chlorosis virus. Plant Disease 90: 814-819. 
WISLER G. C. \& DUFFUS J. E. 2001. 2001. "Transmission properties of whitefly-borne criniviruses and their impact on virus epidemiology," in Virus-Insect-Plant Interactions eds Harris K. F, Smith O. P., Duffus J. E., editors. San Diego: Academic Press.

WISLER, G. C.; DUFFUS, J. E.; LIU, H. Y. \& LI, R. H. 1998. Ecology and epidemiology of whitefly-transmitted closteroviruses. Plant Disease 82: 270-280.

ZERBINI, F. M.; ANDRADE, E. C.; BARROS, D. R.; FERREIRA, S. S.; LIMA, A. T. M.; ALFENAS, P. F. \& MELLO, R. N. 2005. Traditional and novel strategies for geminivirus management in Brazil. Australasian Plant Pathology 34: 475-480. 


\section{Conclusões Gerais da Tese}

O cultivo do tomate para consumo in natura e para processamento é de grande relevância econômica para o País. As doenças de origem viral causadas por espécies de Begomovirus e Crinivirus afetam significativamente a produção de tomateiro seja devido à alta incidência. Diversos fatores contribuem para agravar esse cenário como a falta de informação por parte dos agricultores; a inexistência de serviços satisfatórios de extensão rural; a baixa qualidade técnica dos produtores; a carência de cultivares resistentes com características desejadas principalmente para o segmento indústria; a alta população dos insetos vetores; o plantio contínuo, e muitas vezes contíguo, de tomateiro durante todo o ano; a presença de inúmeras hospedeiras alternativas com potencial de atuar como fonte de inóculo para esses vírus; a associação do cultivo do tomateiro com cultivos que são susceptíveis aos vírus ou que são excelentes hospedeiras dos insetos vetores; e falta de um manejo integrado e regional nas áreas de produção de tomateiro no Brasil.

Epidemias de doenças de plantas transmitidas por insetos vetores como é o caso da maioria das fitoviroses apresentam um fator de complicação a mais, o vetor, tornando o manejo mais complexo. A característica de dispersão do vetor é a chave para o entendimento das epidemias para esse tipo de doença. Além do comportamento de dispersão do vetor, outro importante ponto na distribuição de plantas infectadas é a inter-relação desse com o agente causal da doença. Uma mesma espécie de inseto vetor pode apresentar diferente inter-relação com o agente causal da doença como é o caso dos begomovirus e crinivirus que são transmitidos por espécies de mosca-branca, possuem inclusive uma espécie vetora em comum, B. tabaci, porém apresentam inter-relação vetor-vírus distinta. Os begomovirus possuem um período de latência no corpo do inseto e após esse período adultos de B. tabaci tornam-se capazes de transmiti-lo durante toda sua vida. Por outro lado, os crinivirus não necessitam desse período de latência, e após aquisição perdem gradativamente a capacidade 
de transmitir o vírus. Devido a essa diferença na inter-relação vetor vírus esperava-se que a distribuição espacial das plantas infectadas de crinivirus e begomovirus em campo apresentasse padrão distinto. No entanto, nenhuma diferença significativa tanto no progresso temporal como espacial foi observada para essas viroses. Acredita-se que isso se deve principalmente ao uso intensivo de inseticidas nas áreas de cultivo, o que leva à quase eliminação das diferenças entre essas duas viroses.

Os resultados obtidos nesse trabalho demonstraram que a begomovirose em tomateiro rasteiro e estaqueado e crinivirose em tomateiro estaqueado apresentam uma dinâmica de distribuição temporal e espacial bem semelhante. Em geral, o progresso temporal é rápido e a distribuição espacial das plantas sintomáticas é levemente agregada. A dinâmica espacial e temporal dessas viroses é dependente de pelo menos três mecanismos distintos de disseminação, um predominantemente ao acaso (infecção primária) e dois predominantemente agregados (infecção secundária e "falsa" infecção secundária) que atuam em diferentes níveis de importância no desenvolvimento das epidemias virais. A infecção primária, resultante da chegada de insetos virulíferos no cultivo alvo, parece ser o principal mecanismo de disseminação da begomovirose e crinivirose em tomateiro. Os outros dois mecanismos de disseminação possuem menor importância, mas também contribuem para o desenvolvimento dessas epidemias. Nos patossistemas estudados acredita-se que a disseminação secundária é principalmente resultante da introdução de insetos avirulíferos que adquirem os vírus dentro do cultivo alvo e inoculam plantas sadias próximas a plantas infectadas. A "falsa disseminação secundária" é resultante do hábito das moscas-brancas se alimentarem em mais de uma planta sadia próxima umas as outras acarretando a inoculação de um grupo de plantas pela ação de apenas um inseto virulífero proveniente de fora da área de cultivo.

Sendo a disseminação primária a principal responsável pelas epidemias de begomovirose e crinivirose, a atual estratégia de manejo adotada para o controle dessas 
viroses a partir da aplicação frequente de inseticidas apenas nos cultivos-alvo apresenta baixa probabilidade de sucesso. A ação dos inseticidas para retardar o avanço dessas epidemias é ineficiente, pois antes que ocorra a mortalidade dos insetos vetores uma parte da população foi capaz de inocular plantas sadias. Assim, uma baixa população de moscas-brancas em campo não é necessariamente relacionada à baixa incidência das viroses. A aplicação de inseticidas no cultivo-alvo visando à diminuição populacional dos insetos virulíferos não possui efeito significativo no mesmo, sua ação é necessária e importante para a redução da disseminação dessas viroses para cultivos futuros próximos a essa área de produção.

O sucesso do controle de doenças transmitidas por vetores cujo componente primário é continuo, como as begomoviroses e criniviroses, definitivamente não é fácil de ser realizado. O controle químico dos vetores não é eficiente e a presença de boas hospedeiras alternativas cultivadas ou não em campo tanto do vetor como dos vírus dificulta mais ainda o manejo. A soja, por exemplo, é uma excelente hospedeira de mosca-branca, mas não é afetada economicamente por viroses transmitidas por esse vetor o que consequentemente leva a negligência do controle da população desse inseto. Em face a todos esse fatores um manejo adequado e eficiente de begomovirose e crinivirose dificilmente será alcançado se medidas de controle não forem adotadas de maneira integrada e regional. No entanto, o grande gargalo no manejo dessas viroses é a falta de informação dos produtores que dificulta a implementação de medidas de controle em uma ampla área de produção. Outro ponto importante é o custo da implementação de um manejo macro-regional, produtores que não cultivam espécies que são fortemente afetadas por essas viroses não veem a necessidade participarem de um manejo integrado. Assim, essas viroses tendem a apresentarem importância econômica ainda por um período de tempo indeterminado.

Trabalhos que possuem como foco os mecanismos que afetam as epidemias de doenças de origem viral ainda são escassos devido a diversos fatores como: a presença de um 
fator pouco previsível; a dispersão dos insetos vetores; e à aplicação de inseticidas e procedimentos de manejo da cultura que são variáveis em diferentes áreas de produção e que acabam por interferir no comportamento dos insetos vetores, levando assim a uma grande dificuldade de obtenção de resultados confiáveis e reproduzíveis com significado epidemiológico real. Os resultados obtidos nesse trabalho ajudaram a preencher algumas importantes lacunas na epidemiologia de begomovirose e crinivirose, mas outros aspectos epidemiológicos não abordados nesse trabalho, como a determinação da principal fonte de inóculo dos vírus permanece inconclusivo e merece ser estudado mais detalhadamente para a melhor compreensão de como ocorrem as epidemias de viroses em tomateiro. 


\section{PRODUÇÃO CIENTÍFICA 2012-2016}

\section{ARTIGO CIENTÍFICOS}

BERGAMIN FILHO, A. ; INOUE-NAGATA, A. K. ; BASSANEZI, R. B. ; BELASQUE, J. ; AMORIM, L. ; MACEDO, M. A. ; BARBOSA, J. C. ; WILLOCQUET, L. ; SAVARY, S. . The importance of primary inoculum and area-wide disease management to crop health and food security. FOOD SECUR, v. 8, p. 221-238, 2016.

BORGES, R.C.F. ; SANTOS, M.D.M. ; MACEDO, M.A. ; MARTINS, I. ; NASCIMENTO, A.G. ; CAFÉ-FILHO, A.C. ; BOITEUX, L.S. ; FONSECA, M.E.N. ; INÁCIO, C.A. ; MELLO, S.C.M. . A trunk canker disease of Tectona grandis induced by Lasiodiplodia theobromae in Brazil. New Disease Reports, v. 31, p. 26, 2015.

MACEDO, MÔNICA A.; MICHEREFF FILHO, MIGUEL ; NAVAS-CASTILLO, JESÚS ; INOUE-NAGATA, ALICE K. . Host range and whitefly transmission efficiency of Tomato severe rugose virus and Tomato golden vein virus in tomato plants. TROP PLANT PATHOL, v. 1, p. 1, 2015.

Adriana Ribeiro Silva Batista ; Cícero Nicolini ; Kelly Barreto Rodrigues, ; Fernando Lucas Melo ; Raquel Medeiros Vasques ; MACEDO, M. A. ; Alice Kazuko Inoue-Nagata ; Tatsuya Nagata . Unique RNA 2 sequences of two Brazilian isolates of Pepper ringspot virus, a tobravirus. Virus Genes, v. 49, p. 169-173, 2014.

BORGES, R.C.F. ; SANTOS, M.D.M. ; MACEDO, M.A. ; MARTINS, I. ; NASCIMENTO, A.G. ; BOITEUX, L.S. ; FONSECA, M.E.N. ; MELLO, S.C.M. . First report of a wilt disease of Tectona grandis caused by Thielaviopsis basicola in Brazil. New Disease Reports, v. 30, p. $17,2014$.

MACEDO, M. A.; BARRETO, S. S. ; HALLWASS, M. ; INOUE-NAGATA, A. K. . High incidence of Tomato chlorosis virus alone and in mixed infection with begomoviruses in two tomato fields in the Federal District and Goiás state, Brazil. Tropical Plant Pathology (Impresso), v. 39, p. 449-452, 2014.

\section{ARTIGOS SUBMETIDOS À PUBLICAÇÃO}

Macedo, MA, Costa, TM', Barbosa, JC, Pereira, JL. Michereff Filho, M, Gilbertson, RL, Inoue-Nagata, AK, Bergamin Filho, A.Temporal and spatial dynamics of a begomovirus disease in processing tomato in central Brazil. Plant Pathology.

M. A. Macedo, S. S. Barreto and T. M. Silva. First report of Tomato severe rugose virus in common beans in Brazil. Plant Diasease.

\section{TEXTO EM REVISTAS}

INOUE-NAGATA, A. K. ; MACEDO, M. A. ; SOUZA, J. O. ; MICHEREFF, M. F . Tomate Manejo regional. Cultivar Hortaliças e Frutas, p. 10 - 11. 


\section{APRESENTAÇÕES DE TRABALHO EM CONGRESSOS}

MACEDO, M. A.; BARRETO, S. S. ; HALLWASS, M. ; INOUE-NAGATA, A. K. . ALTA INCIDENCIA DEL Tomato chlorosis virus Y BEGOMOVIRUS EN TOMATE EN LA REGIÓN CENTRAL DE BRASIL. 2013. (Apresentação de Trabalho/Congresso).

MACEDO, M. A.; BARBOSA, J. C. ; MICHEREFF, M. F ; BERGAMIN FILHO, A. ; INOUE-NAGATA, A. K. . Epidemiology of begomovirus and crinivirus diseases in tomato plants in Brazil. 2013. (Apresentação de Trabalho/Simpósio).

\section{TRABALHOS COMPLETOS PUBLICADOS EM ANAIS DE CONGRESSOS}

MACEDO, M. A.; BARBOSA, J. C. ; MICHEREFF, M. F ; BERGAMIN FILHO, A. ; INOUE-NAGATA, A. K. . Epidemiology of begomovirus and crinivirus diseases in tomato plants in Brazil. In: 7th geminiviruses symposium and 5th single stranded DNA workshop, 2013, Hangzhou. geminiviruses symposium, 2013.

\section{RESUMOS EXPANDIDOS PUBLICADOS EM ANAIS DE CONGRESSOS}

MACEDO, M. A.; SILVA, J. ; JORGE, M. H. A. ; Boiteux, LS ; INOUE-NAGATA, A. K. . Efeito da aplicação foliar de nutrientes na produção e na qualidade de sementes de plantas de tomateiro infectadas com um begomovirus bipartido. In: Congresso Brasileiro de Oleiricultura, 2014, Palmas. Horticultura brasileira, 2014.

\section{RESUMOS PUBLICADOS EM ANAIS DE CONGRESSOS}

MACEDO, M. A.; MALIANO, M. ; ROJAS, M. ; SOUZA, J. O. ; INOUE-NAGATA, A. K. ; GILBERTSON, R. . MOLECULAR CHARACTERIZATION AND PRODUCTION OF INFECTIOUS CLONES OF A NEW BEGOMOVIRUS SPECIES INFECTING SIDA SP. FROM THE STATE OF PIAUÍ. In: Congresso Brasileiro de Virologia, 2015, Florianópolis. Virologia, 2015.

MACEDO, M. A.; GILBERTSON, R. L. ; BERGAMIN FILHO, A. ; INOUE-NAGATA, A. $\mathrm{K}$. . Incidence of begomovirus and tospovirus diseases in processing tomato fields in three midwest states of Brazil in 2013 and 2014.. In: APS Annual meeting, 2015, Pasadena. APS, 2015.

VU, S. ; SOUZA, J. O. ; MELGAREJO, T. A. ; CHEN, L. ; MACEDO, M.A. ; INOUENAGATA, A. K. ; GILBERTSON, R. . Evidence that Tomato mottle leaf curl virusfrom Northeastern Brazil is an indigenous New World monopartite begomovirus. In: APS annual meeting, 2015, Pasadena. APS, 2015.

MACEDO, M. A.; BARBOSA, J. C. ; GILBERTSON, R. L. ; BERGAMIN FILHO, A. ; INOUE-NAGATA, A. K. . Incidência de begomovirose e tospovirose em tomateiro de crescimento determinado nos três principais estados brasileiros produtores no ano de 2013 . In: Congresso Brasileiro de Fitopatologia, 2014, Londrina. Fitopatologia Brasileira, 2014.

MICHEREFF, M. F ; INOUE-NAGATA, A. K. ; MACEDO, M. A. . Manejo de viroses associadas à mosca-branca, Bemisia tabaci. In: XXV Congresso Brasileiro de Entomologia, 2014, Goiânia. Anais do XXV Congresso Brasileiro de Entomologia, 2014. v. 1.

Lima, MT ; MACEDO, M.A. ; NAGATA, T. ; INOUE-NAGATA, A. K. . OCORRÊNCIA DE PEPPER RINGSPOT VIRUSPepper ringspot virus EM TOMATEIRO RASTEIRO. In: 
Congresso Brasileiro de Tomateiro Industriaç, 2014, Goiania. Congresso Brasileiro de Tomateiro Industrial, 2015.

COSTA, T. M. ; MACEDO, M.A. ; INOUE-NAGATA, A. K. . Incidência de begomovirus de tomateiro em amostras de soja coletadas durante o período do vazio fitossanitário em 2013/2014.. In: Congresso Brasileiro de Tomate Industrial, 2014, Goiânia. Congresso Brasileiro de tomate industrial, 2014.

MACEDO, M. A.; BARBOSA, J. C. ; GILBERTSON, R. ; BERGAMIN FILHO, A. ; INOUE-NAGATA, A. K. . Incidência de begomovirose e tospovirose em tomateiro de crescimento determinado nos três principais estados brasileiros produtores no ano de 2013 . In: Congresso Brasileiro de tomate industrail, 2014, Goiânia. Congresso Brasileiro de tomate industrial, 2014.

Borges, RCF ; Santos, MD ; Chaves ZM ; MACEDO, M. A. ; Fonseca, MEN ; Boiteux, LS ; Mello, SCM . Presence of Thielaviopsis basicola en cultivos de Teca (Tectona grandis) del medio-oeste brasileiro. In: XXII Congreso Peruano y XVII Congreso Latinoamericano de Fitopatología, 2013, Lambayeque. XXII Congreso Peruano y XVII Congreso Latinoamericano de Fitopatología, 2013.

MACEDO, M. A.; BARRETO, S. S. ; BARBOSA, J. C. ; MICHEREFF, M. F ; BERGAMIN FILHO, A. ; HALLWASS, M. ; SOUZA, J. O. ; LEMOS, P. P. F. ; INOUE-NAGATA, A. K. . Advances in the epidemiological studies of tomato begomoviruses in Brazil.. In: IV Brazilian Workshop of Plant Disease Epidemiology, 2013, curitiba. Proceedings of the IV WPDE, 2013.

Borges, RCF ; MACEDO, M. A. ; Reis, MT ; Dias, LJC ; MARTINS, I. ; MELLO, S.C.M. . Efficiency in vitro de aislados Trichoderma spp. en el control de Lasiodiplodia grandis. In: XXII Congreso Peruano y XVII Congreso Latinoamericano de Fitopatología, 2013, Lambayeque. XXII Congreso Peruano y XVII Congreso Latinoamericano de Fitopatología, 2013.

BATISTA, A R S ; NICOLIN, C. ; RODRIGUES, K. B. ; VASQUEZ, R. M. ; MACEDO, M. A. ; INOUE-NAGATA, A. K. ; NAGATA, T. . Unique sequence characteristics of RNA 2 genome segment of new Pepper ringspot virus, tobravirus isolated in Brazil.. In: XXIV Brazilian Congress of Virology, 2013, Porto seguro. Virus Reviews \& Research, 2013.

MACEDO, M. A.; BARRETO, S. S. ; HALLWASS, M. ; INOUE-NAGATA, A. K. ALTA INCIDENCIA DEL Tomato chlorosis virus Y BEGOMOVIRUS EN TOMATE EN LA REGIÓN CENTRAL DE BRASIL. 2013. In: XVII Congreso Latinoamericano de Fitopatología, 2013, Guanajuato. Asociacion Latinoamericana de fitopatología, 2013.

MACEDO, M. A.; BARBOSA, J. C. ; BERGAMIN FILHO, A. ; INOUE-NAGATA, A. K. . ANÁLISE ESPACIAL PRELIMINAR DE VIROSES TRANSMITIDAS POR MOSCABRANCA NO DISTRITO FEDERAL. In: $45^{\circ}$ Congresso Brasileiro de Fitopatologia, 2012, Manaus- AM. Revista Brasileira de Fitopatologia, 2012.

MACEDO, M. A.; BARBOSA, J. C. ; HALlWASS, M. ; MICHEREFF, M. F ; BERGAMIN FILHO, A. ; INOUE-NAGATA, A. K. EFFECT OF CONTIGUOUS PLANTING OF BUSHY-TYPE TOMATOES ON THE INCIDENCE OF VIRUSES TRANSMITTED BY WHITEFLIES. In: $23^{\circ}$ Congresso Nacional de Virologia, 2012, Foz do Iguaçu. Revista Brasileira de Virologia, 2012. 